$2 b^{5}<6^{6}$
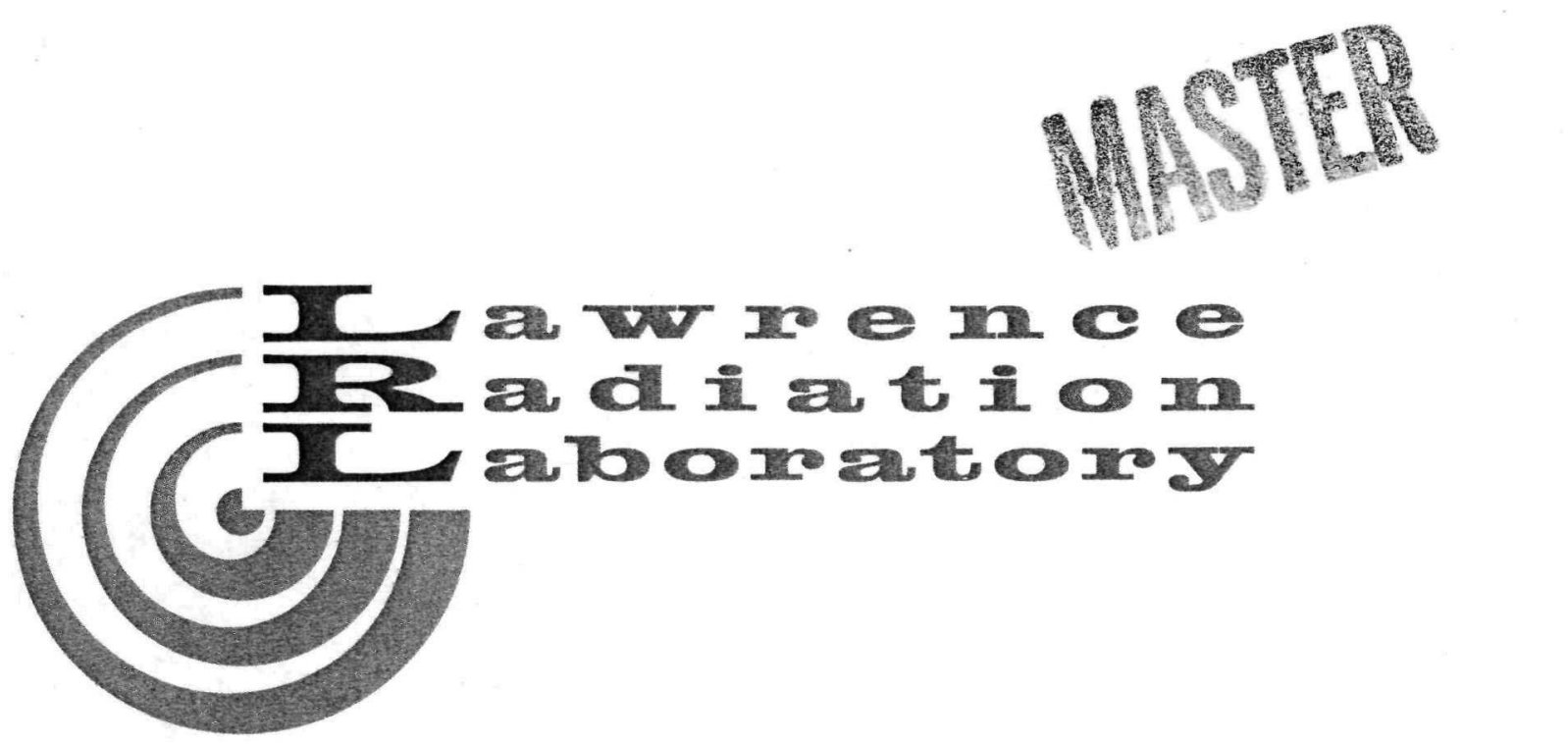

UNIVERSITY Of CALIFORNIA

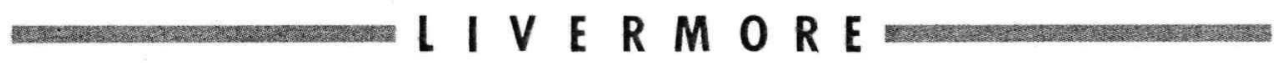




\section{DISCLAIMER}

This report was prepared as an account of work sponsored by an agency of the United States Government. Neither the United States Government nor any agency Thereof, nor any of their employees, makes any warranty, express or implied, or assumes any legal liability or responsibility for the accuracy, completeness, or usefulness of any information, apparatus, product, or process disclosed, or represents that its use would not infringe privately owned rights. Reference herein to any specific commercial product, process, or service by trade name, trademark, manufacturer, or otherwise does not necessarily constitute or imply its endorsement, recommendation, or favoring by the United States Government or any agency thereof. The views and opinions of authors expressed herein do not necessarily state or reflect those of the United States Government or any agency thereof. 


\section{DISCLAIMER}

Portions of this document may be illegible in electronic image products. Images are produced from the best available original document. 
TID-4500, UC-33

Propulsion Systems and Energy Conversion

Iavoremeo Fadiation Iaboxatory

UNIVERSITY OF CALIFORNIA

LIVERMORE

\section{UCRL-50004-68-1, Part I \\ QUARTERLY REPORT \\ ADVANCED SPACE NUCLEAR POWER PROGRAM \\ January Through March 1968}

\section{LEG A L NOTICE}

This report was prepared as an account of Government sponsored work. Neither the United States, nor the Commission, nor any person acting on behalf of the Commission:

A. Makes any warranty or representation, expressed or implied, with respect to the accuracy, completeness, or usefulness of the information contained in this report, or that the use of any information, apparatus, method, or process disclosed in this report may not infringe of any information, apparatus, method, or process disclosed in this report may not infringe
privately owned rights; or privately owned rights; or

B. Assumes any liabilities with respect to the use of, or for damages resulting from the use of any information, apparatus, method, or process disclosed in this report.

As used in the above, "person acting on behalf of the Commission" includes any employee or contractor of the Commission, or employee of such contractor, to the extent that such employee or contractor of the Commission, or employee of such contractor prepares, disseminates, or provides access to, any information pursuant to his employment or contract with the Commission, or his employment with such contractor. 


\section{Foreword}

Starting with the 1967 third-quarter report, each quarterly report of the Advanced Space Nuclear Power Program is published in two parts. The first contains unclassified material only, the second contains classified material only. Hence the two volumes of this report, for example, are numbered UCRL-50004-68-1, Part I, and UCRL-50004-68-1, Part II. 


\title{
Highlights and Summary
}

\author{
Highlights
}

Materials

- A W-Re-Mo capsule containing circulating Li was operated for $1004 \mathrm{hr}$ at temperatures near $1400^{\circ} \mathrm{C}$. A preliminary examination of this capsule has shown that corrosion was negligible (p. 29 ).

Power System Design

- The SPR-4, Rankine cycle 300-kWe reference design is described (p. 34 ).

\section{Summary}

As a result of recommendations made by the Congressional Joint Committee on Atomic Energy, notice was given by the AEC that the LRL Space Power Program would be terminated at the end of the current fiscal year.

Anticipation of severe reductions in funding had already brought cancellation of the tungsten alloy/liquid metal loop early in the past quarter, together with a sharp reduction in design and experimental activities outside of the materials field. The remaining work will now be phased out in as orderly a way as possible. One more progress report after this one will be issued, and any remaining work not described there will be covered by separate topical reports. 


\section{Related Publications During the Quarter}

1. P.S. Brown, J. L. Watts, and R. J. Doyas, Effects of Cross Section Uncertainties in Compact Space Power Reactors, Lawrence Radiation Laboratory, Livermore, Rept. UCRL-70797 Preprint (1968), presented at the Second Conference on Neutron Cross Sections and Technology, Washington, D. C., March 4-7, 1968.

2. E. Garelis, J. P. Layton, W. N. Podney, and B. Koponen, Advanced Nuclear Reactors for Space Auxiliary Power Applications in the 1980's, Lawrence Radiation Laboratory, Livermore, Rept. UCRL-70913 Abstract (1968), for presentation at the 1968 Intersociety Energy Conversion Conference, Boulder, Colorado, August 12-16, 1968.

3. V. E. Hampel, E. H. Canfield, V. Hansen, S. P. Stone, and J. A. Wade, Adaptation of "ZOOM" to Small Fast Systems by Means of Linearly-Anisotropic Corrections to Asymptotic Diffusion Theory, Lawrence Radiation Laboratory, Livermore, Rept. UCRL-70983 Summary (1968), presented at the Annual ANS Meeting, Toronto, Canada, June 9-13, 1968.

4. V.E. Hampel and V. Hansen, Nuclear Safety of Small Fast Space Reactors, When Immersed in Water, by Use of Permanent Neutron Filters of Europium Compounds, Lawrence Radiation Laboratory, Livermore, Rept. UCRL-70959 Summary (1968), presented at the Annual ANS Meeting, Toronto, Canada, June 9-13, 1968.

5. W. E. Loewe, Out-of-Core Thermionic Space Power, Lawrence Radiation Laboratory, Livermore, Rept. UCRL-70816 (1968), presented at the Second International Conference on Thermionic Power Generation, Stresa, Italy, May 27-31, 1968.

6. W. E. Loewe, Investigation of Performance of an Out-of-Core Thermionic Space Power System, Lawrence Radiation Laboratory, Livermore, Rept. UCRL-70984 Preprint (1968), for presentation at the 1968 Intersociety Energy Conversion Conference, Boulder, Colorado, August 12-16, 1968.

7. J.H. Pitts and C.E. Walter, Conceptual Design of a 10-MW $\mathrm{e}_{\text {Nuclear Rankine }}$ System for Space Power, Lawrence Radiation Laboratory, Livermore, Rept. UCRL-50382 (1968). 


\section{Contents}

HIGHLIGHTS AND SUMIMARY .

Related Publications During Quarter

TABLE OF CONVERSIONS

MATERIALS .

Development of Refractory Metal Alloys.

Chemical Vapor Deposition of W-Re Alloys

Tube Deposition Apparatus

Mechanical Properties

Fluorine Analysis of Alloy Deposits

Dissimilar Refractory Alloy Joining

Elevated Temperature Deformation Behavior of Tungsten and

Tungsten Alloys

Fuel Studies

Uranium Nitride Synthesis and Fabrication

Synthesis

Fabrication .

Uranium Nitride Phase Equilibria and Vaporization . . . . . 13

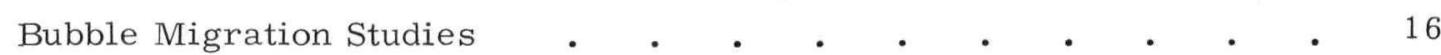

Elastic Properties of Uranium Nitride at $298^{\circ} \mathrm{K} \quad$. $\quad . \quad$. $\quad . \quad$. 17

Liquid-Metal Studies . . . . . . . . . . . . . 18

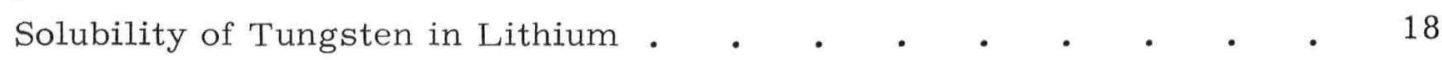

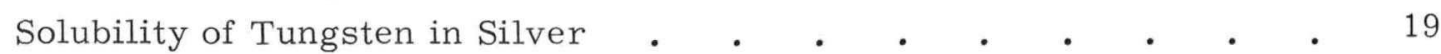

Some Interactions Between Cesium and Barium in Thermionic Diodes

The Cesium-Barium Phase Diagram

Cesium-Barium Activities

Discussion

Heat Capacity of Lithium

Configurational Heat Capacity, $\mathrm{C}_{\mathrm{V}}^{*} \mathrm{R} \quad \cdot \quad \cdot \quad \cdot \quad \cdot \quad \cdot 26$

The Kinetic Term, $\mathrm{C}^{\mathrm{k}}$. . . . . . . . . . 28

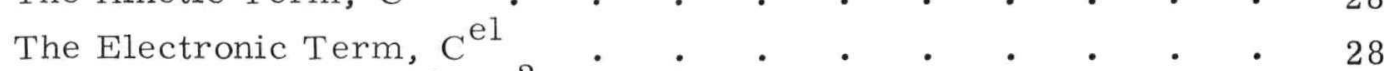

The Dilation Term, $\mathrm{C}^{\mathrm{d}}=\frac{\alpha^{2} \mathrm{VT}}{\beta_{\mathrm{T}}} \cdot . \quad \cdot \quad \cdot \quad \cdot \quad \cdot \quad \cdot 28$

Dynamic Corrosion Studies . . . . • . • • • . 29

Pumped-Capsule Experiment • • • • • • • • . 29

Lithium Still • • • • • • • • • • • • • • 31

Fixture and Welding Studies for Corrosion Loop • • • • 32 
REACTOR SYSTEM AND COMPONENT ENGINEERING • • • • • • 34

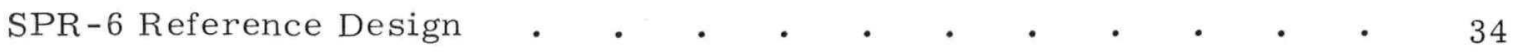

SPR-4 Reference Design . • • • • • • • • • • • 34

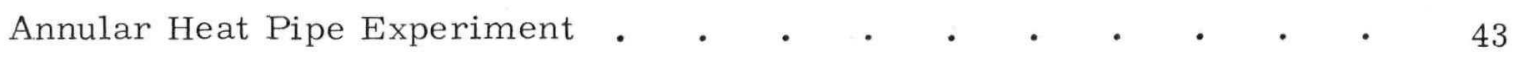

REFERENCES • • • • • • • • • • • • • • • • 44 


\section{Table of Conversions}

\section{Temperature conversion chart}

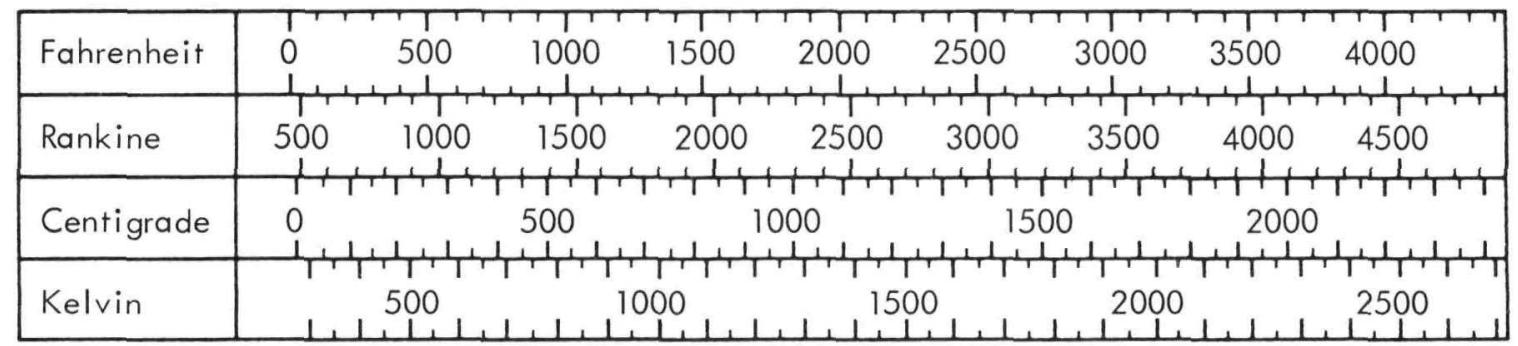

Length

$$
\begin{aligned}
& 1 \mathrm{~cm}=0.394 \mathrm{in} . \\
& 1 \mathrm{~m}=3.28 \mathrm{ft}
\end{aligned}
$$

Area

$$
\begin{aligned}
& 1 \mathrm{~cm}^{2}=0.155 \mathrm{in.}^{2} \\
& 1 \mathrm{~m}^{2}=10.8 \mathrm{ft}^{2}
\end{aligned}
$$

Volume

$$
\begin{aligned}
& 1 \mathrm{~cm}^{3}=6.10 \times 10^{-2} \text { in. }^{3} \\
& 1 \mathrm{~m}^{3}=35.3 \mathrm{ft}^{3}
\end{aligned}
$$

Speed

$$
\begin{aligned}
1 \mathrm{~m} / \mathrm{sec} & =2.24 \mathrm{miles} / \text { hour } \\
& =3.28 \mathrm{ft} / \mathrm{sec}
\end{aligned}
$$

Mass

$$
1 \mathrm{~kg}=2.201 \mathrm{~b} \mathrm{~m}
$$

Density

$$
\begin{aligned}
1 \mathrm{~g} / \mathrm{cm}^{3} & =62.4 \mathrm{lb} / \mathrm{ft}^{3} \\
& =3.61 \times 10^{-2} 1 \mathrm{~b}_{\mathrm{m}} / \mathrm{in}^{3}
\end{aligned}
$$

Force

$$
\begin{aligned}
1 \text { newton }(\mathrm{N}) & =10^{5} \text { dynes } \\
& =0.2251 \mathrm{~b}_{\mathrm{f}}
\end{aligned}
$$

Pressure

$$
\begin{aligned}
1 \mathrm{~N} / \mathrm{cm}^{2} & =9.87 \times 10^{-2} \mathrm{~atm} \\
& =1.45 \mathrm{lb}_{\mathrm{f}} / \text { in. }^{2}
\end{aligned}
$$

$$
\begin{aligned}
1 \mathrm{~kg}_{\mathrm{f}} / \mathrm{cm}^{2} & =0.968 \mathrm{~atm} \\
& =14.2 \mathrm{lb}_{\mathrm{f}} / \mathrm{in}^{2} \\
1 \mathrm{bar} & =0.987 \mathrm{~atm} \\
& =10 \mathrm{~N} / \mathrm{cm}^{2} \\
1 \mathrm{torr} & =1 \mathrm{~mm} \mathrm{Hg}\left(0^{\circ} \mathrm{C}\right) \\
& =1.32 \times 10^{-3} \mathrm{~atm}
\end{aligned}
$$

Energy

$$
\begin{aligned}
1 \text { joule } & =1 \mathrm{~W}-\mathrm{sec} \\
& =0.738 \mathrm{ft}-1 \mathrm{~b}_{\mathrm{f}} \\
& =9.48 \times 10^{-4} \mathrm{Btu} \\
& =0.239 \mathrm{cal}
\end{aligned}
$$

Power

$$
\begin{aligned}
1 \mathrm{~kW} & =1.34 \mathrm{hp} \\
& =3.41 \times 10^{3} \mathrm{Btu} / \text { hour } \\
& =7.38 \times 10^{2} \mathrm{ft}-1 \mathrm{~b}_{\mathrm{f}} / \mathrm{sec}
\end{aligned}
$$

Power density

$$
1 \mathrm{~kW} / \mathrm{cm}^{3}=28.3 \mathrm{MW} / \mathrm{ft}^{3}
$$

Acceleration due to gravity (standard for units)

$$
\begin{aligned}
g & =980.7 \mathrm{~cm} / \mathrm{sec}^{2} \\
& =32.17 \mathrm{ft} / \mathrm{sec}^{2}
\end{aligned}
$$




\section{QUARTERLY REPORT \\ ADVANCED SPACE NUCLEAR POWER PROGRAM January Through March 1968}

\section{Materials}

DEVELOPMENT OF REFRACTORY

METAL ALLOYS

Chemical Vapor Deposition of W-Re Alloys

W-Re alloy is deposited when the premixed metal fluorides are reduced by hydrogen during transverse flow over a hot, rotating cylindrical mandrel (see Fig. 1).

A scaled-up apparatus for producing 1 -ft lengths of 1/2-in. diam W-Re tubing is being tested and modified. The me- chanical properties of three vapordeposited W-Re tubes made with this apparatus have been measured. Fluorine analyses were obtained on the standard, 1 -in.-long $\mathrm{W}$-Re tubes prepared in the original apparatus.

\section{Tube Deposition Apparatus}

Important mechanical changes have been made during scale-up of the 1 -in. plating rig. ${ }^{1}$

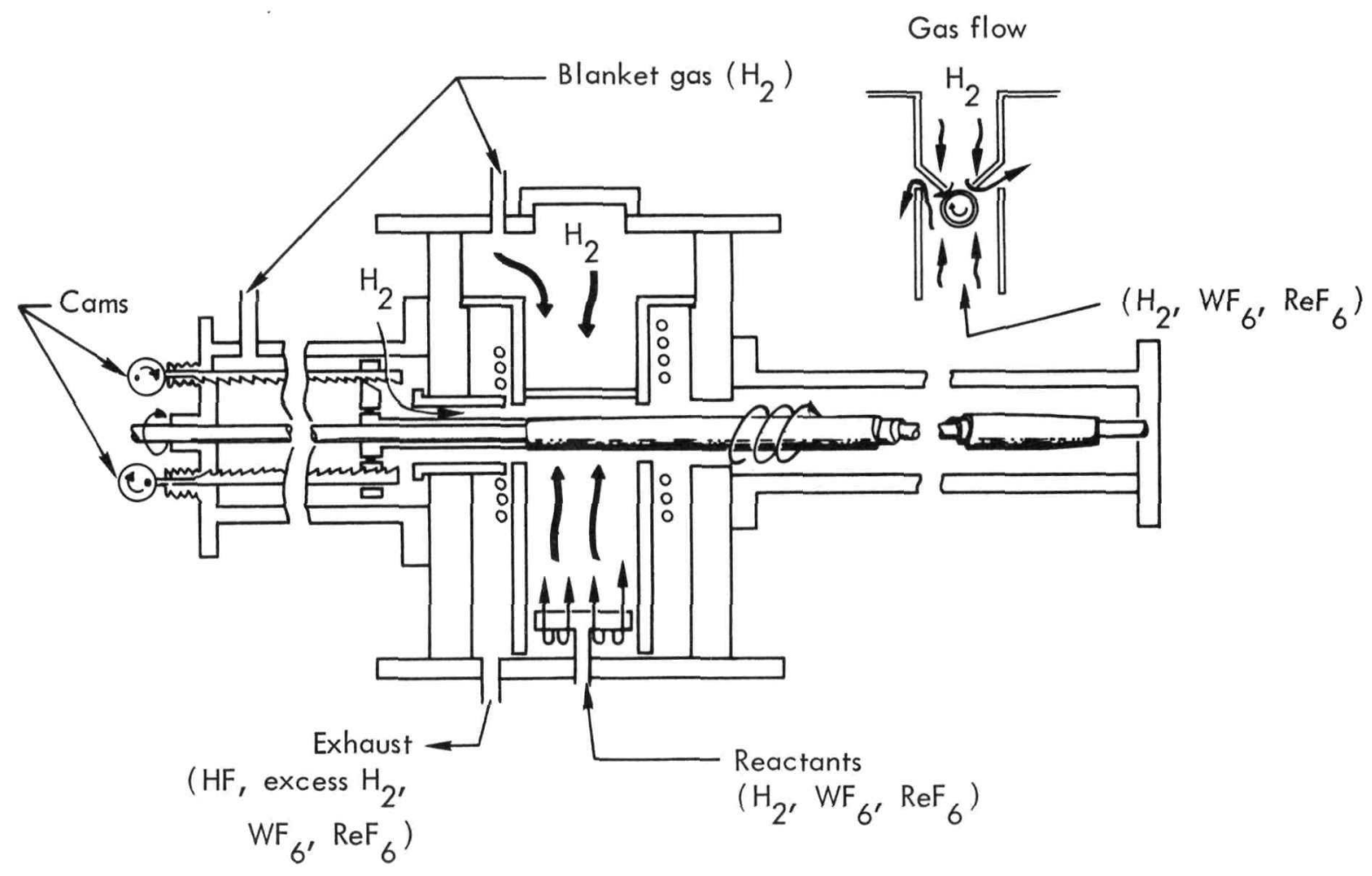

Fig. 1. Apparatus for fabrication of 12 -in.-long tubes by chemical vapor deposition. 
A schematic of the new 12-in. CVD* tube fabricator is shown in Fig. 1. The chief operating principle remains the same: transverse feed gas flow over an induction-heated molybdenum mandrel. A premixed tungsten-rhenium fluoride solution passes into a flash evaporator, and the metal fluoride vapor enters the bottom of the chamber through an inverted gas sparger. After contacting the bottom portion of the mandrel, the vapor is diverted to the sides of the plating chamber, and then is redirected downward to the exhaust line by a hydrogen counterflow from the top of the chamber (detailed in the cross section in the upper right of Fig. 1). The reduction reaction is confined to about three quarters of the rotating mandrel surface. This exclusion of reactants and products from the top of the mandrel will permit future investigations which involve alternating deposition-brushing treatment where reduction on the bristles of the tungsten wire brush must be avoided. The brushing studies on pure tungsten deposits ${ }^{1}$ have shown that for effective brushing there must be: (1) many individual points of contact, (2) low, delicately controlled contact pressures, and (3) brush flexibility.

In the new apparatus, the production rate was increased by lengthening the plating chamber to 4 in. Earlier work showed that at any selected temperature and pressure, the maximum rate of deposition of strong deposits becomes essentially constant and cannot be increased by increasing the flow of feed gas.

\footnotetext{
* CVD = chemical vapor deposition.
}

A controlled translation rate along the guide rod is imparted by a pair of cams which alternately push two spring-loaded ratchet rods (shown at the left in Fig. 1). Horizontal movement is accumulated by the sequential engagement of individual spring-loaded pawls with the ratchets. Translation rates between $1-1 / 2$ and $2 \mathrm{in} . / \mathrm{hr}$ have been used to produce tubing with wall thicknesses in the range: 0.030 to $0.040 \mathrm{in}$.

Where the mandrel enters the plating chamber proper, a small amount of hydrogen is introduced to suppress deposition in the low temperature region. Since, under certain conditions, ${ }^{1}$ rhenium deposition is favored at low temperatures, a flow of cover gas at this point restricts the deposit on this relatively cool portion of the mandrel to 1 or 2 mils. Although a similar effect occurs at the exit side, the off-composition material will be removed when the outside diameter is finish ground.

\section{Mechanical Properties}

The apparatus must be modified to provide greater control of mandrel temperature, feed-gas flow rate, and mandrel translation before best results can be obtained. Nevertheless, the room temperature properties of rings taken from several sections of two of the three tubes were comparable to those previously reported for the 1 -in. deposits; i.e., after a $1400^{\circ} \mathrm{C}$ anneal, $17 \%$ Re deposits measured: U.T.S., 91 to $97 \mathrm{~kg} / \mathrm{mm}^{2}$; yield strength, $90-92$ $\mathrm{kg} / \mathrm{mm}^{2}$; and measurable uniform elongation, 0 to $0.26 \%$.

\section{Fluorine Analysis of Alloy Deposits}

Table I shows fluorine contents for a number of the $1-$ in. W-Re tubes prepared 
on the original apparatus. The table also gives the plating conditions and plating rates. There is no apparent dependence of fluorine content on a particular variable such as temperature, rhenium content, pressure, mol ratio of $\mathrm{H}_{2} / \mathrm{MF}_{6}$, $\mathrm{MF}_{6}$ flow rate, or plating rate. The values obtained compare favorably with previous fluorine analyses on pure tungsten deposits.

Analyses of five pure tungsten deposits are included in Table I for comparison.

\section{Dissimilar Refractory Alloy Joining}

A tantalum-alloy power conversion system coupled to a tungsten-alloy reactor system will contain joints between dissimilar alloys. We are thus examining techniques for fusion welding or diffusion bonding such alloys. At the very least, techniques for coupling dissimilar alloys will require an examination of the effect of diffusive interaction between the two alloys.

We have made the following joints between $\mathrm{W}-25 \% \operatorname{Re}-30 \% \mathrm{Mo}$ (at. \%) alloy and $\mathrm{T}-111$, i. e., $\mathrm{Ta}-8 \% \mathrm{~W}-2 \% \mathrm{Hf}$ (wt \%):

1. Direct weld - an electron beam fusion butt-weld made directly between the W-Re-Mo and T-111.

2. Mo transition - accomplished by electron beam fusing an 0.018-in. thick transition piece of pure Mo between the W-Re-Mo and T-111 alloys.

3. Mo-50Re transition-similar to (2) except the transition piece was Mo-50\%Re (wt \%).

These joints were made with 0.5-in. o. d., 0.040-in. wall tubing. Each joint cracked on cooling, because the alloy formed on fusion could not sustain shrinkage strains. Fig. 2 shows metallographic sections of the direct weld (Fig. 2a) and the Mo transition weld (Fig. 2b). The

Table I. Fluorine analyses for 1 -in. long tubes prepared by chemical vapor deposition (CVD).

\begin{tabular}{|c|c|c|c|c|c|c|c|}
\hline $\begin{array}{l}\text { Specimen } \\
\text { No. }\end{array}$ & $\begin{array}{c}\text { Temperature } \\
\left({ }^{\circ} \mathrm{C}\right)\end{array}$ & $\begin{array}{l}\text { Pressure } \\
\text { (torr) }\end{array}$ & $\begin{array}{c}\mathrm{H}_{2} / \mathrm{MF}_{6} \\
\left(\mathrm{~cm}^{3} / \mathrm{min}\right)\end{array}$ & $\begin{array}{c}\text { Composition } \mathrm{MF}_{(\% \operatorname{ReF} 6)} \\
(\%)\end{array}$ & $\begin{array}{c}\text { Rate } \\
\text { (mils/min) }\end{array}$ & $\begin{array}{c}\text { Composition } \\
(\% \operatorname{Re})\end{array}$ & $\begin{array}{l}\text { Fluorine } \\
\text { (ppm) }\end{array}$ \\
\hline 552 & $1000^{\circ}$ & 10 & $1000 / 70$ & 14.3 & 0.61 & 15.0 & 25 \\
\hline $548^{a}$ & $800^{\circ}$ & 10 & $1000 / 70$ & 14.3 & - & 15.0 & 27 \\
\hline $548^{\mathrm{b}}$ & $800^{\circ}$ & 10 & $1000 / 70$ & 14.3 & 0.42 & 16.0 & 25 \\
\hline $548^{C}$ & $800^{\circ}$ & 10 & $1000 / 70$ & 14.3 & - & - & 23 \\
\hline 547 & $750^{\circ}$ & 10 & $1000 / 70$ & 14.3 & - & 18.5 & $13(18)^{\mathrm{d}}$ \\
\hline $546^{b}$ & $700^{\circ}$ & 10 & $1000 / 70$ & 14.3 & 0.35 & 19.0 & 28 \\
\hline $546^{c}$ & $700^{\circ}$ & 10 & $1000 / 70$ & 14.3 & - & - & 20 \\
\hline 543 & $650^{\circ}$ & 10 & $1000 / 70$ & 14.3 & 0.31 & 21.0 & 11 \\
\hline $545^{b}$ & $600^{\circ}$ & 10 & $1000 / 70$ & 14.3 & 0.25 & 26.0 & 12 \\
\hline $545^{\mathrm{c}}$ & $600^{\circ}$ & 10 & $1000 / 70$ & 14.3 & - & 26.0 & 11 \\
\hline 488 & $600^{\circ}$ & 40 & $500 / 70$ & 14.3 & - & 21.5 & 4 \\
\hline 489 & $600^{\circ}$ & 40 & $500 / 70$ & 14.3 & - & 14.0 & 15 \\
\hline 441 & $700^{\circ}$ & 20 & $500 / 70$ & 14.3 & 0.44 & 20.0 & $5(24)^{\mathrm{d}}$ \\
\hline 542 & $700^{\circ}$ & 20 & $500 / 70$ & 14.3 & 0.44 & 19.5 & 10 \\
\hline 744 & $500^{\circ}$ & 5 & $500 / 70$ & 6.8 & 0.11 & 39.5 & 13 \\
\hline 733 & $1000^{\circ}$ & 10 & $1500 / 500$ & 6.8 & 1.53 & 8.5 & $10(13)^{\mathrm{d}}$ \\
\hline 732 & $800^{\circ}$ & 10 & $1500 / 500$ & 6.9 & 0.83 & 11.5 & $21(20)^{\mathrm{d}}$ \\
\hline 734 & $550^{\circ}$ & 10 & $1500 / 500$ & 6.8 & 0.23 & 32.5 & $36(26)^{d}$ \\
\hline 486 & $700^{\circ}$ & 40 & $2800 / 140$ & 14.3 & - & 17.5 & 4 \\
\hline 482 & $600^{\circ}$ & 40 & $2800 / 140$ & 10.0 & 0.34 & 6.5 & 12 \\
\hline 621 & $1000^{\circ}$ & 20 & $250 / 140$ & 6.8 & 1.07 & 8.0 & 14 \\
\hline
\end{tabular}

${ }^{a}$ End sample.

${ }^{\mathrm{b}}$ Center sample.

COpposite end sample.

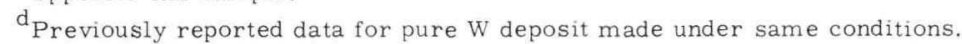


Mo-50\%Re transition weld (not shown in Fig. 2) contains a crack running completely through the weld nugget. The severity of cracking decreases in the order: direct weld, Mo-50\%Re transition, Mo transition; but electron fractography indicates failure by cleavage, with no indication of ductile behavior in any of these cases. Optical examination up to $1000 \times$ did not reveal a second phase.

Figures 3 and 4 show results of hardness and microprobe analyses through the nugget for both the direct and Motransition welds. The great increase in hardness associated with the alloy formed in the direct weld (Fig. 3) contrasts with the moderate hardening associated with the Mo transition weld (Fig. 4). This difference is probably associated with the anomalous solid solution strengthening known to exist in the Mo-Ta system. ${ }^{2}$ Such an association is supported by microprobe results which indicate that $\mathrm{Ta}$ is effectively

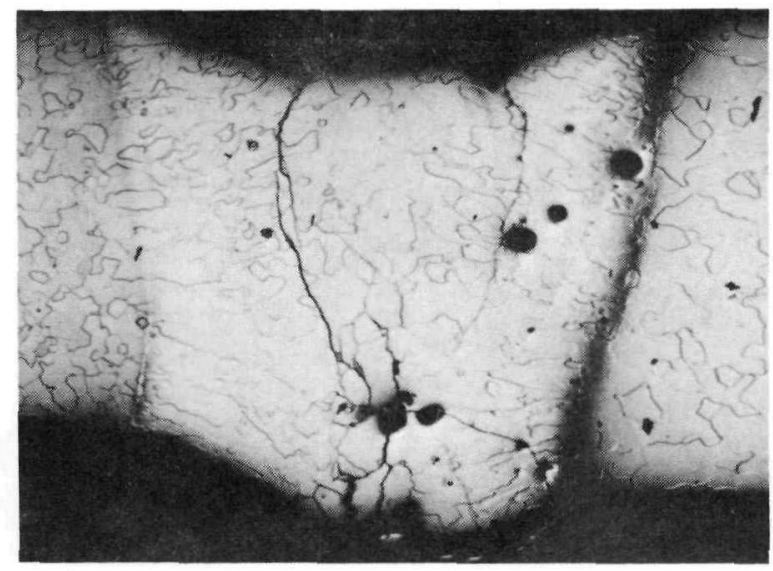

$\mathrm{T}-111$
W-Re-Mo

a. "Direct weld." diluted by Mo in the case of the Mo transition weld (compare Figs. 3 and 4).

Table II summarizes the results for all three welds.

Weld hardness varies in relation to the amount of $\mathrm{Ta}$ in the weld, whereas the Re content apparently has little if any in-

fluence. The correlation between Ta content and hardness is shown in Fig. 5.

These results suggest that high hardness and low resistance to cleavage are associated with solid solution demixing similar to that indirectly observed by Van Torne and Thomas ${ }^{2}$ in Mo-Ta single crystals. These workers report: lowstress (100) plane cleavage for single crystals of compositions between Mo-19\%Ta and Mo-58\% Ta (at. \%); no phase separation observable by transmis sion electron microscopy; (100) plane segregation deduced by $\mathrm{x}$-ray line broadening and Kikuchi line analysis; and very pronounced solution strengthening at the

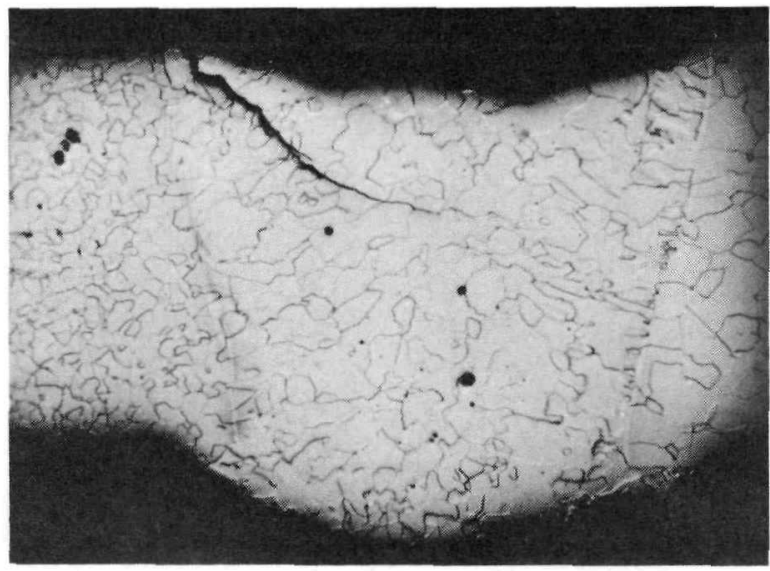

$\mathrm{T}-111$

Alloy

W-Re-Mo

b. Mo transition piece (0.018 in. thick).

Fig. 2. Electron-beam fusion welds between T-111, i.e., Ta-8\%W-2\%Hf (wt \%), and $\mathrm{W}-25 \% \mathrm{Re}-30 \%$ Mo (at. $\%$ ). 

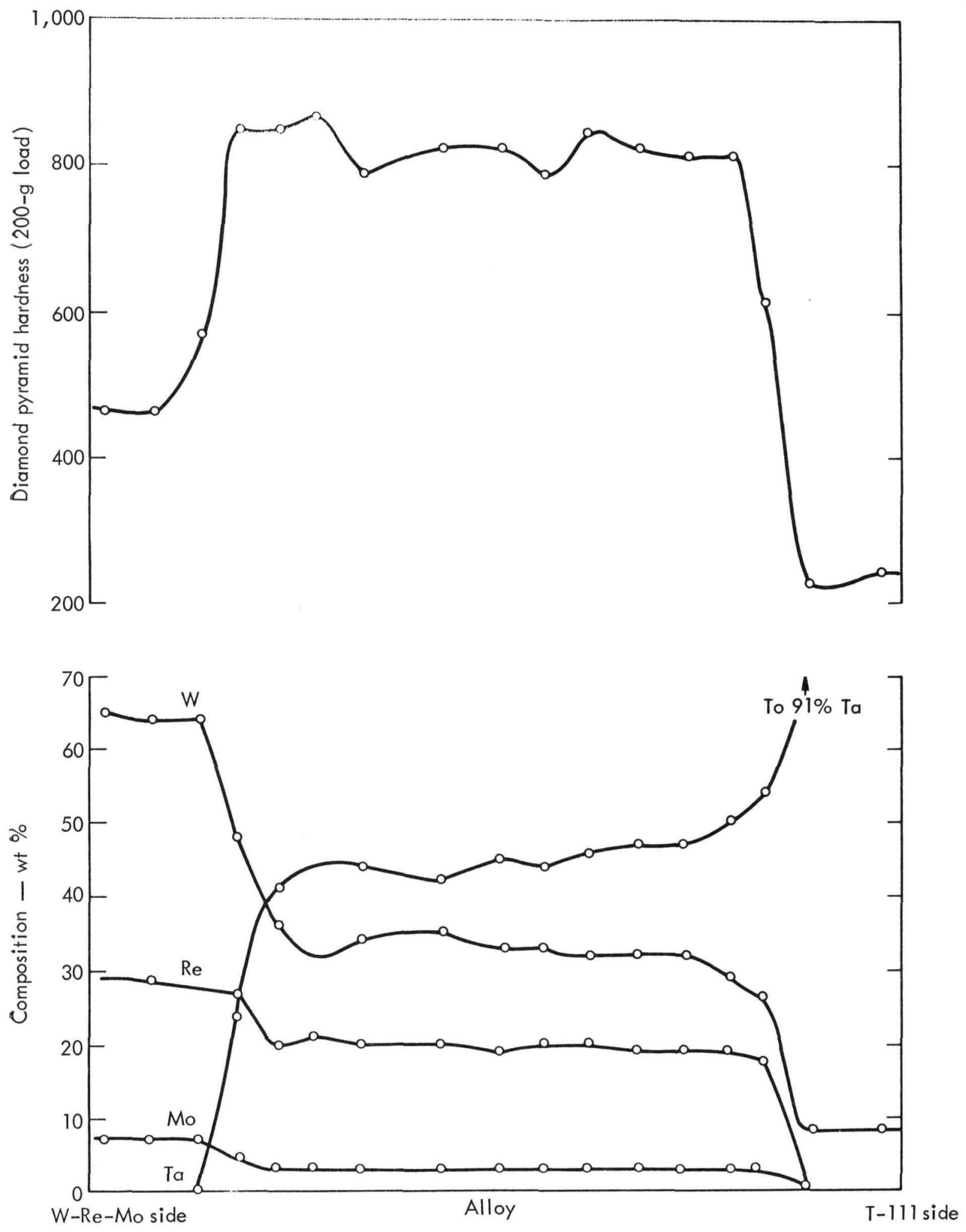

Fig. 3. Hardness and microprobe traverses across the weld nugget alloy formed by a direct weld between $\mathrm{T}-111$ and $\mathrm{W}-25 \% \mathrm{Re}-30 \% \mathrm{Mo}$. (Hf content neglected in microprobe analysis.) 

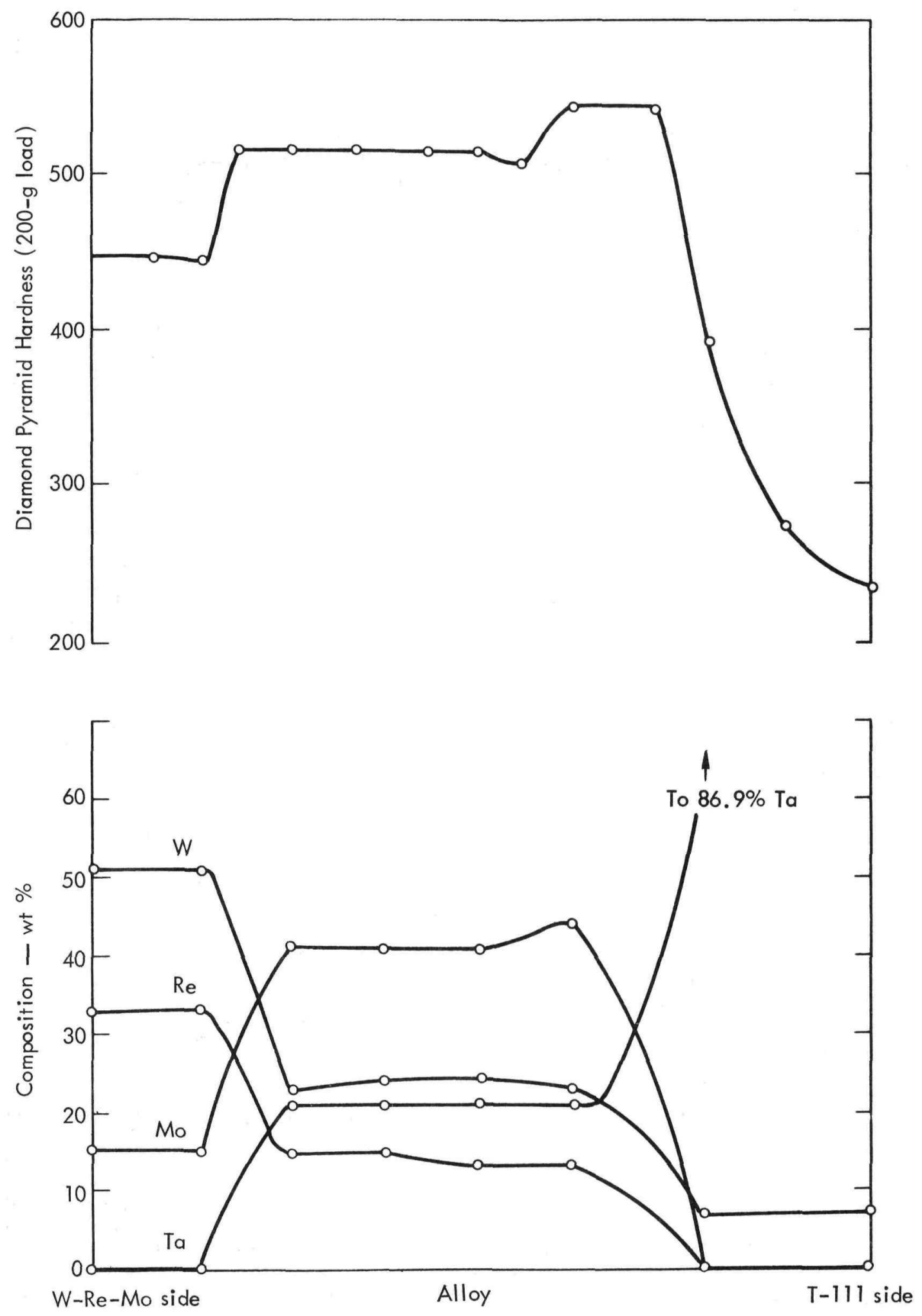

Fig. 4. Hardness and microprobe traverses across a weld between $\mathrm{T}-111$ and $\mathrm{W}-25 \% \mathrm{Re}-30 \%$ Mo with a 0.018-in. Mo transition piece. (Hf content neglected in microprobe analysis.) 
Table II. Composition and hardness for some weld combinations.

\begin{tabular}{|c|c|c|}
\hline $\begin{array}{c}\text { Alloy } \\
\text { Composition }\end{array}$ & $\begin{array}{c}\text { Composition of weld } \\
(\text { at. \%) }\end{array}$ & $\begin{array}{l}\text { Average DPH hardness } \\
\text { for } 200 \text { g loadb }\end{array}$ \\
\hline W-Re-Mo base alloy & $45 \mathrm{~W}, 25 \mathrm{Re}, 30 \mathrm{Mo}$ & 465 \\
\hline $\begin{array}{l}\mathrm{T}-111: \mathrm{Ta}-8 \% \mathrm{~W}-2 \% \mathrm{Hf} \\
\text { (wt } \% \text { ), welded directly } \\
\text { to W-Re-Mo alloy }\end{array}$ & $31.1 \mathrm{~W}, 5.6 \mathrm{Mo}, 43.8 \mathrm{Ta}, 18.5 \mathrm{Re}$ & 840 \\
\hline $\begin{array}{l}\mathrm{T}-111 \text { to W-Re-Mo with } \\
0.018-\text { in. transition of } \\
\text { pure Mo }\end{array}$ & $17.6 \mathrm{~W}, 57.5 \mathrm{Mo}, 15.4 \mathrm{Ta}, 9.5 \mathrm{Re}$ & 530 \\
\hline $\begin{array}{l}\text { T-111 to W-Re-Mo with } \\
0.018-\text { in. transition of } \\
\text { Mo-50\%Re (wt \%) }\end{array}$ & 19.0W, 33.2Mo, 23.3Ta, 24.5Re & 610 \\
\hline
\end{tabular}

${ }^{a}$ At center of weld nugget, and neglecting Hf content.

$\mathrm{b}_{\text {Average hardness across weld nugget. }}$

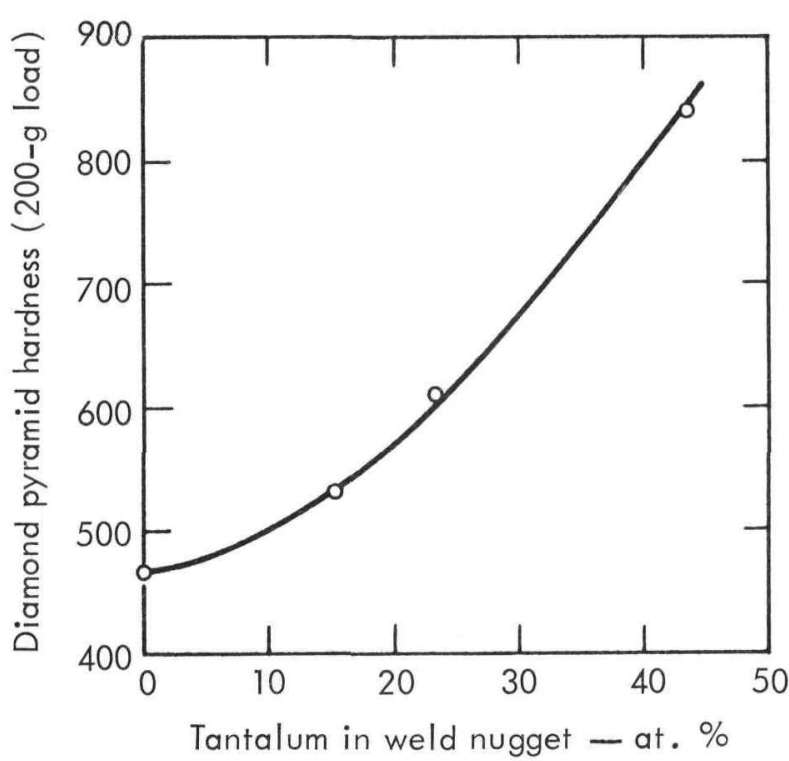

Fig. 5. Correlation between tantalum content and hardness (from Table II).

Mo- and Ta-rich ends of the system. The similarities between the results of Van

Torne and Thomas and the observations reported here include: (1) the absence of a detectable second phase (our examination was limited to optical inspection at 1000X), (2) a low resistance to cleavage failure, and (3) the same type of exponential dependence of strength on Ta content (see Fig. 5). It is reasonable to conclude that demixing, leading to pronounced solution strengthening and embrittlement, occurs in the W-Re-Mo-Ta system. A proposed model of this demixing ${ }^{2}$ suggests that embrittlement will occur at certain compositions for any combination between Group V (Mo and W) and Group VI (Nb and $\mathrm{Ta}$ ) metals, and that direct fusion welds between these metals or their alloys should be avoided.

Cracking might be prevented if a Mo transition were used to dilute the Ta. The Ta concentration in the weld could probably be reduced to an acceptable minimum if a thicker transition were used and/or if welding conditions were such as to minimize alloying. Diffusion bonding to minimize the volume of alloy in critical concentration might solve the cracking problem. In each case however, the propensity for room temperature cracking would persist and be aggravated by high temperature exposure, due to diffusive 
mixing. Research is continuing in these areas.

Elevated Temperature Deformation Behavior of Tungsten and Tungsten Alloys

In this program, the deformation behavior of tungsten and tungsten alloys is being investigated at temperatures from 1400 to $1900^{\circ} \mathrm{C}$, and at stresses from 0.7 to $7 \mathrm{~kg} / \mathrm{mm}^{2}$ ( $10^{3}$ to $10^{4} \mathrm{psi}$ ). The effects of temperature, stress, substructure, and alloy composition on the strain rate are being evaluated, and the ratecontrolling deformation mechanisms governing the creep behavior are being determined. Materials for initial study in this program include $\mathrm{W}, \mathrm{W}-5 \% \mathrm{Re}$, $\mathrm{W}-25 \% \mathrm{Re}, \mathrm{W}-30 \% \mathrm{Re}$, and $\mathrm{W}-30 \% \mathrm{Re}-18 \% \mathrm{Mo}$ (wt \%).

Creep tests have been completed on $\mathrm{W}$, $\mathrm{W}-25 \% \mathrm{Re}$, and $\mathrm{W}-30 \% \mathrm{Re}$ at $1700^{\circ} \mathrm{C}$ and stresses of 3.52 and $5.28 \mathrm{~kg} / \mathrm{mm}^{2}$. Test specimens were $0.050 \mathrm{in}$. thick, and the gage section was $0.125 \mathrm{in}$. wide and 0.075 in. 1ong. Overall specimen length was about $2.5 \mathrm{in}$. The alloys were consolidated by powder metallurgy techniques, extruded to sheet bar, and then hot rolled to final thickness. Before testing, the W and $\mathrm{W}-25 \% \mathrm{Re}$ specimens were annealed for $50 \mathrm{hr}$ at $1800^{\circ} \mathrm{C}$, and the $\mathrm{W}-30 \% \mathrm{Re}$ specimens were solution-annealed for $2 \mathrm{hr}$ at $2250^{\circ} \mathrm{C}$ and then aged for $50 \mathrm{hr}$ at $1800^{\circ} \mathrm{C}$. All tests and heat treatments were conducted in a vacuum of $10^{-8}$ to $10^{-9}$ torr. Deformation in the specimens was measured by tracking fiducial marks on the gage section with an optical comparator.

Figures 6 and 7 show strain-time curves for $\mathrm{W}, \mathrm{W}-25 \% \mathrm{Re}$, and $\mathrm{W}-30 \% \mathrm{Re}$ during creep testing at $1700^{\circ} \mathrm{C}$ and 1.76 and $7.03 \mathrm{~kg} / \mathrm{mm}^{2}$. At $7.03 \mathrm{~kg} / \mathrm{mm}^{2}$ the $\mathrm{W}-25 \%$ Re has the greatest creep resistance, and $\mathrm{W}$ has the least. Such a result has been reported previously, * for these materials when they were creep tested at $1700^{\circ} \mathrm{C}$ and 3.52 and $5.28 \mathrm{~kg} / \mathrm{mm}^{2}$. How ever, at $1.76 \mathrm{~kg} / \mathrm{mm}^{2} \mathrm{~W}$ has the lowest creep rate and $\mathrm{W}-25 \% \mathrm{Re}$ has the highest. Note that although the creep rate for $\mathrm{W}$ is $20 \%$ lower than that for $\mathrm{W}-\mathrm{Re}$, the total strain at $100 \mathrm{hr}$ is nearly the same (Fig. 7). This is because primary creep is negligible for the W-Re alloys but appreciable for W. The creep curve for the W-25\%Re alloy tested at $7.03 \mathrm{~kg} / \mathrm{mm}^{2}$ shows a tertiary region of creep, beginning at a strain of about $4.5 \%$. This is apparently due to void formation at grain boundaries (Fig. 8). The majority of voids are located on grain boundaries transverse to the applied tensile stress.

The stress-strain rate relationship for these materials at $1700^{\circ} \mathrm{C}$ is shown in Fig. 9. The stress laws for $\mathrm{W}$ and $\mathrm{W}-30 \%$ Re can be described by the equation $\dot{\epsilon}=\sigma^{\mathrm{n}}$, where $\dot{\epsilon}$ is the minimum strain rate, $\sigma$ is the applied stress, and $n$ is a constant. The stress exponent, $\mathrm{n}$, is 5.5 for $\mathrm{W}$ and 4.1 for the $\mathrm{W}-30 \% \mathrm{Re}$. The stress law for the $\mathrm{W}-25 \% \mathrm{Re}$ is more complex and probably involves a change of the rate-controlling deformation mechanism in this stress region.

*See 1967 third-and fourth-quarter reports, UCRL-50004-67-3, Part I, and UCRL-50004-67-4, Part I. 


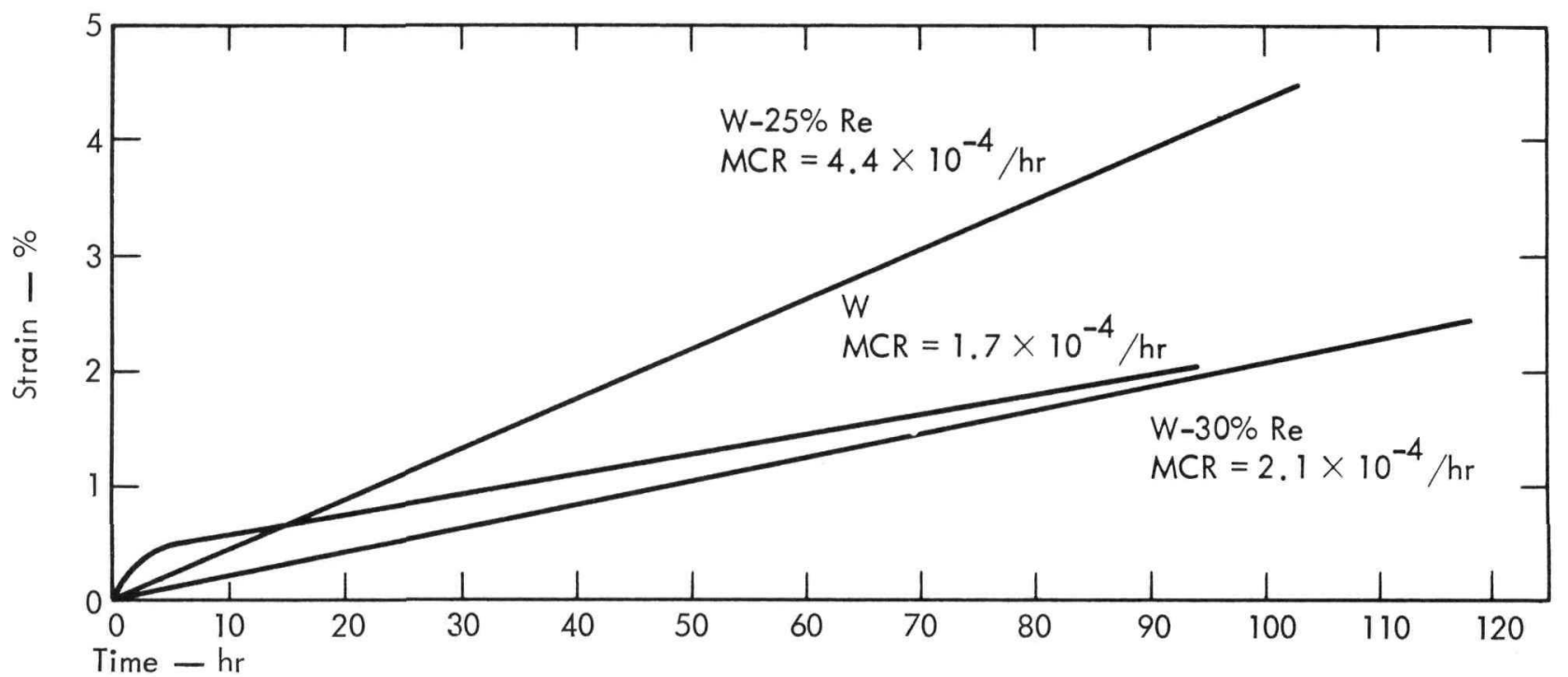

Fig. 6. Creep curves for $\mathrm{W}, \mathrm{W}-25 \% \mathrm{Re}$, and $\mathrm{W}-30 \%$ Re $\left(\mathrm{wt} \%\right.$ ) at $1700^{\circ} \mathrm{C}$ and $1.76 \mathrm{~kg} / \mathrm{mm}^{2}$. MCR = minimum creep rate.

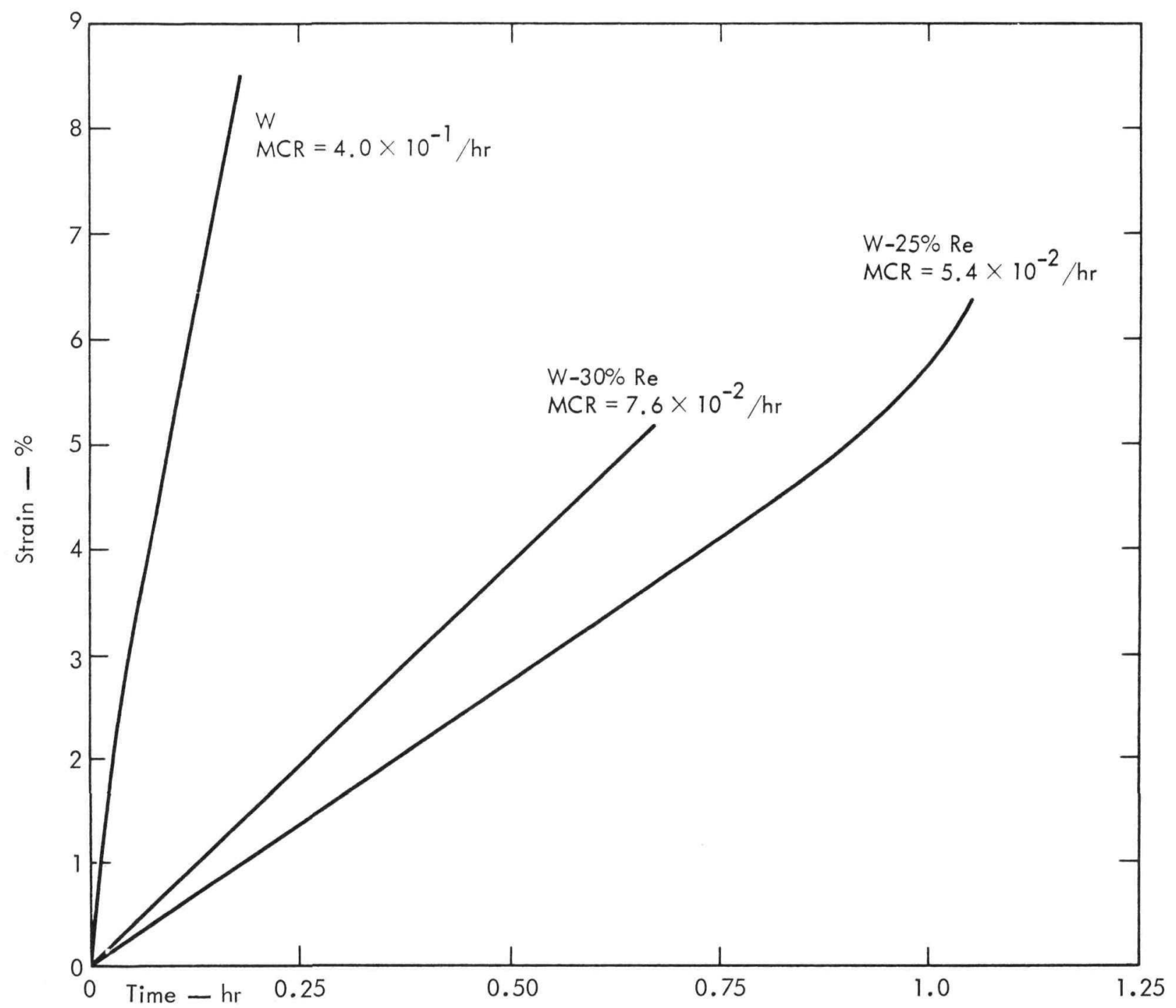

Fig. 7. Creep curves for $\mathrm{W}, \mathrm{W}-25 \% \mathrm{Re}$, and $\mathrm{W}-30 \% \operatorname{Re}\left(\mathrm{wt} \%\right.$ ) at $1700^{\circ} \mathrm{C}$ and $7.03 \mathrm{~kg} / \mathrm{mm}^{2}$. MCR = minimum creep rate. 


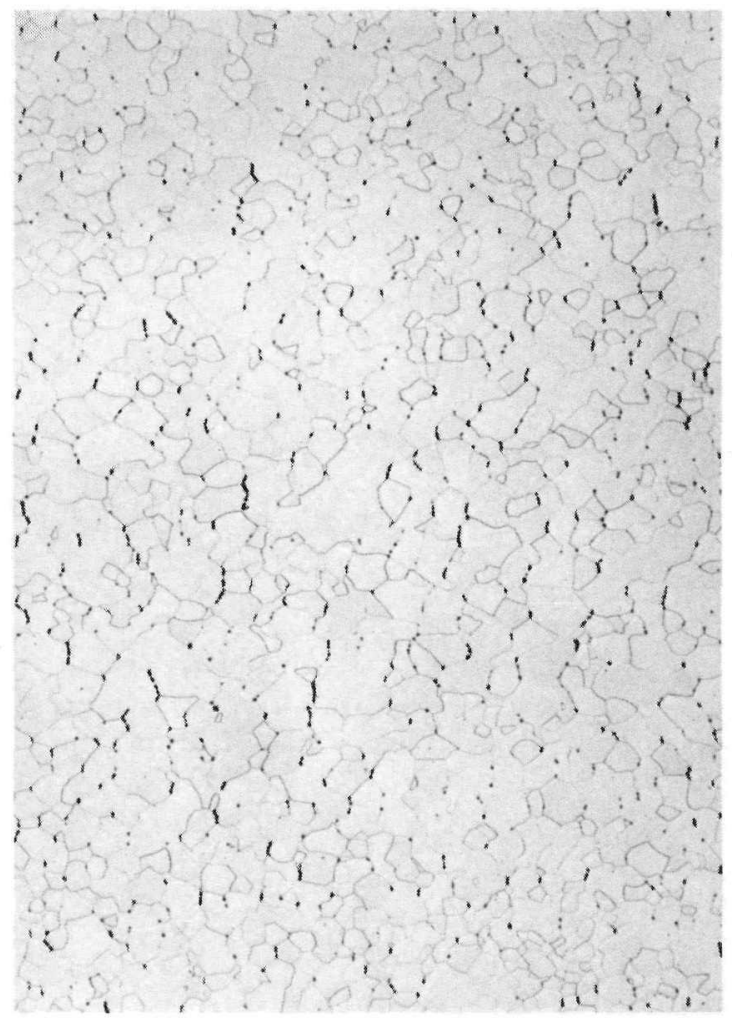

Fig. 8. Void formation at grain boundaries (stress direction horizontal). 100X

FUEL STUDIES

\section{Uranium Nitride Synthesis and Fabrication}

\section{Synthesis}

Our synthesis of UN is based on the ammonia reaction:

$\mathrm{UH}_{3}+\mathrm{xNH}_{3} \underset{340-360^{\circ} \mathrm{C}}{\stackrel{\sim}{\longrightarrow}} \mathrm{UN}_{\mathrm{x}}+\frac{3(\mathrm{x}+1)}{2} \mathrm{H}_{2}$

where $\mathrm{x}$ is 1.6 to 1.8 . UN powders of consistent batch-to-batch properties have been produced. Synthesis parameters are being varied to determine their effects on the UN powder product.

The following method is used to prepare 150- to 200-g batches of the UN powder

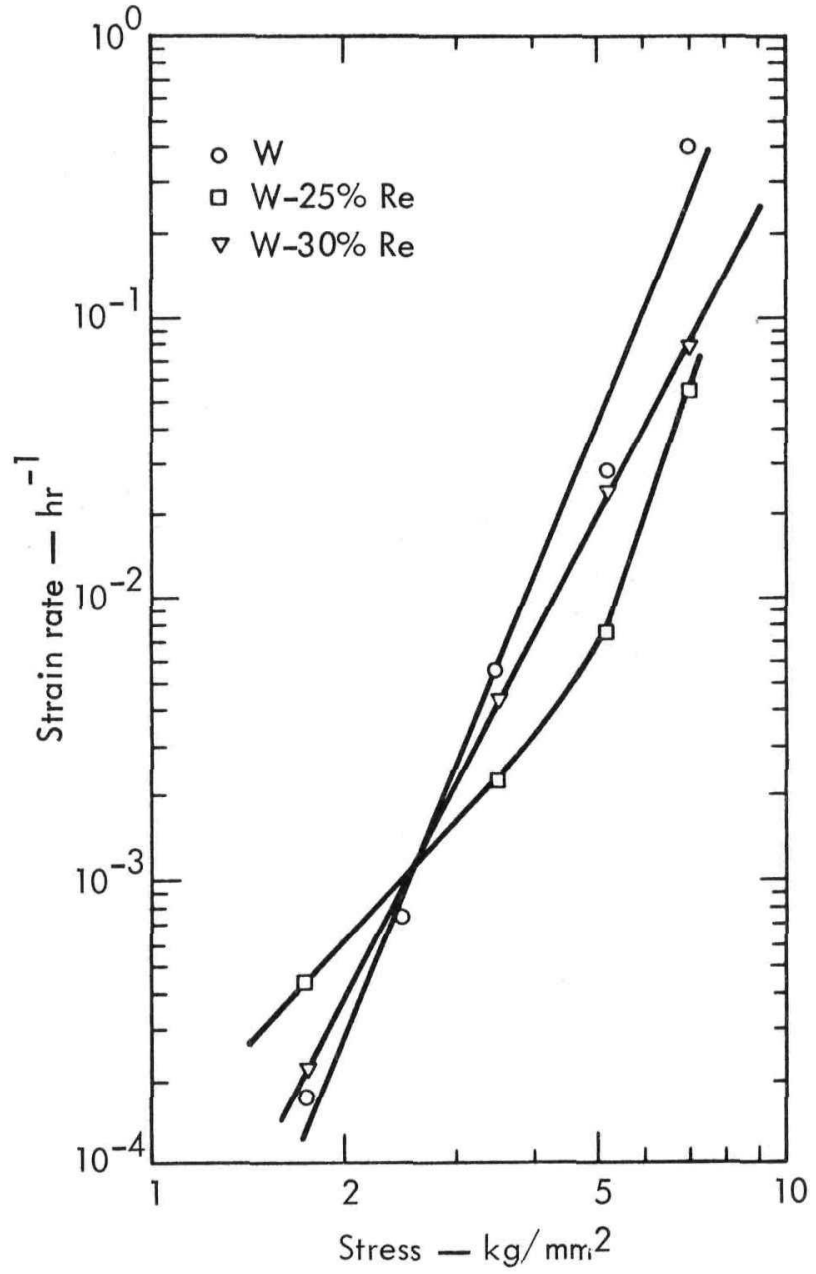

Fig. 9. The effect of stress on strain rate for $\mathrm{W}, \mathrm{W}-25 \% \mathrm{Re}$, and $\mathrm{W}-30 \% \mathrm{Re}$ (wt \%) at $1700^{\circ} \mathrm{C}$.

(about $2-\mathrm{cm}$ powder bed depth):

To obtain a finely divided active material for nitriding, massive uranium is hydrided and then dehydrided. Hydriding for about $1 \mathrm{hr}$ at 90 to $130^{\circ} \mathrm{C}$ and 800 torr hydrogen is followed by dehydriding for about $2 / 3 \mathrm{hr}$ at between 410 and $450^{\circ} \mathrm{C}$. Together with heat-up and cool-down times, each complete operation takes about $2-2 / 3 \mathrm{hr}$. Typically, 6 to 8 hydriding-dehydriding operations are carried out on one batch. The sequence is terminated after a hydriding operation.

The fine hydride powder is nitrided 
until the $\mathrm{N} / \mathrm{U}$ ratio of the product exceeds 1.5 , as estimated by weight gain. To reach such a condition, thirty or more hours at $350^{\circ} \mathrm{C}$ and 830 torr ammonia are required.

After the nitriding, the product is denitrided until a $\mathrm{N} / \mathrm{U}$ ratio of 1.0 is attained This process is carried out under vacuum at $900^{\circ} \mathrm{C}$ for $40 \mathrm{hr}$. The diffusionpumped vacuum system will hold about $10^{-5}$ torr during denitriding.

UN powder obtained as above had a surface area of $0.44 \mathrm{~m}^{2} / \mathrm{g}$, as determined by BET nitrogen adsorption on one batch of the material. This indicates an average equivalent particle diameter of about $1 \mu$.

Contamination by carbon and oxygen occurred during the conversion of the metal to UN. Table III gives analytical results showing decreased carbon contamination for three successive recent UN batches. The data indicate that cryogenic baffles in both the synthesis and sintering vacuum systems have markedly reduced carbon contamination. (The carbon content of the starting metal was 15 ppm.)

The starting metal contains $5 \mathrm{ppm} \mathrm{O}_{2}$, but 1,000 to $>4000 \mathrm{ppm} \mathrm{O}_{2}$ are found in the UN product. This indicates that oxygen is entering the product through leaks during synthesis and subsequent operations. Leaks in the glove box line are currently being eliminated.

Table IV gives analytical results for nitrogen and oxygen in the UN powder and the sintered product. $\mathrm{X}$-ray diffraction measurements on the UN powders consistently give $a_{0}=4.888 \AA$.

Nitrogen determined by vacuum fusion sometimes differs significantly from nitrogen determined by the $\mathrm{C}, \mathrm{H}$, and $\mathrm{N}$ method. Agreement is better for sintered materials
Table III. Analysis of UN for carbon.

\begin{tabular}{cc}
\hline Batch No. & Carbon (ppm) \\
\hline 13 & 300 \\
14 & 163 \\
15 & 34 \\
\hline
\end{tabular}

than for the powder. Fine powders are difficult to handle in vacuum fusion. In general, nitrogen determined by weight gain is closer to the $\mathrm{C}, \mathrm{H}$, and $\mathrm{N}$ result than to the result from vacuum fusion. However, the weight gain includes both oxygen and nitrogen.

\section{Fabrication}

Ammonia-derived UN powders sinter well. However, sintering performance is affected by the conditions under which the powder is compacted, as the following results show:

A hydrostatic pressure of 150,000 psi is required to reach 63 to $65 \%$ of theoretical density in the green compacts. Sinterable compacts are realized at lower pressures $(50,000$ to $100,000 \mathrm{psi})$, but green densities are lower (50 to $55 \%$ of theoretical) and extended time at temperature is required to reach maximum sintered density. Table $\mathrm{V}$ shows results obtained with batch 13 of the UN powder. All firings were made in 525 torr of nitrogen, with a 2 -hr hold at $2260^{\circ} \mathrm{C}$. (This sintering cycle is outlined in a later paragraph.)

The highest density was achieved when both prepacking and high hydrostatic forming pressure were used. The lowest density material continued to sinter when annealed at $2000^{\circ} \mathrm{C}$.

Ammonia has been substituted for nitrogen as a sintering atmosphere. Table VI indicates that under this condition a slight 
Table IV. Analysis of $\mathrm{UN}$ for $\mathrm{N}_{2}$ and $\mathrm{O}_{2}$.

\begin{tabular}{llcccc}
\hline & & \multicolumn{3}{c}{ Percent $\mathrm{N}_{2}$ by: } & ppm $\mathrm{O}_{2}$ by \\
\cline { 3 - 5 } Sample & Description & $\begin{array}{c}\text { Weight } \\
\text { gaina }\end{array}$ & $\begin{array}{c}\text { Vacuum } \\
\text { fusion }\end{array}$ & $\begin{array}{c}\mathrm{C}, \mathrm{H}, \\
\text { and Nb }\end{array}$ & $\begin{array}{c}\text { vacuum } \\
\text { fusion }\end{array}$ \\
\hline 13 & Powder & - & 5.57 & 5.58 & 3530 \\
14 & Powder & 5.53 & 5.08 & 5.48 & 1080 \\
$14-1$ & Sintered & & 5.36 & 5.53 & 2150 \\
15 & Powder & 5.60 & 4.76 & 5.46 & 1320 \\
$15-1$ & Sintered & & 5.34 & 5.40 & 3690 \\
16 & Powder & 5.52 & 5.16 & 5.51 & 4580 \\
17 & Powder & 5.40 & 5.57 & 5.54 & 2644 \\
18 & Powder & 5.72 & 5.69 & 5.55 & 4262 \\
\hline
\end{tabular}

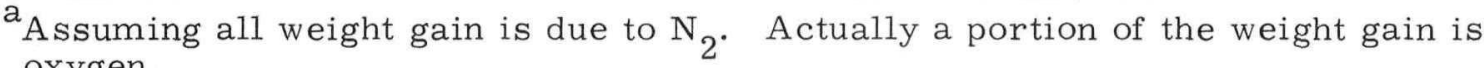
oxygen.

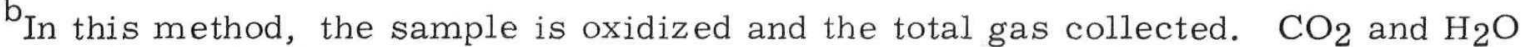
are determined by absorption, and the remaining volume of gas is taken to be $\mathrm{N}_{2}$.

Table V. Compacting studies with batch 13 of UN powder.

\begin{tabular}{|c|c|c|c|c|c|c|}
\hline $\begin{array}{c}\text { Pre- } \\
\text { packed? }\end{array}$ & $\begin{array}{c}\text { Tap } \\
\text { density } \\
(\% \text { theoret })\end{array}$ & $\begin{array}{l}\text { Hydrostatic } \\
\text { pressure } \\
\text { (psi) }\end{array}$ & $\begin{array}{c}\text { Green } \\
\text { density } \\
(\% \text { theoret })\end{array}$ & $\begin{array}{c}\text { Sintered } \\
\text { density } \\
\text { (\% theoret) }\end{array}$ & $\begin{array}{l}\text { Annealed } \\
\text { density } \\
\text { (\% theoret) }\end{array}$ & Comments \\
\hline \multirow[t]{2}{*}{ No } & $\sim 18$ & 50,000 & 51 & 90 & 95 & $\begin{array}{l}24 \mathrm{hr} \text { anneal } \\
\text { at } 2000^{\circ} \mathrm{C} \text { in } \\
\mathrm{N}_{2}\end{array}$ \\
\hline & & & & & 97.5 & $\begin{array}{l}74 \mathrm{hr} \text { anneal } \\
\text { at } 2000^{\circ} \mathrm{C} \text { in } \\
\mathrm{N}_{2}\end{array}$ \\
\hline No & $\sim 18$ & 150,000 & 63 & 94 & & \\
\hline Yes & $\sim 35$ & 50,000 & 55 & 94 & & \\
\hline Yes & $\sim 35$ & 150,000 & 63 & 97 & & \\
\hline
\end{tabular}

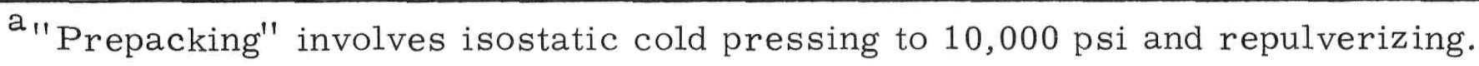

Table VI. Effect of sintering medium on density of UN product.

\begin{tabular}{ccc}
\hline \multirow{2}{*}{$\begin{array}{c}\text { UN } \\
\text { batch No. }\end{array}$} & \multicolumn{2}{c}{ Sintered density (\% theoret) } \\
\cline { 2 - 3 } 535 torr $\mathrm{N}_{2}$ & 825 torr $\mathrm{NH}_{3}$ \\
\hline 14 & 96.6 & 96.1 \\
15 & 97.0 & 96.6 \\
16 & 96.3 & 95.8 \\
\hline
\end{tabular}


decrease in sinter density results; the differences are small but consistent. The sintering cycle was as follows:

1. Room temperature to $1540^{\circ} \mathrm{C}$; vacuum; 1 -hr hold.

2. Raise to $2040^{\circ} \mathrm{C} ; \mathrm{N}_{2}$ or $\mathrm{NH}_{3} ; 2-\mathrm{hr}$ hold.

3. Raise to $2260^{\circ} \mathrm{C} ; \mathrm{N}_{2}$ or $\mathrm{NH}_{3} ; 2-\mathrm{hr}$ hold.

4. Reduce to $\sim 1540^{\circ} \mathrm{C}$; evacuate; no hold.

5. Cool to room temperature.

UN from the ammonia nitriding process sinters to an average grain size of 10 to $16 \mu$ (3- to $38-\mu$ range). Subsequent annealing at $2000^{\circ} \mathrm{C}$ gave increased density (noted above) and increased grain size as follows:

$\begin{array}{cc}\text { Annealing time } & \frac{\text { Average grain size }}{24 \mathrm{hr}} \\ 74 \mathrm{hr} & 32 \mu\end{array}$

The sintering cycle has been used at CANEL in the SNAP-50 program. ${ }^{3}$ This cycle is being simplified and adapted to current needs. It has been shown that increasing the maximum sintering temperature to $2355^{\circ} \mathrm{C}$ does not increase density, that doubling the hold time at $2040^{\circ} \mathrm{C}$ does not improve density, and that lowering the intermediate hold temperature from 2040 to $1800^{\circ} \mathrm{C}$ does not affect densification. In other words, densification of LRL powder compacts seems insensitive to minor changes in the sintering cycle. The purpose of the $1540^{\circ} \mathrm{C}$ vacuum hold at CANEL was to finish the $\mathrm{U}_{2} \mathrm{~N}_{3}$-to-UN conversion and deoxidize the UN surfaces. The present intent is to eliminate both the vacuum hold and the lower temperature hold in nitrogen in favor of a sintering cycle with one hold under about 800 torr of ammonia. If successful, this will avoid problems with vacuum leaks and back-streaming.
Uranium Nitride Phase Equilibria and Vaporization

The vaporization behavior of UN powder from a tungsten Knudsen cell at nitrogen pressures of $130,0.1$, and 0.003 torr has been reported previously. * These results are shown again in Fig. 10, with all the previous data points omitted except for points 25, 29 and 36. The data is now expressed as a rate per unit area of the Knudsen cell orifice. Arrows for the 0.1 and 0.003 torr plots mark the temperatures at which decomposition is reported to take place. $^{4}$ In the 0.003 torr test, the systems corresponding to points 25, 29 and 36 appear to have reached steady state; the discontinuity between point 29 and the straight-line portion of the curve appears to be due to the decomposition. Point 36 was calculated at the end of a 90-min run $\left(2180^{\circ} \mathrm{K}\right)$. The rate was $5 \mathrm{mg} / \mathrm{min} / \mathrm{cm}^{2}$ at the beginning, and gradually became essentially constant at $17.5 \mathrm{mg} / \mathrm{min} / \mathrm{cm}^{2}$. The furnace power was then turned off and the sample was furnace cooled to below $800^{\circ} \mathrm{C}$ in 8.3 minutes. Chemical analysis of the sample after the run indicated 1220 ppm $\mathrm{O}_{2}$ and 1390 ppm $\mathrm{C}$ as compared with $1280 \mathrm{ppm} \mathrm{O}_{2}$ and $560 \mathrm{ppm} \mathrm{C}$ before the run. Nitrogen and uranium analyses were $4.82 \%$ and $95.18 \%$ respectively, giving a $\mathrm{N} / \mathrm{U}$ ratio of 0.86 . Assuming all the oxygen and carbon to be in the form of $\mathrm{UO}_{2}$ and $\mathrm{UC}$, one can calculate the overall composition of the two phase material to be $\mathrm{UN}_{0.90^{\circ}}$ Analyses after test may not be representative because the sample was exposed to air during a short transfer period and the

See 1967 fourth-quarter report, UCRL50004-67-4, Part I. 


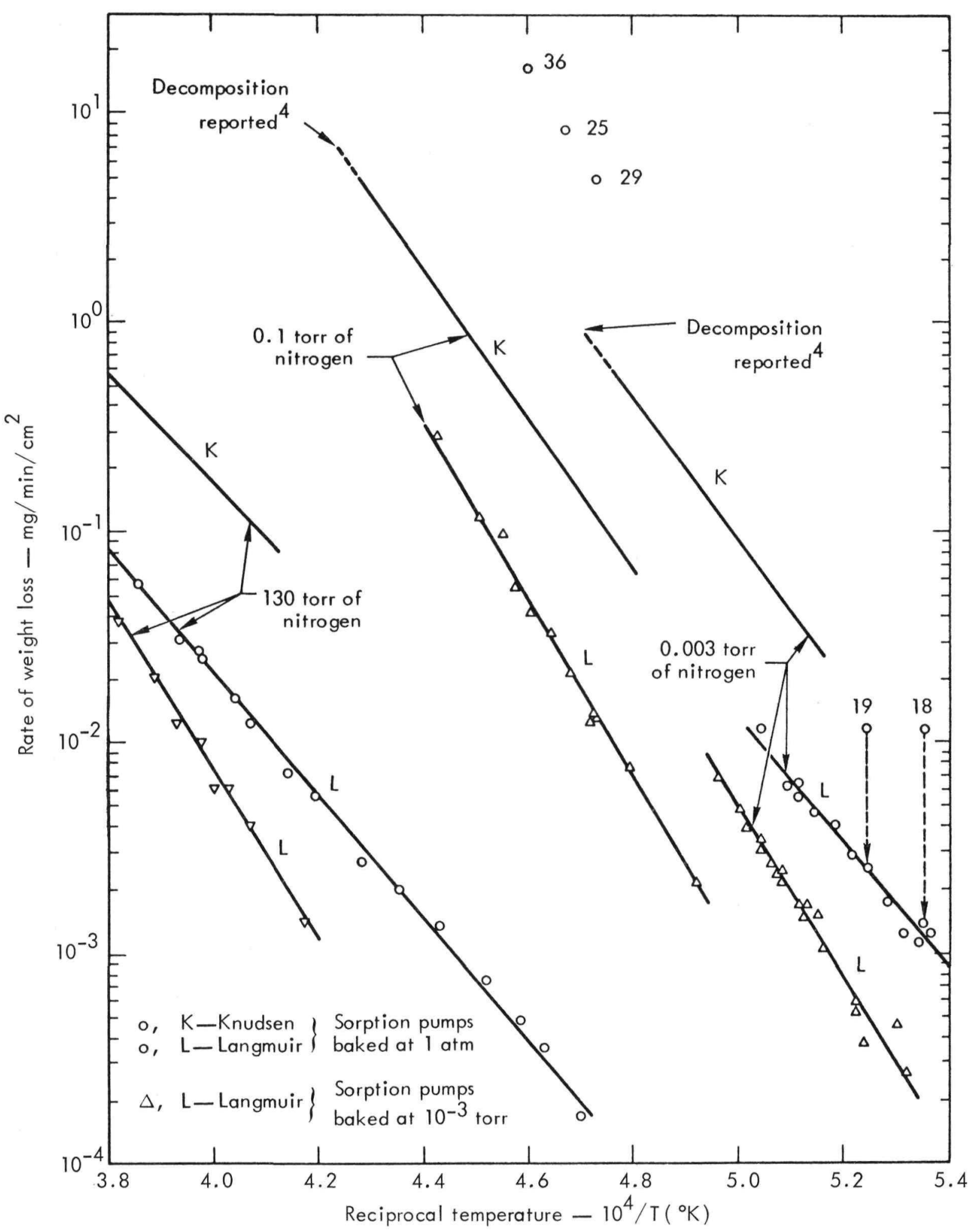

Fig. 10. Rate of weight loss for $U N_{1-x}$, as a function of reciprocal temperature. 
sintered sample material was difficult to extract from the Knudsen cell.

During these studies a Consolidated Electrodynamics Corp. 21-613 Residual Gas Analyzer (RGA) with a special sampling system was used to analyze nitrogen from the furnace at pressures between 0.1 and 760 torr. The nitrogen was fed through a gold leak directly into the ionization chamber of the analyzer. Gas chromatographs of the nitrogen supply were also taken. Combined analyses indicate the following levels of impurities in nitrogen during these tests: $\mathrm{CO},<10 \mathrm{ppm} ; \mathrm{O}_{2}, 2.4 \mathrm{ppm}$; $\mathrm{H}_{2} \mathrm{O}, \sim 30 \mathrm{ppm}$; and $\mathrm{CO}_{2}, \sim 15 \mathrm{ppm}$. Further evaluations are in progress to assess the accuracy of measuring impurities using the RGA, and the effect of the impurities on the vaporization processes.

The tungsten effusion cell was cut open after run 36 and prepared for metallographi and electron microprobe examinations. We were primarily interested in learning to what degree liquid uranium had penetrated the tungsten cell during the several experimental excursions into the two phase $\mathrm{U}_{(1)}{ }^{-\mathrm{UN}}(\mathrm{s})$ region.

Microscopic examination revealed 0.5 to $0.8-\mathrm{mm}$ penetration of uranium liquid into the bottom of the tungsten cell $(4.8-\mathrm{mm}$ thickness). Penetration occurred at the bottom of the cell only. Figure 11 shows a microscopic and electron microprobe view of a typical area of penetration. The vapor-deposited tungsten was typically $97 \%$ of theoretical density. The rounded tungsten grains were characteristic of only those areas where uranium liquid was detected.

In order to complement Knudsen cell vaporization studies of UN powder, Langmuir vaporization tests were run on a

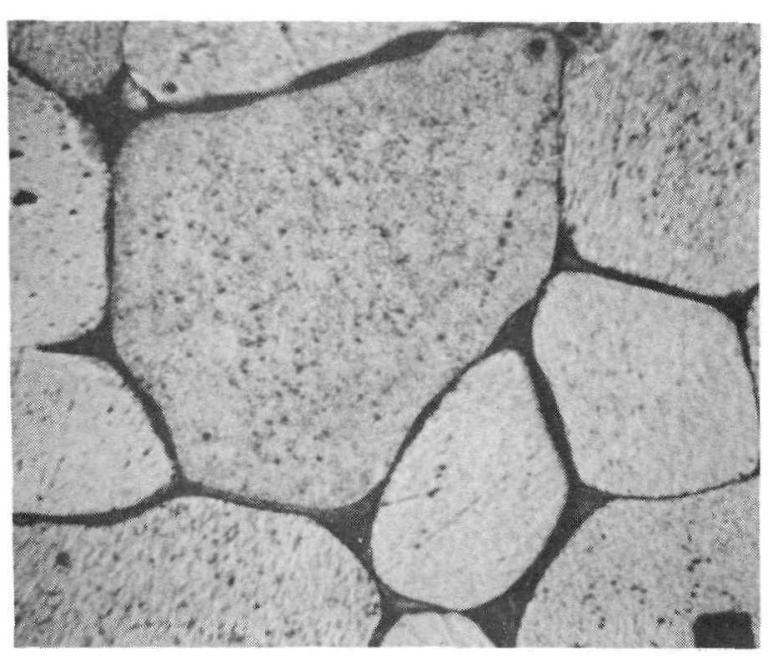

Optical photomicrograph. (325x)

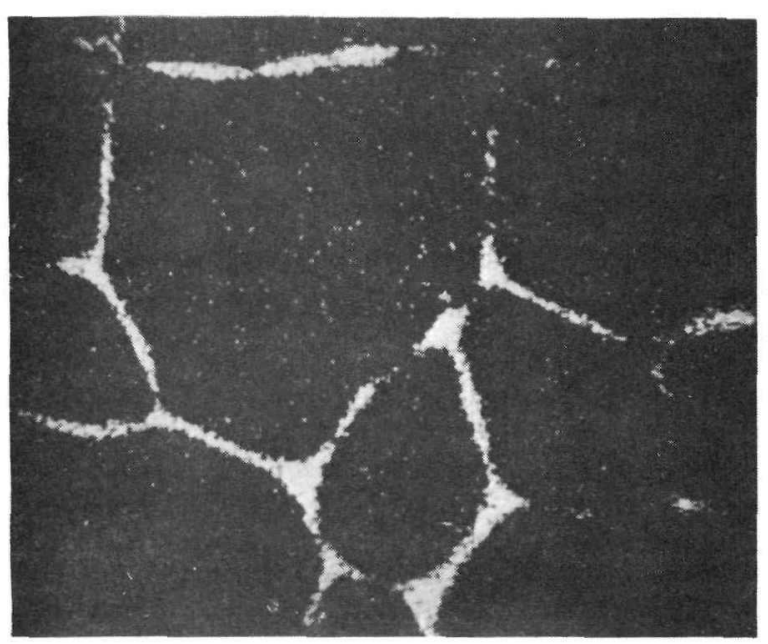

Uranium image by microprobe. (325×)

Fig. 11. Photomicrograph and electron microprobe results for penetration of liquid uranium into the vapor-deposited tungsten can.

pellet of UN. The specimen was a rightcircular cylinder cut from a rod (designated "1 B") prepared by Battelle-Columbus. The specimen was $1.034 \mathrm{~cm}$ in diameter and $0.640 \mathrm{~cm}$ long, weighed 7.6 grams, and had a bulk density $98.6 \%$ of theoretical. 
The supplier reported total metal impurities to be less than $167 \mathrm{ppm}$; $\mathrm{P}$, <60 ppm; $\mathrm{O}_{2}, 85 \mathrm{ppm}$; and C, $150 \mathrm{ppm}$. The reported nitrogen analysis (Kjeldahl) was $5.63 \mathrm{wt} \%$, which is equivalent to an $\mathrm{N} / \mathrm{U}$ ratio of 1.01 .

Initially, we used this pellet to study kinetics of compositional change in the single phase UN region, in order to determine the time required to bring dense UN pellets to equilibrium compositions under various pressures of nitrogen.

The sample was suspended in a shallow tungsten tray, to maximize the solid angle for evaporation. A tungsten blackbody cylinder was placed alongside for temperature measurement.

The sample was first equilibrated at $1300^{\circ} \mathrm{C}$ and $5.8 \times 10^{-8}$ torr for about $20 \mathrm{hr}$, during which time it remained at constant weight. The temperature was then increased to $1600^{\circ} \mathrm{C}$ and the pressure alternately set at 0.003 and 700 torr. The results indicate that a gain in weight of approximately $1 \mathrm{mg}$ (equivalent to an $\mathrm{N} / \mathrm{U}$ ratio change of 0.002 ) can be attributed to an increase in nitrogen content when changing the pressure from 0.003 to 700 torr at $1600^{\circ} \mathrm{C}$. This weight gain took place in 20-30 $\mathrm{min}$, after which time the specimen at 700 torr remained at constant weight for a period of at least $67 \mathrm{hr}$. The weight change was shown to be reversible by alternating the nitrogen pressure between 0.003 and 700 torr.

Using this same specimen, UN vaporization was determined at nitrogen pressures of $0.003,0.1$ and 130 torr. These results are shown in Fig. 10 as Langmuir data (the reference area is that of the total pellet surface). While data were being taken at 0.003 torr nitrogen pressure, it became evident that back streaming of impurities from the sorption pumps was a problem. In Fig. 10, data are compared for runs using pumps baked at $300^{\circ} \mathrm{C}$ in 1 atm air and at $300^{\circ} \mathrm{C}$ under a vacuum of $10^{-3}$ torr. Points 18 and 19 are associated with the 0.003 torr tests. They represent the high initial rates of weight loss which occurred just after pumping the system down to 0.003 torr from higher nitrogen pressures. After $66 \mathrm{hr}$ for point 18 and $24 \mathrm{hr}$ for point 19 , the rate decreased to a value comparable to that in the previous run at 0.003 torr and no further change was noted.

It was found that even lower vaporization rates were obtained using the sorption pumps baked under $\sim 10^{-3}$ torr. Furthermore, tests under static nitrogen without sorption pumps, and dynamic tests using a titanium sublimation pump rather than sorption pumps, gave results comparable to those using sorption pumps baked at $10^{-3}$ torr. The fact that data are self consistent for these methods suggests that the purity of our nitrogen in the furnace is no longer affected by backstreaming from sorption pumps if the pumps are baked at $10^{-3}$ torr.

After the tests at 0.003 torr using the pumps baked at $10^{-3}$ torr, vaporization studies were made at pressures of the order of 0.1 torr and 130 torr, with final points taken at 0.003 torr. These last points confirmed the previous values with the same sorption pumps and showed no pump-down effects.

\section{Bubble Migration Studies}

Attempts were made to determine the nature of the bumps previously observed in replication electron micrographs of 
alpha-irradiated MgO crystals (and reported in the previous Quarterly,UCRL50004-67-4, Part I). Cleavage surfaces of unirradiated $\mathrm{MgO}$ were replicated, and bumps were also observed. At this stage, it can only be concluded that the bumps are artifacts, possibly caused by gas bubbles in the replication process. Additional alpha irradiations of freshly cleaved surfaces of $\mathrm{MgO}$ are planned to further resolve the problem. To avoid the uncertainties of replication electron microscopy, experiments are being performed in which thin films of single-crystal UN will be bombarded with alpha particles and neon and argon ions. These films will be studied by transmission electron microscopy. Techniques for preparing the films were developed during this quarter.

Elastic Properties of Uranium Nitride at $298^{\circ} \mathrm{K}$

The single-crystal, adiabatic elastic constants of uranium mononitride have been determined at room temperature $\left(298^{\circ} \mathrm{K}\right)$. Measurements were made by an ultrasonic pulse-echo technique ${ }^{5}$ on two single-crystal specimens whose acoustic surfaces were oriented normal to $\langle 100\rangle$ and $\langle 110\rangle$. Three waves were measured in each crystal. Table VII presents the results. A Gaussian fit was used to obtain the three elastic constants from the six measurements. The results are:

$$
\begin{aligned}
& \mathrm{C}_{11}=4123 \pm 5 \mathrm{kbar} \\
& \mathrm{C}_{12}=843 \pm 5 \mathrm{kbar} \\
& \mathrm{C}_{44}=763 \pm 3 \mathrm{kbar}
\end{aligned}
$$

From these values the adiabatic bulk modulus is

$B_{S}=\frac{1}{3}\left(C_{11}+2 C_{12}\right)=1936 \pm 5$ kbar.

The Grüneisen constant is

$$
\gamma_{\mathrm{GR}}=\frac{3 \alpha \mathrm{VB}_{\mathrm{s}}}{\mathrm{C}_{\mathrm{p}}}=1.62
$$

and the isothermal bulk modulus is

$$
\mathrm{B}_{\mathrm{t}}=\mathrm{B}_{\mathrm{S}}\left(1+3 \alpha \gamma_{\mathrm{GR}} \mathrm{T}^{-1}=1915 \mathrm{kbar}\right. \text {. }
$$

If we take the effective isotropic (polycrystalline) shear modulus as the mean of the Voigt and Reuss averages, we obtain the following values for the shear modulus

\begin{tabular}{|c|c|c|c|c|}
\hline Orientation & Length $(\mathrm{cm})$ & Wave type & Elastic constant & Result (kbar) \\
\hline \multirow{3}{*}{$\langle 100\rangle$} & \multirow{3}{*}{0.6406} & ( LongitudinaI & $\mathrm{C}_{11}$ & 4118 \\
\hline & & Shear & $\mathrm{C}_{44}^{11}$ & 763 \\
\hline & & Shear & $\mathrm{C}_{44}$ & 763 \\
\hline \multirow{3}{*}{$\langle 110\rangle$} & \multirow{3}{*}{0.5311} & Longitudinal & $\left(\mathrm{C}_{11}+\mathrm{C}_{12}+2 \mathrm{C}_{44}\right) / 2$ & 3250 \\
\hline & & Shear & $\mathrm{C}_{44}$ & 757 \\
\hline & & Shear & $\left(C_{11}-C_{12}\right) / 2$ & 1645 \\
\hline
\end{tabular}
G, Young's modulus E, and Poisson's ratio $\sigma$ :

$$
\begin{aligned}
& \mathrm{E}=2650 \mathrm{kbar}=38.44 \times 10^{6} \mathrm{psi}, \\
& \mathrm{G}=1042 \mathrm{kbar}=15.11 \times 10^{6} \mathrm{psi}, \\
& \sigma=0.272 .
\end{aligned}
$$

Table VII. Determination of the single-crystal, adiabatic elastic constants of UN. 
The calculated values for the polycrystalline moduli are substantially higher than those reported for less dense polycrystalline material. A comparison is made in Table VIII.

The physical constants for UN used in the se calculations are given in Table IX.

\section{LIQUID-METAL STUDIES}

\section{Solubility of Tungsten in Lithium}

Solubility experiments have been carried out at 1500,1600 and $1700^{\circ} \mathrm{C}$. Lithium from the experiments has been submitted for oxygen, carbon, and tungsten analysis by activation methods. The experiments were carried out by cold extruding high purity lithium directly into a tungsten crucible, electron beam welding the crucible shut, and heating it at tempera- ture in vacuo for $7 \mathrm{hr}$. The crucible was then quenched to below the melting point of lithium by dropping it into a liquid metal bath maintained at about $70^{\circ} \mathrm{C}$. The quenching bath was a quaternary alloy of $\mathrm{In}, \mathrm{Pb}$, $\mathrm{Sn}$, and $\mathrm{Bi}$, and had a melting point of $57^{\circ} \mathrm{C}$.

Analytical results were received for a preliminary tungsten-lithium solubility experiment performed last quarter. The tungsten content of the lithium was very high. Chips of tungsten were found in the bottom of the container in which the lithium was dissolved and it was concluded that the sample taken for analysis had been contaminated during the sampling process. Hence, the analysis was discarded.

In cooperation with the Activation Analysis Group, work is continuing on the determination of oxygen and carbon by $\gamma$-activation methods. Consistent results

Table VIII. Comparison of experimentally determined polycrystalline moduli with previously reported values.

\begin{tabular}{|c|c|c|c|c|}
\hline Reference & Density $(\%)$ & $\mathrm{E}\left(\times 10^{6} \mathrm{psi}\right)$ & $\mathrm{G}\left(\times 10^{6} \mathrm{psi}\right)$ & $\sigma$ \\
\hline This work & 100 & 38.44 & 15.11 & 0.272 \\
\hline 6 & 97 & 31.0 & 14.1 & 0.098 \\
\hline 7 & 90 & - & - & 0.26 \\
\hline 7 & 88 & 28.0 & 10.0 & 0.40 \\
\hline 7 & 81 & 21.6 & 8.7 & 0.241 \\
\hline
\end{tabular}

Table IX. Physical constants for UN used in these calculations.

\begin{tabular}{lccc}
\hline \multicolumn{1}{c}{ Constant } & Symbol & Value & Reference \\
\hline Density & $\rho$ & $14.32 \mathrm{~g} / \mathrm{cm}^{3}$ & 8 \\
Specific heat & $\mathrm{C}_{\mathrm{p}}$ & $11.31 \mathrm{cal} / \mathrm{mole} /{ }^{\circ} \mathrm{K}$ & 9 \\
Molar volume & $\mathrm{V}$ & $17.60 \mathrm{~cm}^{3} / \mathrm{mole}$ & 10 \\
Linear thermal & $\alpha$ & $7.5 \times 10^{6}\left({ }^{\circ} \mathrm{K}\right)^{-1}$ & 10 \\
expansion & $\mathrm{M}$ & 252.23 & 8 \\
Molecular weight & & & \\
\hline
\end{tabular}


have now been obtained on high purity lithium used in the solubility experiments. Oxygen was found to be $49 \pm 6 \mathrm{ppm}$ and carbon $27 \pm 4 \mathrm{ppm}$. The errors are expressed as twice the standard deviation of the mean. To obtain consistent results, the lithium was sealed in high purity aluminum capsules, irradiated, removed from the capsules, etched in methyl alcohol for $20 \mathrm{sec}$, and finally counted. The etching technique removes surface oxides that form during handling and storage.

\section{Solubility of Tungsten in Silver}

Work on this system is nearly complete. Analytical results for two experiments run last quarter give a solubility of $0.5 \mathrm{ppm}$ tungsten in silver at $2100^{\circ} \mathrm{C}$. Further analyses are being made. These results fall on the straight-line plot of log (mole fraction) vs reciprocal absolute temperature reported in a previous Quarterly.*

Some Interactions Between Cesium and Barium in Thermionic Diodes

Thermally controlled reservoirs may be used to generate and maintain fixed partial pressures of cesium and barium for thermionic diodes. Migration of the less volatile barium into the cesium reservoir may lead to lowering of the cesium vapor pressure, and also to obstruction of the cesium passages.

Estimates have been made for a $\mathrm{Cs}-\mathrm{Ba}$ phase diagram, and for activities of cesium and barium in the diagram. The results indicate that if a cesium reservoir

\footnotetext{
* For further details contact J. W. Hadley, Lawrence Radiation Laboratory, Livermore, Calif.
}

were normally operated at $650^{\circ} \mathrm{K}$, its temperature would have to be raised to $719^{\circ} \mathrm{K}$ to maintain a constant cesium pressure as the cesium became saturated with solid barium.

A critical aspect of the design and operation of thermionic diodes is to maintain the very narrow width of the diode gap within close limits over long periods of time. The highest diode currents and efficiencies are realized for the narrowest gap widths that can be sustained without shorting. There is some theoretical and experimental evidence that greater gap widths can be used with little sacrifice in diode current or efficiency, if barium vapor is added to the cesium that is normally used in the diode gap. Experimental studies are needed to evaluate the function of the barium.

Cesium gas for the diode may be generated and maintained at a pressure of a few torr by using a reservoir operated at about $650^{\circ} \mathrm{K}$. If barium is generated in a separate reservoir at a similar pressure, a temperature of about $1300^{\circ} \mathrm{K}$ would be required, a temperature about equal to the collector temperature of the diode. With separate reservoirs, it is likely that barium would migrate into the cooler cesium reservoir, dissolve in the liquid cesium, and lower its activity and vapor pressure. Barium may also condense on surfaces of the system that are below the temperature of the barium reservoir. High rates of barium transfer would also lead to depletion of the barium reservoir, and to possible obstruction of passages of the cesium reservoir. The solubility of cesium in barium is probably very limited, and transfer of cesium to the barium reservoir should present no 
problems. The evaluation of the significance of the above problems requires knowledge of the $\mathrm{Cs}-\mathrm{Ba}$ phase diagram, the cesium and barium vapor pressures, and variation of cesium and barium activities across the diagram.

\section{The Cesium-Barium Phase Diagram}

There is no information presently available on the $\mathrm{Cs}-\mathrm{Ba}$ system, so estimates need to be made. In order to establish a basis for estimation, comparisons will be made among intercombinations of alkali and alkaline earth metal systems. Other metals will be excluded from these comparisons because of differences in bonding characteristics.

There are some rough rules of thumb that are used to predict solubilities in metallic systems. The relative atomic radii of solvent and solute are known to markedly affect solubilities. The size factor rule states that in order for solid solubilities to be high the metallic radii must differ by less than $15 \% .{ }^{11}$ This is not a sufficient condition for solubility, however. Other factors that need to be considered are compound formation, electronegativity differences, solubility parameter differences, valences, and electronic configurations. ${ }^{11-13}$

If compound formation occurs, solubilities in the end members will generally be lower than expected because of lowered metal activities in the compound(s). Large differences in electronegativities indicate tendencies toward compound formation, and are usually correlated with lowered solubilities. Large differences in solubility parameters also indicate low solubilities according to regular solution theory, as will be discussed later in this report. $^{13}$ Solubilities in the liquid states generally follow the same trends as in the solids, but at higher levels of solubility. The size factor rule is far less important for the liquid state. Compound formation in the solid state is expected to lead to enhanced solubilities in the liquid state because of increased tendencies toward interaction of the constituent atoms.

Systems with radius ratios about the same as for the Cs-Ba system will be examined first to see if a fixed radius ratio is sufficient to establish similar behavior in these systems. Table $X$ lists radius

Table X. Maximum solid solubilities and various factors relating to solubility for binary alkali and alkaline earth systems with radius ratios of about 1.2 .

\begin{tabular}{|c|c|c|c|c|c|c|}
\hline \multirow[b]{2}{*}{ Metal } & \multirow{2}{*}{$\begin{array}{c}\text { Electro- } \\
\text { negativity, } \\
\epsilon(\mathrm{eV})\end{array}$} & \multicolumn{2}{|c|}{$\begin{array}{l}\text { Energy of } \\
\text { vaporization } \\
\text { (kcal/mole) }\end{array}$} & \multicolumn{2}{|c|}{$\begin{array}{c}\text { Molar } \\
\text { volume } \\
\left(\mathrm{cm}^{3} / \mathrm{mole}\right) \\
\end{array}$} & \multirow{2}{*}{$\begin{array}{c}\text { Solubility } \\
\text { parameter, } \delta, \\
\text { at } 298^{\circ} \mathrm{K} \\
\left(\mathrm{cal} / \mathrm{mole}^{3} / \mathrm{cm}^{3}\right)\end{array}$} \\
\hline & & Solid, $298^{\circ} \mathrm{K}$ & Liq. , $1000^{\circ} \mathrm{K}$ & Solid, $298^{\circ} \mathrm{K}$ & Liq., $1000^{\circ} \mathrm{K}$ & \\
\hline $\mathrm{Li}$ & 0.95 & 37.82 & 34.37 & 13.02 & 14.97 & 53.9 \\
\hline $\mathrm{Na}$ & 0.90 & 25.16 & 21.65 & 23.81 & 29.57 & 32.5 \\
\hline $\mathrm{K}$ & 0.80 & 20.72 & 17.15 & 45.64 & 58.25 & 21.3 \\
\hline $\mathrm{Rb}$ & 0.78 & 19.01 & 15.3 & 55.55 & 71.52 & 18.5 \\
\hline $\mathrm{Cs}$ & 0.75 & 18.08 & 14.3 & 70.47 & 92.23 & 16.0 \\
\hline $\mathrm{Mg}$ & 1.2 & 34.71 & 29.75 & 14.00 & 15.50 & 49.8 \\
\hline $\mathrm{Ca}$ & 1.0 & 41.78 & 36.51 & 26.28 & 28.79 & 39.9 \\
\hline $\mathrm{Ba}$ & 0.9 & 42.83 & 38.00 & 38.09 & 41.36 & 33.5 \\
\hline
\end{tabular}


ratios and other pertinent information for relevant systems for which phase diagrams have been reported. ${ }^{14-16}$ The maximum solid solubilities are seen to fall within the range of 0.6 - 5\% for four of these systems, but appear to be much lower in the other three systems. For the systems with the higher solubilities, the "smaller atom" solutes show a higher solubility in the "larger atom" solvents, rather than vice versa. Although fixed size factor alone does not seem to be a sufficient criterion to define the behavior in these systems, it seems appropriate to explore the effect on solubility of changing the size factor.

Data on other systems ${ }^{14,15}$ show a general dependence of solubility on size factor. For systems such as Cs-K, $\mathrm{Ba}-\mathrm{Ca}$, and $\mathrm{Mg}-\mathrm{Li}$, where the radius ratio drops below about 1.16, either complete miscibilities or very high solubilities are found in both liquid and solid states. For the systems Ba-Li, $\mathrm{K}-\mathrm{Mg}$, and $\mathrm{Ba}-\mathrm{Mg}$, with radius ratios above 1.36, solubilities in the solid state are very low, but in the liquid state may be high or low, depending upon the presence of compounds in the solid state. Exceptions to this general behavior may also be found. Solid solubilities in the Sr-Li system are 1 at. \% lithium in strontium, and 2 at. \% strontium in lithium, although the radius ratio is 1.41 . Even though the $\mathrm{Ca}-\mathrm{Na}$ system has a radius ratio of only 1.06, the solubility of calcium in sodium is quite low, as evidenced by a melting point lowering of only $0.025^{\circ} \mathrm{K}$. It can only be concluded that size factor alone is not sufficient to fix the behavior in these systems.

Since the systems in Table $\mathrm{X}$ all have roughly equal radius ratios, additional factors will need to be explored to explain observed differences in solubilities. It is apparent from Table $\mathrm{X}$ that these differences cannot be explained by an electronegativity effect, since all of the metals have nearly the same electronegativities. An electronegativity difference of at least $0.4 \mathrm{eV}$ is believed to be needed to be significant. ${ }^{11}$ The presence of compounds in some of these systems in spite of the small electronegativity differences indicates that electronegativities are also poor predictors of compound formation in metallic systems. Perhaps this should not be too surprising in view of the fact that the electronegativity scale is primarily based upon bonding strengths in ionic compounds.

Some information may be provided by regular solution theory, since the highest solubility parameter differences in Table $\mathrm{X}$ are for the systems with the lowest solubilities. Regular solution theory assumes that there are no specific interactions between solvent and solute atoms (such as formation of specific atom pairs, solvated atoms, polymers, etc.), and that bonding energies between solvent atoms $\mathrm{A}$ and solute atoms $\mathrm{B}$ may be approximated by the geometric mean of the $\mathrm{A}-\mathrm{A}$ and $\mathrm{B}-\mathrm{B}$ bonding energies. The entropy of mixing is assumed to be ideal. The free energy change for transferring a mole of $B$ to a dilute saturated solution in $\mathrm{A}$ is given by

$\Delta F=-R T \ln X_{B}($ sat. $)=V_{B}\left(\delta_{A}-\delta_{B}\right)^{2}$,

where $X_{B}$ (sat.) is the mole fraction of $B$ in $\mathrm{A}, \mathrm{V}_{\mathrm{B}}$ is the molar volume of pure $\mathrm{B}$, and $\delta_{\mathrm{A}}$ and $\delta_{\mathrm{B}}$ are solubility parameters, i. e., the square root of the energies of 
vaporization per unit volume for pure $A$ and pure $B$. If $A$ and $B$ differ in state, a free energy of solidification (or fusion) term must be added to the right side of the above equation, since the solute must assume the state of the solvent upon entering the solution. Also, in cases where compound formation or extensive solubility occurs, a correction term of the form - RT $\ln \mathrm{a}_{\mathrm{B}}$, where $\mathrm{a}_{\mathrm{B}}$ is the activity of $B$, must be added to the right side of the equation.

Solubilities calculated by the regular solution equation are compared in Table XI with experimental values. The necessary data for making the calculations is given in Tables $\mathrm{X}$ and XI and in the various phase diagrams. ${ }^{14-16}$ Whenever compound formation occurs, the activity of the solute phase is estimated to be equal to the mole fraction of solute in the liquid composition that is nearest the solvent on a peritectic or eutectic isotherm. The calculated solubilities show a rough correlation with the experimental values, but quantitative predictions are not possible. The calculations appear to indicate, however, that solid solubilities in the $\mathrm{Cs}-\mathrm{Ba}$ system should be very low.

In order to compare the phase diagrams, we group them into three general types, as shown in Fig. 12. The type I diagram is for systems without compounds, where solubilities in the solid and liquid states are low. Type II is a eutectic-melting system which may have one or morẹ compounds that decompose peritectically. Solubilities in the solid state may range from low to moderate. Type III is similar to type II except that a congruently melting compound may be present. The $\mathrm{Cs}-\mathrm{Ba}$ system is probably similar to type II. A peritectically melting compound may exist. An estimated phase diagram based on these assumptions is presented in Fig. 13.

\section{Cesium and Barium Activities}

The vapor pressures of cesium and barium are determined by their activities in the reservoirs. The expression,

Table XI. Temperatures of maximum solid solubility for some binary alkali and alkaline earth systems, and solid solubilities calculated by the regular solution equation.

\begin{tabular}{|c|c|c|c|c|c|c|}
\hline \multirow{3}{*}{$\begin{array}{c}\text { System } \\
\text { A-B }\end{array}$} & \multirow{2}{*}{\multicolumn{2}{|c|}{$\begin{array}{l}\text { Temperature of maximum } \\
\text { solid solubility }\left({ }^{\circ} \mathrm{K}\right) \\
\end{array}$}} & \multicolumn{4}{|c|}{$\begin{array}{l}\text { Maximum solid solubility } \\
\text { (atom fraction) }\end{array}$} \\
\hline & & & \multicolumn{2}{|c|}{ By regular solution Eq. } & \multicolumn{2}{|c|}{ Experimental } \\
\hline & $\mathrm{B}$ in $\mathrm{A}$ & $\mathrm{A}$ in $\mathrm{B}$ & $\mathrm{B}$ in $\mathrm{A}$ & $\mathrm{A}$ in $\mathrm{B}$ & $\mathrm{B}$ in $\mathrm{A}$ & $A$ in $B$ \\
\hline $\mathrm{Cs}-\mathrm{Ba}$ & est. 280 & est. 450 & $5 \times 10^{-11}$ & $1 \times 10^{-11}$ & - & - \\
\hline $\mathrm{Na}-\mathrm{Li}$ & 369.4 & 443.8 & $2 \times 10^{-4}$ & $3 \times 10^{-6}$ & Low & Low \\
\hline $\mathrm{Na}-\mathrm{Mg}$ & 370.7 & 911 & $3 \times 10^{-3}$ & $5 \times 10^{-3}$ & Low & Low \\
\hline $\mathrm{Ca}-\mathrm{Li}$ & 504 & 415 & 0.07 & $2 \times 10^{-4}$ & 0.03 & 0.021 \\
\hline $\mathrm{Ca}-\mathrm{Mg}$ & 729 & 800 & 0.12 & 0.03 & 0.021 & 0.006 \\
\hline $\mathrm{Ba}-\mathrm{Na}$ & 470 & 355 & 0.58 & 0.05 & 0.05 & 0.03 \\
\hline $\mathrm{K}-\mathrm{Na}$ & 260.7 & 279.8 & $1.1 \times 10^{-3}$ & $2 \times 10^{-5}$ & 0.045 & 0.03 \\
\hline $\mathrm{Rb}-\mathrm{Na}$ & 268.2 & 268.2 & $1.5 \times 10^{-4}$ & $1.0 \times 10^{-9}$ & Low & Low \\
\hline
\end{tabular}




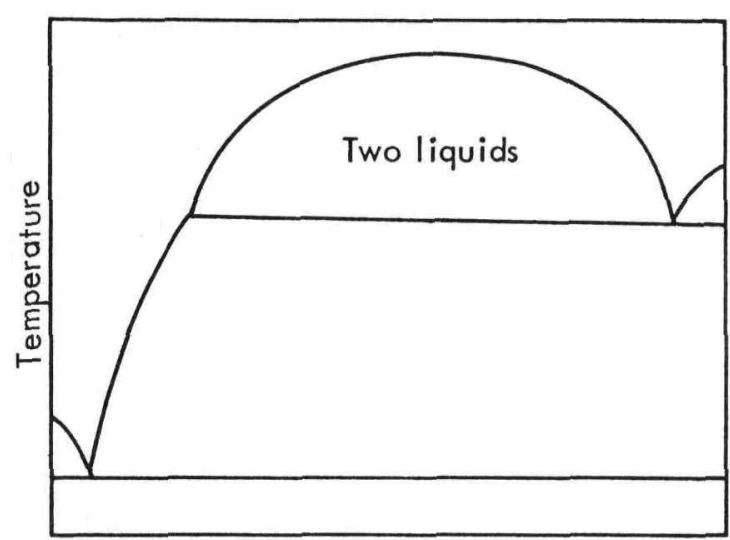

$100 \% \mathrm{~A}$

$100 \%$ B

Type I. Na-Li, Na-Mg

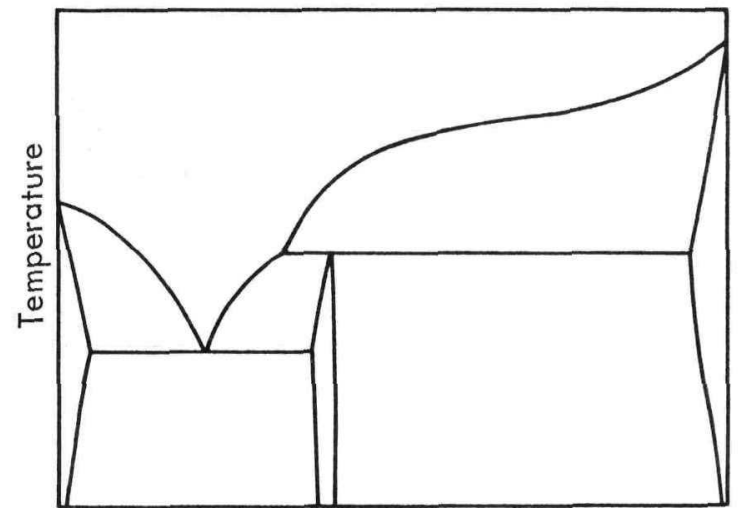

$100 \% \mathrm{~A}$

$100 \%$ B

Type II. Li-Ca, Na-Ba, K-Na, Rb-Na (no compound)

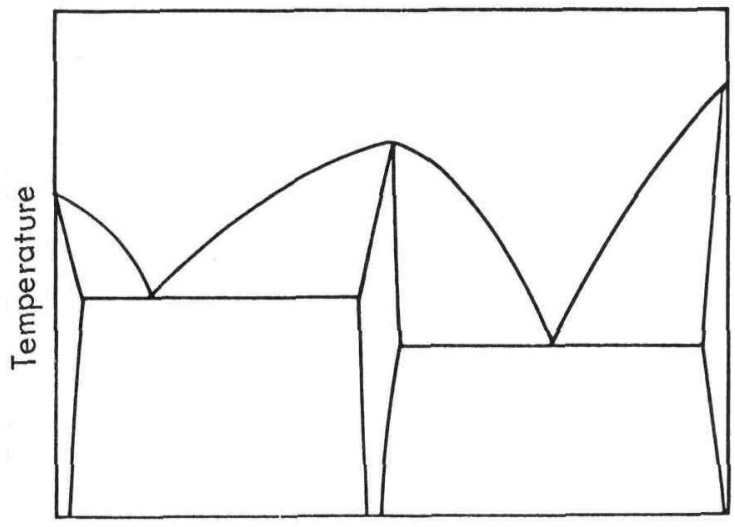

$100 \% \mathrm{~A}$

Type III. Mg-Ca

Fig. 12. Phase diagram types for alkali and alkaline earth metal systems.

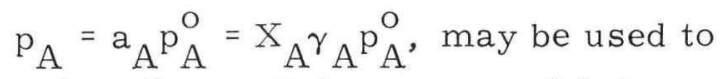
relate the partial pressure of $A$ to $a_{A}$, its activity in the solution, where $\mathrm{p}_{\mathrm{A}}^{\mathrm{O}}$ refers to the vapor pressure of $\mathrm{A}$ in pure A. The product $X_{A} \gamma_{A}$ may be substituted for $a_{A}$, where $X_{A}$ is the atom fraction of $\mathrm{A}$, and $\gamma_{\mathrm{A}}$ is an activity coefficient for $\mathrm{A}$.

Of the systems considered here, activity coefficient data are only available for the $\mathrm{K}-\mathrm{Na}$ system, ${ }^{17}$ and the data are given only for $298^{\circ} \mathrm{K}$. The data clearly show that the $\mathrm{K}-\mathrm{Na}$ solutions are close to ideal, i. e. , that $\gamma_{\mathrm{K}}$ and $\gamma_{\mathrm{Na}}$ are both close to unity over the range of interest. At higher temperatures, ideality is expected to be approached even more closely. If we also assume for the Cs-Ba system that the solutions are ideal, then $\mathrm{p}_{\mathrm{A}}=\mathrm{X}_{\mathrm{A}} \mathrm{p}_{\mathrm{A}}^{\mathrm{O}}$. Values of the vapor pressures of cesium 17 and barium ${ }^{18}$ are summarized in Table XII, together with partial pressures along the liquidus. The data of Table XII may be used to plot approximate isobars for the cesium partial pressures across the diagram. The cesium partial pressures along the liquidus may be readily interpolated from a $\log \mathrm{p}_{\mathrm{Cs}}$ vs $1 / \mathrm{T}$ plot. Results are shown in Fig. 13.

\section{Discussion}

The estimated phase diagram results indicate that if the cesium reservoir is maintained at $650^{\circ} \mathrm{K}$, solution of barium in the cesium will lower the cesium activity by a factor of 2.5 upon saturation with solid barium. The vapor pressure of cesium will in turn be reduced by a factor of 2.5. In order to reestablish the initial vapor pressure of cesium, the temperature of cesium saturated with barium would have to be raised to $719^{\circ} \mathrm{K}$. 
Table XII. Vapor pressures and partial pressures along the liquidus, for the Cs-Ba system.

\begin{tabular}{|c|c|c|c|c|c|c|}
\hline \multirow[b]{2}{*}{$\mathrm{T}\left({ }^{\circ} \mathrm{K}\right)$} & \multicolumn{2}{|c|}{ Vapor pressure (atm) } & \multicolumn{2}{|c|}{ Atom fraction } & \multicolumn{2}{|c|}{ Partial pressure (atm) } \\
\hline & $\mathrm{p}^{\mathrm{O}} \mathrm{Cs}$ & $\mathrm{p}_{\mathrm{O}}^{\mathrm{Ba}}$ & ${ }^{\mathrm{x}_{\mathrm{CS}}}$ & $\mathrm{x}_{\mathrm{Ba}}$ & ${ }^{\mathrm{p}} \mathrm{Cs}$ & $\mathrm{p}_{\mathrm{Ba}}$ \\
\hline 400 & $2.9 \times 10^{-6}$ & $4.8 \times 10^{-18}$ & 0.82 & 0.18 & $2.4 \times 10^{-6}$ & $9 \times 10^{-17}$ \\
\hline 500 & $2.5 \times 10^{-4}$ & $9.5 \times 10^{-14}$ & 0.66 & 0.34 & $1.7 \times 10^{-4}$ & $3.2 \times 10^{-14}$ \\
\hline 600 & $4.8 \times 10^{-3}$ & $7.0 \times 10^{-11}$ & 0.47 & 0.53 & $2.3 \times 10^{-3}$ & $3.7 \times 10^{-11}$ \\
\hline 700 & $3.8 \times 10^{-2}$ & $7.8 \times 10^{-9}$ & 0.31 & 0.69 & 0.012 & $5.4 \times 10^{-9}$ \\
\hline 800 & 0.18 & $2.6 \times 10^{-7}$ & 0.19 & 0.81 & 0.034 & $2.1 \times 10^{-7}$ \\
\hline 900 & 0.58 & $4.1 \times 10^{-6}$ & 0.08 & 0.92 & 0.046 & $3.8 \times 10^{-6}$ \\
\hline 1000 & 1.49 & $3.7 \times 10^{-5}$ & 0.00 & 1.00 & 0.00 & $3.7 \times 10^{-5}$ \\
\hline
\end{tabular}

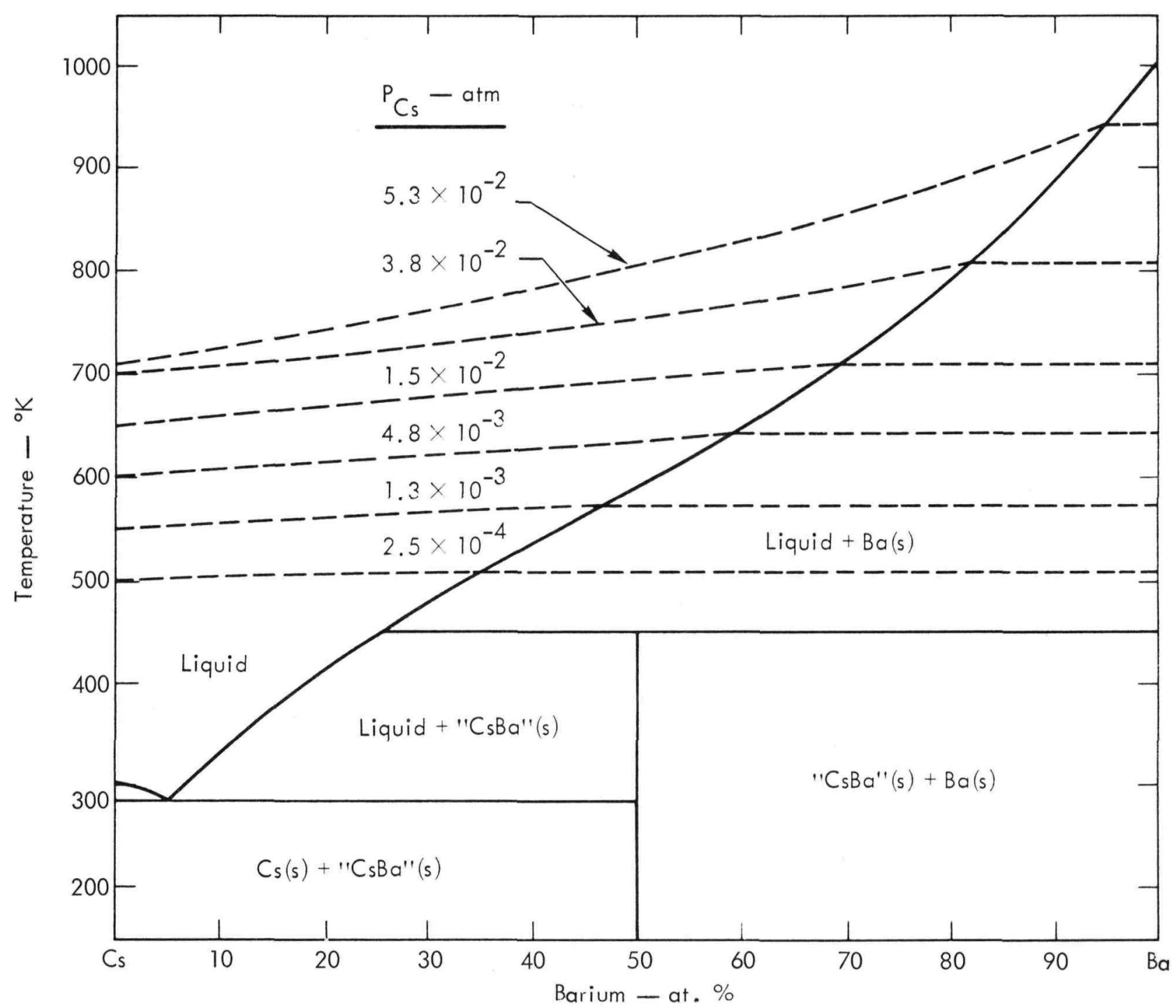

Fig. 13. An estimated phase diagram for the Cs-Ba system. 
With higher initial reservoir temperatures, larger increases in temperature would be required to sustain the cesium vapor pressure at the saturation point. Above an initial reservoir temperature of $\sim 720^{\circ} \mathrm{K}$, cesium can no longer be saturated with solid barium for the isobaric condition, and a continuous series of liquid solutions prevail.

The barium partial pressures are many orders of magnitude below those of cesium. Thus it appears unlikely that a single reservoir could be used to generate mixed vapors of barium and cesium for the diode. The highest ratio of barium to cesium partial pressures that can be achieved with a Cs-Ba liquid solution in equilibrium with solid barium is about

$$
\frac{3.7 \times 10^{-5} \mathrm{~atm}}{0.53 \mathrm{~atm}}=7 \times 10^{-4}
$$

at just below the melting point of barium.

A strategically located condensation trap should keep the barium from entering the cesium reservoir. If the barium is trapped as a liquid, it is conceivable that it may even be returned to the barium reservoir with a capillary wicking arrangement. If barium is to be frozen out, however, the trap temperature must be maintained below the melting point of barium, but above the temperature of the liquidus corresponding to the partial pressure of cesium in the reservoir. Below this liquidus temperature, cesium, as well as barium, will condense and form a liquid solution of the appropriate liquidus composition for that temperature.

The results given here are not intended to be quantitative, but are meant to illustrate the behavior to be expected. An experimental determination of the $\mathrm{Cs}-\mathrm{Ba}$ phase diagram would be useful both in supplying some of the information indicated in this report, as well as providing insight into the factors determining solubilities and compound formation in metallic systems.

Heat Capacity of Lithium

A method has been developed for extrapolating available lithium heat capacity data to the high temperatures of space-power systems. The heat capacity of lithium is important to LRL because the mass flow rate of lithium through a space power reactor operating at a fixed power level is proportional to the heat capacity of lithium at reactor temperatures.

In a Rankine space power system employing a liquid metal cooled nuclear reactor, the coolant loop corrosion, erosion, and pumping power all increase with coolant flow rate.

The heat capacity at constant pressure of a liquid metal is made up of four contributions: a configurational term, a kinetic term, an electronic term, and a dilation term:

$$
\mathrm{C}_{\mathrm{p}}=\mathrm{C}_{\mathrm{v}}{ }^{*} \mathrm{R}+\mathrm{C}^{\mathrm{k}}+\mathrm{C}^{\mathrm{el}}+\mathrm{C}^{\mathrm{d}}
$$

The dilation term represents the difference between constant pressure and constant volume heat capacity

$$
\mathrm{C}_{\mathrm{p}}-\mathrm{C}_{\mathrm{v}}=\mathrm{C}^{\mathrm{d}}=\frac{\alpha^{2} \mathrm{VT}}{\beta_{\mathrm{T}}}
$$

where $\alpha$ is the coefficient of thermal expansion, $\mathrm{V}$ is the molar volume, $\mathrm{T}$ is the absolute temperature, and $\beta_{\mathrm{T}}$ is the isothermal compressibility. 
In the following discussion, each of the four contributions is estimated independently. Figure 14 gives the total heat capacity, $\mathrm{C}_{\mathrm{p}}$, and the temperature dependence of the individual contributions.

Figure 15 shows predicted lithium heat capacity as compared to the data of others.

Configurational Heat Capacity, $\mathrm{C}_{\mathrm{V}}^{*} \mathrm{R}$

Configurational heat capacity arises from the potential energy associated with molecular interaction in the liquid.

Chapman has developed a correspondingstates correlation of the configurational heat capacity of six low-melting metals

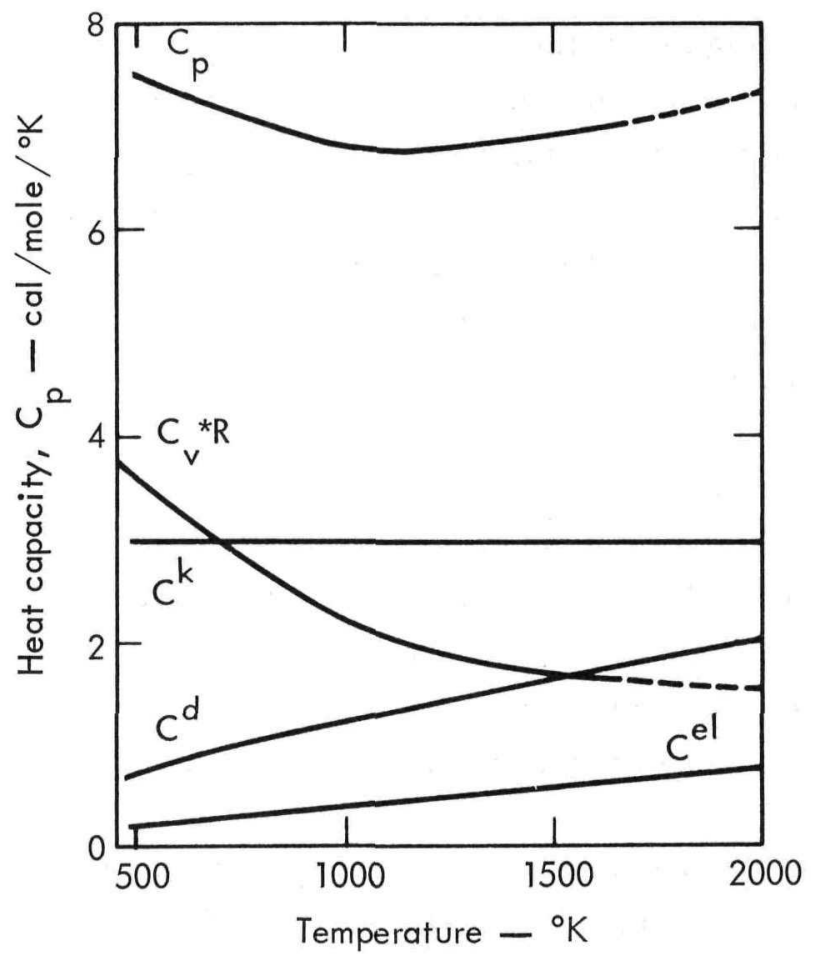

Fig. 14. Predicted heat capacity of lithium.

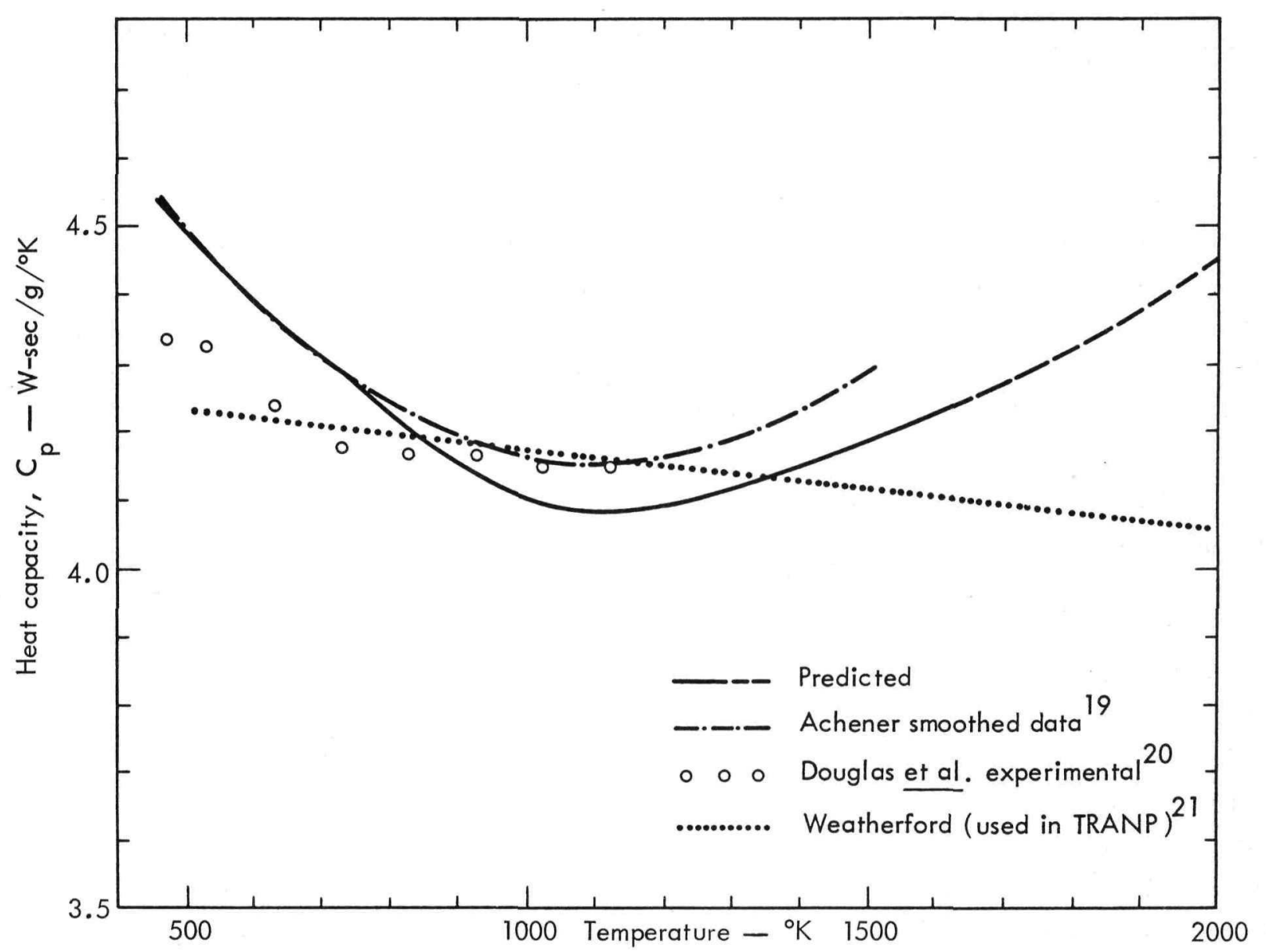

Fig. 15. Heat capacity of lithium. 
(sodium, potassium, mercury, indium, tin, and lead). ${ }^{22}$ The correlation is based on the theory of the radial distribution function, and results in a graph similar to that shown in Fig. 15. The reduced quantities $\mathrm{C}_{\mathrm{V}}^{*}, \mathrm{~V}^{*}$ and $\mathrm{T}^{*}$ are defined as follows:

$$
\begin{aligned}
\mathrm{C}_{\mathrm{V}}^{*} \equiv \frac{\mathrm{C}_{\mathrm{V}}}{\mathrm{R}}-\frac{3}{2}-\frac{\mathrm{C}^{\mathrm{el}}}{\mathrm{R}} \\
\quad=\frac{1}{\mathrm{R}}\left[\mathrm{C}_{\mathrm{p}}-\frac{\alpha^{2} \mathrm{VT}}{\beta_{\mathrm{T}}}-\mathrm{C}^{\mathrm{el}}\right]-\frac{3}{2} \\
\mathrm{~V}^{*} \equiv \frac{\mathrm{V}}{\mathrm{N}_{\mathrm{O}} \delta^{3}} \\
\mathrm{~T}^{*}=\frac{\mathrm{kT}}{\epsilon}
\end{aligned}
$$

The reducing parameters $\epsilon$ and $\delta$ represent the energy and distance parameters of the intermolecular potential function for the liquid metals. These parameters have been independently determined by Chapman and are given in Table XIII.

Table XIII. Distance and energy parameters of the intermolecular potential function for some metals. 22

\begin{tabular}{lll}
\hline Metal & $\delta(\AA)$ & $\frac{\epsilon}{\mathrm{k}}\left({ }^{\circ} \mathrm{K}\right)$ \\
\hline Li & 3.14 & 2350 \\
$\mathrm{Na}$ & 3.84 & 1970 \\
$\mathrm{~K}$ & 4.76 & 1760 \\
\hline
\end{tabular}

In constructing Fig. 16, heat capacity data of the National Bureau of Standards 23,24

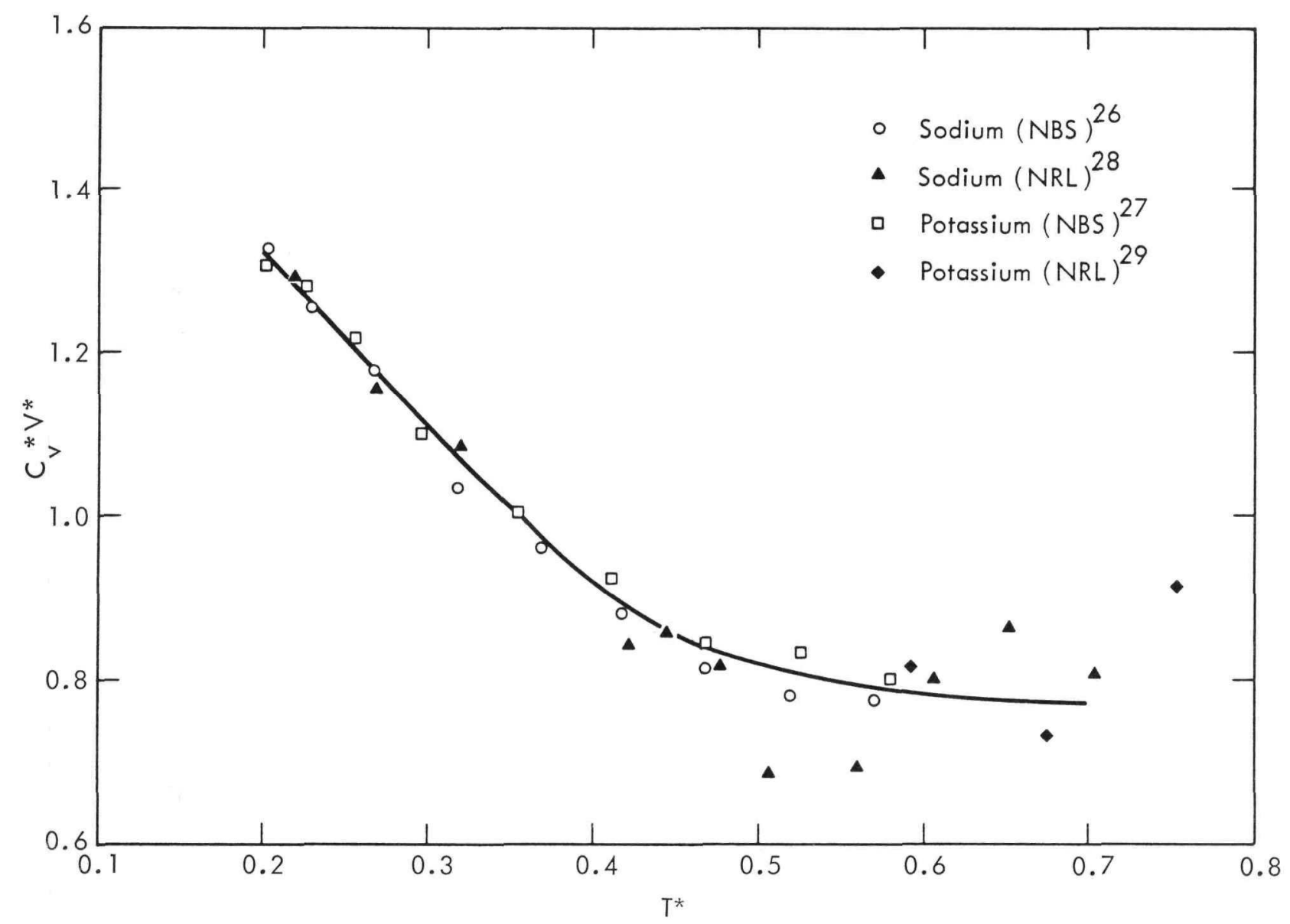

Fig. 16. Reduced configurational heat capacity of liquid sodium and potassium. 
and the Naval Research Laboratory ${ }^{25,26}$ have been used along with the density data of Gol'tsova ${ }^{27}$ and the isothermal compressibility data of Trelin et al. ${ }^{28}$ Trelin's compressibility data have been extended (from 1073 to $1383^{\circ} \mathrm{K}$ for sodium and from 1073 to $1330^{\circ} \mathrm{K}$ for potassium) by means of the relationship

$$
\beta_{T}=\beta_{\mathrm{O}} \mathrm{e}^{\mathrm{bt}}
$$

suggested by Moelwyn Hughes. ${ }^{29}$ Trelin's data fit this exponential relationship very well.

One advantage of the corresponding states correlation approach is that it permits the use of data for low-melting metals in the prediction of high temperature properties of the higher-melting metals. This is because the energy parameters for the metals (such as those given in Table XIII) are approximately proportional to the melting points $\left(\epsilon / \mathrm{k} \sim 5.2 \mathrm{~T}_{\mathrm{m}}\right)$. Thus potassium at $1230^{\circ} \mathrm{K}$ or sodium at $1380^{\circ} \mathrm{K}$ (reduced temperature, $\mathrm{T}^{*}=0.7$ ) is in a corresponding state with lithium at $1645^{\circ} \mathrm{K}$. The correlation of Fig. 16 has been used to estimate configurational heat capacities $\left(C_{\mathrm{V}}^{*} \mathrm{R}\right)$ for lithium. Values of $\mathrm{C}_{\mathrm{V}}^{*} \mathrm{R}$ are shown in Fig. 14.

The Kinetic Term, $\mathrm{C}^{\mathrm{k}}$

The kinetic contribution to heat capacity is a constant equal to $\frac{3}{2} \mathrm{R}$ and arises from the thermal energy of translation.

\section{The Electronic Term, $\mathrm{C}^{\mathrm{el}}$}

The electronic contribution to $\mathrm{C}_{\mathrm{V}}$ is relatively small except near absolute zero where it accounts for most of the total heat capacity. It is proportional to the absolute temperature:

$$
\mathrm{C}^{\mathrm{el}}=\gamma \mathrm{T}
$$

where $\gamma$ is the temperature coefficient of electronic heat capacity. For lithium, 30 $\gamma$ is $4.04( \pm 0.14) \times 10^{-4} \mathrm{cal} / \mathrm{g}$ at. $/{ }^{\circ} \mathrm{K}^{2}$. The proportional relationship of Eq. (8) is valid at temperatures well below the effective Fermi temperature which, for normal metals, is of the order of $30,000^{\circ} \mathrm{K}^{31}$

The Dilation Term, $\mathrm{C}^{\mathrm{d}}=\frac{\alpha^{2} \mathrm{VT}}{\beta_{\mathrm{T}}}$

The dilation term is the difference between $\mathrm{C}_{\mathrm{p}}$ and $\mathrm{C}_{\mathrm{v}}$. At $1500^{\circ} \mathrm{K}$ it represents about $24 \%$ of the total heat capacity of lithium. In calculating this term, the density data of Gol'tsova were used (extrapolated linearly with temperature above $\left.1873^{\circ} \mathrm{K}\right)$. There are no data in the literature for the isothermal compressibility of lithium. Values of $\beta_{\mathrm{T}}$ were estimated by a corresponding states correlation for the isothermal compressibility of the liquid alkali metals. ${ }^{32}$ The correlation was used to predict $\beta_{\mathrm{T}}$ for lithium to $1430^{\circ} \mathrm{K}$; the logarithmic extrapolation of Eq. (7) was used to estimate compressibilities of lithium between 1430 and $2000^{\circ} \mathrm{K}$.

\section{Notation}

$$
\begin{aligned}
\mathrm{C}_{\mathrm{p}}= & \text { Heat capacity at constant pressure, } \\
& \text { cal } / \mathrm{g}-\mathrm{mole} /{ }^{\circ} \mathrm{K} \text { or } \mathrm{W}-\mathrm{sec} / \mathrm{g} /{ }^{\circ} \mathrm{K} . \\
\mathrm{C}_{\mathrm{V}}= & \text { Heat capacity at constant volume, } \\
& \text { cal } / \mathrm{g}-\mathrm{mole} /{ }^{\circ} \mathrm{K} . \\
\mathrm{C}_{\mathrm{V}} \mathrm{R}= & \text { Configurational heat capacity, } \\
& \text { cal } / \mathrm{g}-\mathrm{mole} /{ }^{\circ} \mathrm{K} . \\
\mathrm{T}= & \text { Absolute temperature, }{ }^{\circ} \mathrm{K} . \\
\mathrm{T}_{\mathrm{m}}= & \text { Melting point, }{ }^{\circ} \mathrm{K} . \\
\mathrm{V}= & \text { Molar volume, } \mathrm{cm}^{3} / \mathrm{g} \text {-mole. }
\end{aligned}
$$

Constants

$$
\begin{aligned}
\mathrm{N}_{\mathrm{O}}= & \text { Avogadro's Number, } 6.0232 \times 10^{23} \\
& \mathrm{~mole}^{-1} .
\end{aligned}
$$


$\mathrm{R}=$ Gas constant, $1.987 \mathrm{cal} / \mathrm{g}-\mathrm{mole} /{ }^{\circ} \mathrm{K}$.

Greek Letters

$\alpha=$ Coefficient of thermal expansion, $\equiv \frac{1}{\mathrm{~V}}\left(\frac{\mathrm{dV}}{\mathrm{dT}}\right)_{\mathrm{P}}$.

$\beta_{\mathrm{T}}=$ Isothermal compressibility, $\equiv-\frac{1}{\mathrm{~V}}\left(\frac{\mathrm{dV}}{\mathrm{dP}}\right)_{\mathrm{T}}$.

$\beta=$ Temperature coefficient of electronic heat capacity, cal/g-at. $/{ }^{\circ} \mathrm{K}^{2}$.

$\delta=$ Distance parameters, $\AA$.

$\epsilon / \mathrm{k}=$ Energy parameter, ${ }^{\circ} \mathrm{K}$.

\section{Superscripts}

* Reduced value.

d Dilational contribution.

el Electronic contribution.

k Kinetic contribution.

\section{Dynamic Corrosion Studies}

\section{Pumped-Capsule Experiment}

The first pumped-capsule experiment has been completed after $1004 \mathrm{hr}$ at temperature. Nominal operating conditions are shown in Table XIV. Preliminary examination of the splitter plate under an optical microscope at $100 \times$ reveals only minor etching attack by lithium of the $\mathrm{W}-25 \% \operatorname{Re}-30 \% \mathrm{Mo}$ (at. \%) grain boundaries at the hot end of the plate. Depth of attack is roughly 1 to $2 \mu$, which is about the same as would be expected in the alloy when exposed to a vacuum for $1000 \mathrm{hr}$ at these temperatures. Preliminary electron beam probe measurements show some migration of molybdenum from the hot to the cold end of the splitter plate. There are numerous small $(<1-$ mil diam) spots on the cold end of the splitter plate. Material from both the hot and cold end of the splitter plate has been bent through a 90 deg angle at room temperature without breaking. This indicates that the material has retained some ductility through the test.

Table XIV. Nominal operating conditions in first pumped-capsule test.

\begin{tabular}{ll}
\hline Liquid metal & Lithium \\
Capsule & $\mathrm{W}-25 \% \mathrm{Re}-30 \% \mathrm{Mo}$ (at.\%) \\
$\begin{array}{l}\text { Time } \\
\text { Hot end } \\
\text { temperature }\end{array}$ & $1004 \mathrm{hr}$ \\
$\begin{array}{l}\text { Cold end } \\
\text { temperature }\end{array}$ & $1250^{\circ} \mathrm{C}$ \\
$\begin{array}{l}\text { Temperature at } \\
\text { top weld }\end{array}$ & $1540^{\circ} \mathrm{C}$ \\
$\begin{array}{l}\text { Flow rate } \\
\text { EM pump current }\end{array}$ & $100 \mathrm{~A}$ \\
$\begin{array}{l}\text { Heater power } \\
\text { Heater element } \\
\text { temperature }\end{array}$ & $4 \mathrm{~kW}$ \\
$\begin{array}{l}\text { Fin temperature } \\
\text { Fin }\end{array}$ & $800^{\circ} \mathrm{C}$ \\
\hline
\end{tabular}

When the capsule was first opened, using the laser dissection facility, a black deposit was observed inside the hot end. This layer, probably due to splatter from the laser hole cutting, was removed when the last traces of lithium were washed from the capsule with a water rinse. In all other respects, the laser opening technique was successful and will be used on further tests.

The capsule and splitter plate will be dissected for further analyses by vacuum fusion, wet chemistry, and emission spectrography. Surfaces will be examined by electron beam probing, X-ray diffraction, gas-ion mass spectrography, and by metallurgical replicating and shadowing. Lithium will be examined for W, Re, Mo, $\mathrm{C}$, and $\mathrm{O}_{2}$ by activation analysis, for $\mathrm{N}_{2}$ by wet chemistry, and for trace metals by emission spectrography. 
In general, the test proceeded smoothly considering it was the first run of a complex experiment. During the test, there were two building power failures of several minutes each. Several short-term shutdowns (of seconds) occurred when temporary power interruptions gave a loss of vacuum signal to the controller. Power to the heaters was automatically decreased during these interruptions. No damage to the capsule or facility occurred during the rapid cooling and reheating associated with these power outages.

The lithium pumping action in the first test was not as positive as desired. This was probably because the capsule was only about $80 \%$ full of lithium at the operating temperature and most of the EM pump pressure head was used to lift the lithium over the top of the splitter plate. The first capsule test was filled to a conservative level to avoid breaking the capsule open with thermally expanded lithium at $1500^{\circ} \mathrm{C}$. Lithium expands about $25 \%$ from room temperature to $1500^{\circ} \mathrm{C}$, but density data are meager and somewhat scattered at higher temperatures.

The poor pumping action had two effects on test operations. First, the lithium flow could not be started until the EM pump current was raised to $150 \mathrm{~A}$, although the pump ran well at $100 \mathrm{~A}$ once flow began. Also the pumping action was worse at higher temperatures. Apparently there were current losses through a short circuit created by thermal expansion of components in the fixture holding the capsule.

Some argon was inadvertently put into the capsule when the capsule was filled with lithium. As a result, the lithium was under 100-150 psi (of argon plus lithium pressure) rather than under 35 psi (of pure lithium vapor) as planned. No noticeable diameter enlargement by creep was observed in the capsule after the test, despite the higher internal pressure.

The uncertainty in the maximum lithium temperature is due to the lack of reliable temperature measurements at the hot end of the capsule. The bare thermocouple leads, hanging vertically in the hot zone, sagged and touched one another at temperatures greater than $1200^{\circ} \mathrm{C}$. These thermocouple readings were intermittent or erratic during the test. The occasional good temperature readings indicated that the lithium was spilling over the splitter plate and free falling to the downstream surface. The capsule temperatures were uniformly high $\left(\sim 1500^{\circ} \mathrm{C}\right)$ in the downflow side and considerably lower in the upstream side, as would be expected in this situation.

The most reliable thermocouple reading at a position a few inches below the top of the hot end of the capsule was about $1320^{\circ} \mathrm{C}$. The temperature of the metal at the weld on top of the capsule cap was $1540^{\circ} \mathrm{C}$. This top point is separated by $1 / 2$ in. of argon gas and $1 / 2$ in. of metal from the lithium flowing over the top of the splitter plate. Hence the estimate of $1370^{\circ} \mathrm{C} \pm 20^{\circ} \mathrm{C}$, made from intermittent "good" readings of the shorted thermocouples, appears reasonable. The cold-end thermocouples read consistently well throughout the test. None of the thermocouple junctions failed during the test. These junctions had been spot welded (in air) to the capsule and heater element.

A second capsule test is planned with W-30\%Re-30\%Mo alloy from GE-NIMPO. On the basis of recent creep data on this material taken at LRL, a maximum safe operating temperature of $1600^{\circ} \mathrm{C}$ has been set for a $1000 \mathrm{hr}$ test of a 1/2-in. o.d. 
capsule with a 40-mil wall. In the second test the splitter plate weir will be raised and more lithium placed in the capsule so the lithium will contact the top of the capsule. The maximum lithium temperature should be near $1600^{\circ} \mathrm{C}$. A new lithium filling procedure will eliminate trapping of argon when lithium is poured into the capsule. For the second test, the test facility is being modified to allow direct control of the heater power supply using power setting (rather than have it set by control thermocouples) because of the problems incurred by failures of control thermocouples during the first test. Wherever possible, thermocouple leads will be insulated with $\mathrm{ThO}_{2}$ in the second test to prevent shorting.

\section{Lithium Still}

The large still, built to produce pound quantities of ultrapure lithium for loop tests, has completed its first and only run. The first one-pound feed batch was distilled and divided into four portions as follows: A first portion was run to distill over volatile impurities such as $\mathrm{K}$ and $\mathrm{Na}$. A second portion was carried out to make "product" material. Then, most of the remaining lithium was distilled into a $4-\mathrm{ft}$ long, 1-1/2-in. stainless steel tube. During the distillation, a cooling coil was kept at the lithium product surface, which was located with an eddy current, NDT tube inspection device. The final portion was the residual feed material in the melt pot.

The stainless tube was cut into small sections with a tube cutter in a glovebox. Each of these sections comprises a timesequenced sample from the still, i.e., a separate cut from the batch distillation. Hopefully, analysis of these cuts will provide data to trace the relative volatility of the lithium impurities throughout the test. This technique should identify those portions of the lithium from a batch distillation which comprise the ultrapure product.

The analyses of distillate samples from the first two portions are presented in Table XV. Evidently the second portion had

Table XV. Analysis of lithium from the large lithium still.

\begin{tabular}{|c|c|c|c|}
\hline \multirow[b]{2}{*}{ Portion } & \multicolumn{3}{|c|}{$\mathrm{C}, \mathrm{O}$, and $\mathrm{N}$ (two samples from each portion) } \\
\hline & Nitrogen ${ }^{a}$ & Carbon ${ }^{b}$ & Oxygen $^{\mathrm{b}}$ \\
\hline 1 & 3 & 45,77 & 76,78 \\
\hline \multirow[t]{2}{*}{2} & 49,51 & 28,30 & 96,250 \\
\hline & \multicolumn{3}{|c|}{ Trace metal concentration $(\mathrm{ppm})^{\mathrm{C}}$} \\
\hline Metal & Original charge & Portion 1 & Portion 2 \\
\hline $\mathrm{Ba}$ & 15,20 & 3 & 3 \\
\hline $\mathrm{Ca}$ & 25,50 & 25 & 20 \\
\hline $\mathrm{Cu}$ & 80,100 & 25 & 10 \\
\hline $\mathrm{Fe}$ & 10,500 & 10 & 10 \\
\hline $\mathrm{K}$ & 40,40 & 20 & 10 \\
\hline $\mathrm{Mg}$ & 3,6 & 15 & 3 \\
\hline $\mathrm{Na}$ & 30,30 & 20 & 3 \\
\hline
\end{tabular}


been contaminated by air, because most

other distillation samples at LRL have had

$<10$ ppm N $\mathrm{N}_{2}$.

Fixture and Welding Studies for

Corrosion Loop

Fixtures for loop welding are nearly

complete. Welding parameter development has been carried out for tubular alloy

(0.5-in. o. d. by 0.040-in. wall) prepared at GE by the W-Re-Mo powder process; results were reported in the previous Quarterly (UCRL-50004-67-4).

Figure 17 shows low-temperaturemechanical properties of specimens

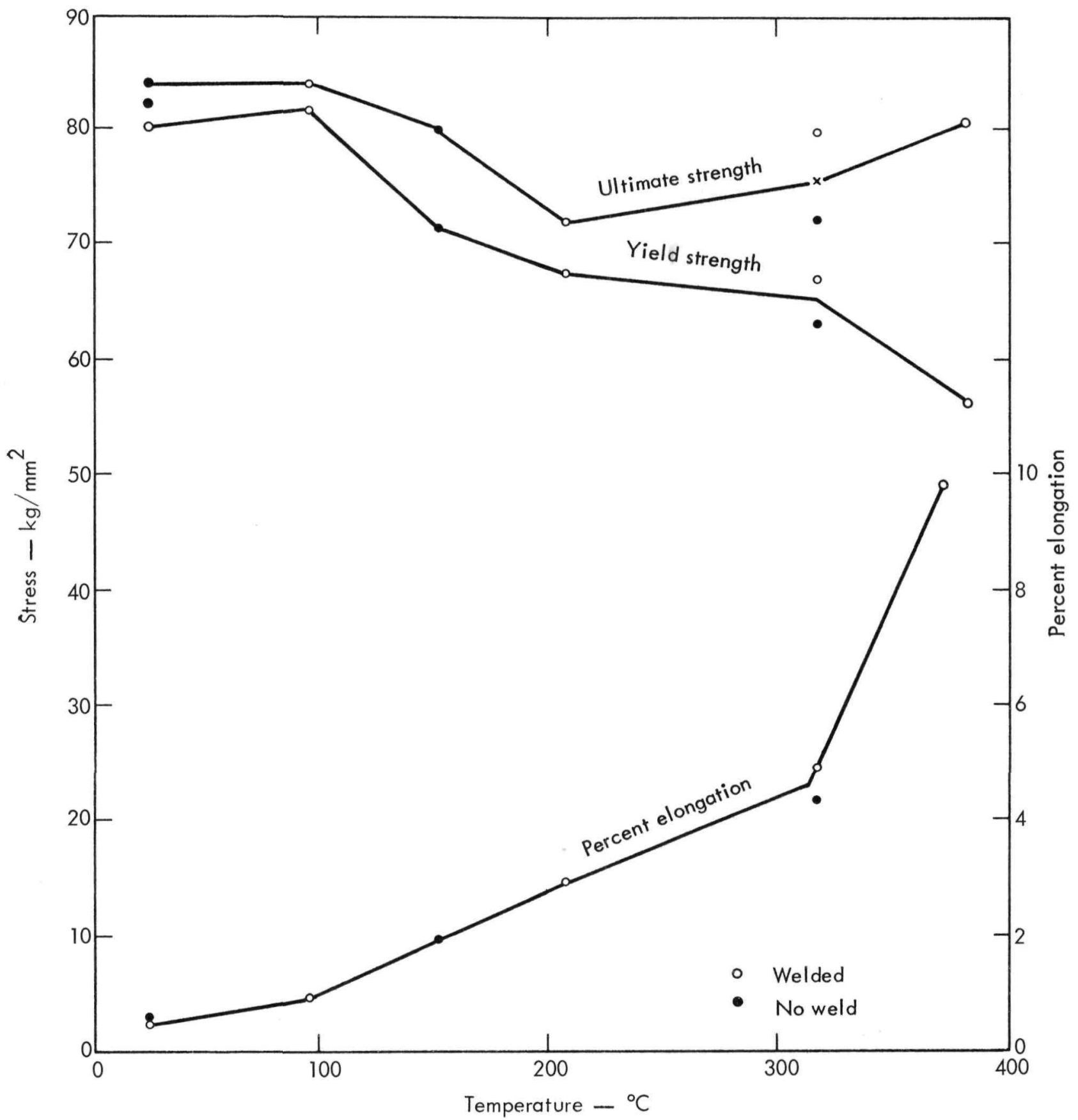

Fig. 17. Temperature dependence of engineering tensile properties for $\mathrm{W}-25 \% \mathrm{Re}-30 \% \mathrm{Mo}$ (at. \%) tubing (0.5-in. o. d. by 0.040-in. wall) supplied by General ElectricNMPO. 
machined from as-received and buttwelded tubes. The specimens were cut longitudinally from the tubes. (Welding parameters are given in Reference 1; the as-received tube was stress relieved for $1 / 2 \mathrm{hr}$ at $1450^{\circ} \mathrm{C}$.) Nominal gauge lengths of $0.040 \times 0.070 \times 0.5 \mathrm{in}$. were formed by electrostatic discharge machining. The strain rate averaged $0.05 \mathrm{in.} / \mathrm{in.} / \mathrm{min}$ during testing. In no case did fracture occur at the weld. Fracture of the buttwelded specimens always occurred away from the weld, and, as noted in Fig. 17, with essentially the properties of the parent material. The present material exhibited substantial ductility; there was no well defined ductile-to-brittle transition over the range of temperature investigated. The absence of any detrimental effects such as embrittlement or weakened heat-affected zones is further supported by room temperature hardness measurements made across the weld nugget. These measurements gave hardnesses of $445 \pm 25 \mathrm{DPH}$ through the parent material, potentially heat-affected zones, and weld nugget. The fractographs shown in Fig. 18 also illustrate the tractability of the material. The room temperature fractures are intergranular with some clean separations and some showing considerable resistance to separation, as evidenced by the ductile tearing on the rupture surface. This is the type of fracture usually associated with the rhenium alloying effect in tungsten. 33

One noteworthy difference between the tensile stress-strain results of the asreceived and welded specimens are the

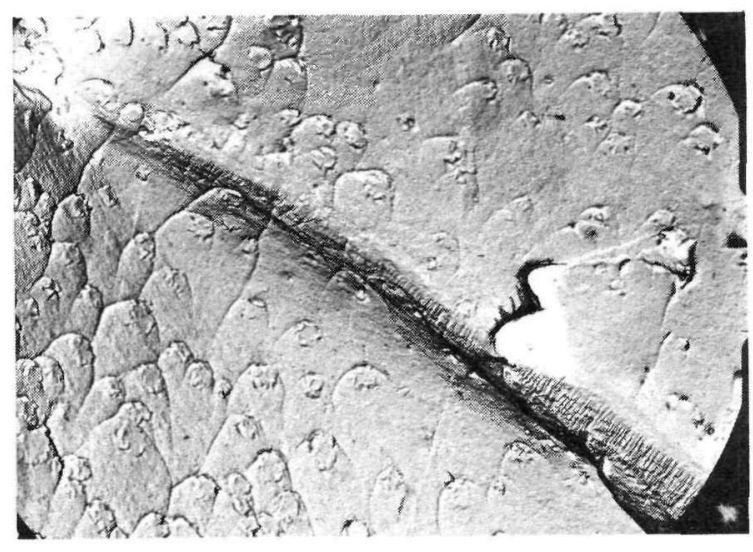

b. "Dimpled" intergranular separation. The diagonal marking is partly a result of plastic deformation during replica removal.

Fig. 18. Fracture surface of a longitudinally tensile-tested tube specimen of $\mathrm{W}-25 \% \mathrm{Re}-30 \% \mathrm{Mo}$ (at room temperature). 6000X 
presence of $\sim 2500$ psi yield drops ${ }^{*}$ in the former and their absence in the latter. Such yield drops are usually associated with either interstitial impurities or deformation twinning. Metallographic examination of the deformed gage lengths of tested specimens showed that mechanical twinning had occurred in both cases, thus indicating the possibility of an impurityinduced yield drop in the stress relieved material. It is conceivable that the welding process removed the yield drop by quenching in a more random impurity distribution in the short gage length. The presence of such discontinuous yielding effects are known to be associated with highly rate- and temperature-dependent rupture ductility behavior in iron. ${ }^{34}$ In the present case, the results indicate that fabricability would be enhanced by using as low a rate and as high a temperature (within the warm-working realm) as possible. Alternatively, one might successfully use higher rates and lower temperatures if the material were very slightly deformed prior to taking heavier reductions. However, these considerations may only apply to thin sections. In addition to the above, the rupture ductility results (Fig. 17) show that substantial increases in ductility, and therefore (potentially) in fabricability, accrue at temperatures above $300^{\circ} \mathrm{C}$.

\section{Reactor System and Component Engineering}

\section{SPR-6 REFERENCE DESIGN}

The SPR-6 Reference Design Study was completed and the final summary report is being published. 35

\section{SPR-4 REFERENCE DESIGN}

The SPR-4 system, with a 2000-kW nuclear heat source, would provide 300 to $400 \mathrm{~kW}$ of electric power from a turboalternator for 20,000 hr. A design requirement was for the system to have a ground test capability ca 1977 . With this requirement, and in the light of available materials information, $1500^{\circ} \mathrm{K}$ was chosen as the

\footnotetext{
* Yield drop refers to a drop in load after the inception of yielding. It is then followed by work-hardening. The load-strain curve therefore shows a maximum followed by a minimum and finally an increase of load to fracture.
}

reactor-outlet coolant temperature.

The SPR-4 reactor and boiler are integrated into the same pressure vessel (Fig. 19). Heat from the reactor is removed at both ends by sodium-filled heat pipes. The portion of the heat pipes projecting from the reactor core forms a boiler for potassium working fluid in a Rankine-cycle loop. The heat pipes, numbering about 375 on each end, provide about 750 separate "reactor loops," so that essentially the unit is a boiling reactor with a small temperature difference $\left(\sim 40^{\circ} \mathrm{K}\right)$ in the primary coolant loop.

The decision to cool the reactor using heat pipes instead of a flow-through coolant was arbitrarily made in order that this interesting method of cooling could be further explored. It is expected, though not assured, that heat pipe cooling will result in a better SPR-4 reactor system. Once the decision was made to use heat 


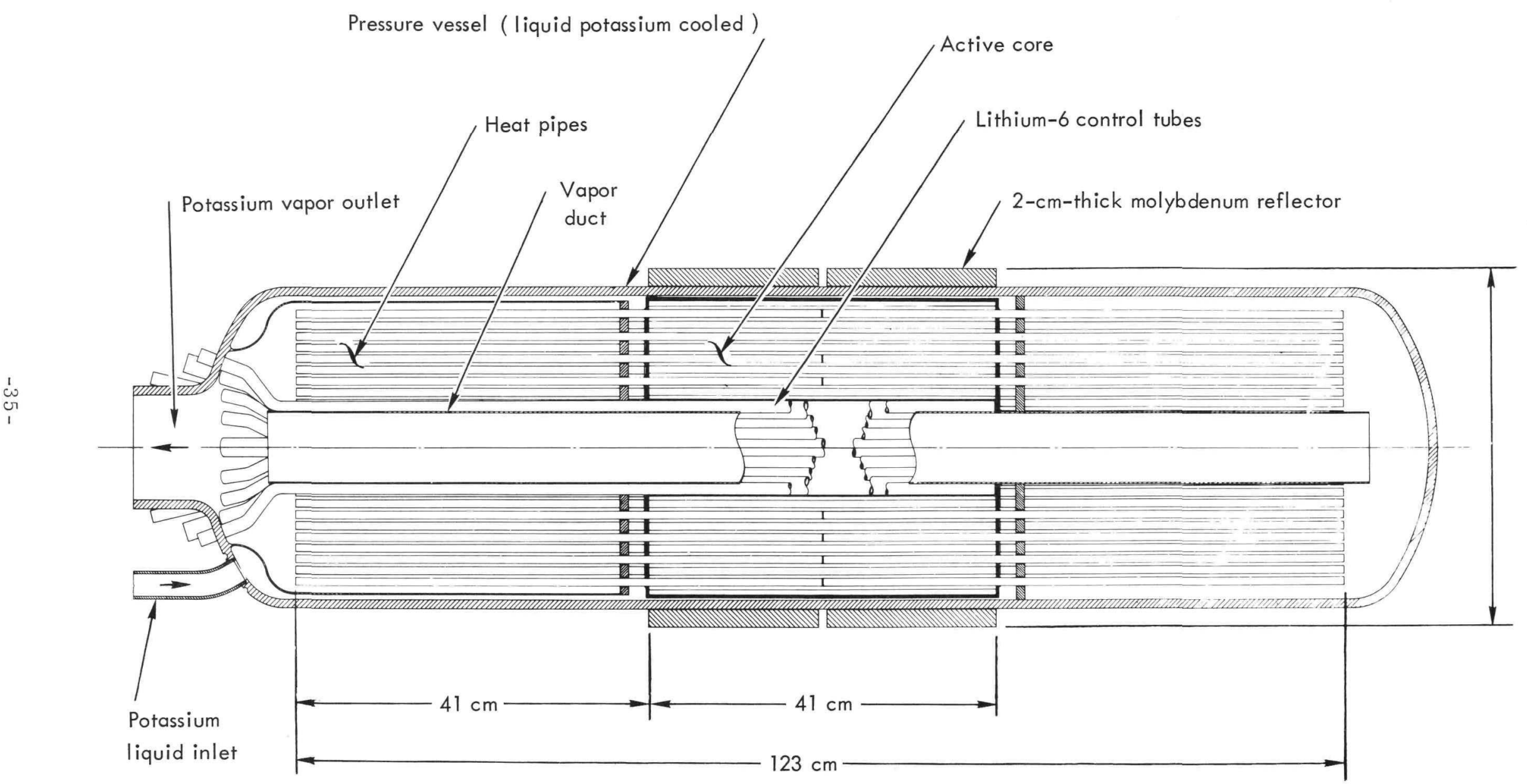

Fig. 19a. Longitudinal cross section of the SPR-4 integrated reactor and boiler. 
pipes, an exploration of possible configurations was undertaken. A configuration with heat pipes coming out of both ends of the reactor was chosen for two reasons:

1. The reactor radius can be made smaller with such a configuration (using a central duct for vapor return) than if all the heat pipes were brought out one end.

Studies were made with a one-dimensional neutronic code on a model having $\sim 10 \%$ of the core area devoted to central liquid control and alternatively 0, 2, 4, and $6 \%$ of the core area for central vapor return.
The model with no vapor return duct had heat pipes coming out of only one end of the core (single-ended configuration). The others had heat pipes out of both ends (double-ended configuration).

The characteristics of the se cores are shown in Table XVI. The $4 \%$ coolant vapor area case has been identified as version 1 of the SPR-4 reference design and is being used as the base case for subsequent investigations.

2. The fabrication, proof test, and assembly of heat pipes into the reactor is

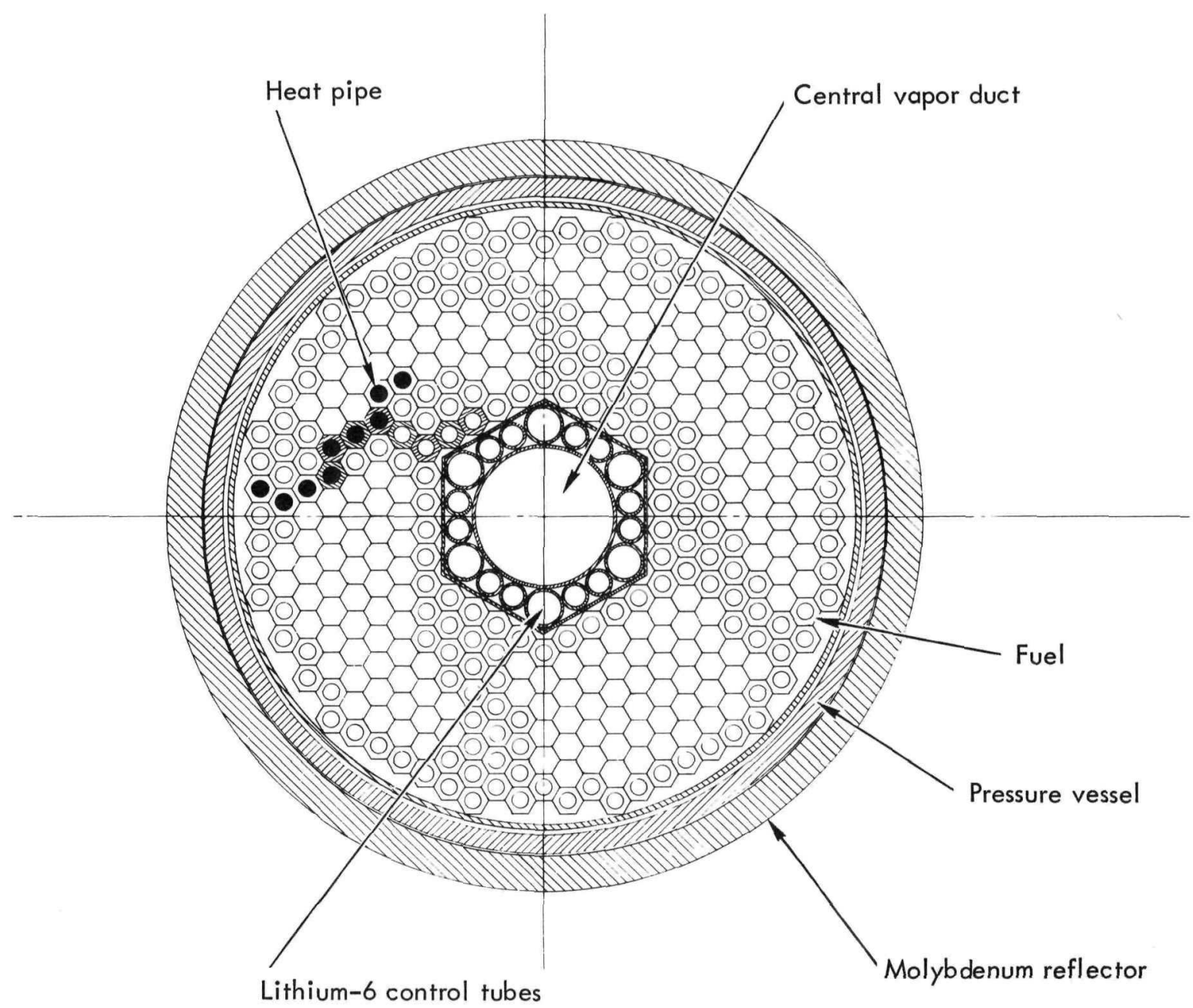

Fig. 19b. Transverse cross section through the active core of the SPR-4 integrated reactor and boiler. 
Table XVI. Summary of data from core studies of the SPR-4 heat pipe reactor (UN hexagonal fuel; uranium is $93.5 \% \mathrm{U} 235$ ).

\begin{tabular}{|c|c|c|c|c|}
\hline \multirow{2}{*}{$\frac{\text { Type }}{\text { Coolant vapor area }}$} & \multirow{2}{*}{$\frac{\text { Single-ended }}{-}$} & \multicolumn{3}{|c|}{ Double-ended (version 1) } \\
\hline & & $2 \%$ & $4 \%$ & $6 \%$ \\
\hline Vapor pipe radius $(\mathrm{cm})$ & - & 2.23 & 3.12 & 3.79 \\
\hline Core length $(\mathrm{cm})$ & 47.22 & 41.09 & 40.51 & 40.31 \\
\hline Core inside radius $(\mathrm{cm})$ & 6.07 & 6.42 & 6.36 & 6.30 \\
\hline Core outside radius $(\mathrm{cm})$ & 19.10 & 16.67 & 16.66 & 16.66 \\
\hline $\begin{array}{l}\text { Pressure vessel inside } \\
\quad \text { radius }(\mathrm{cm})\end{array}$ & 19.73 & 17.22 & 17.22 & 17.22 \\
\hline Length/diameter & 1.24 & 1.20 & 1.22 & 1.21 \\
\hline Pressure vessel thickness $(\mathrm{cm})$ & 1.36 & 1.19 & 1.19 & 1.19 \\
\hline $\begin{array}{l}\text { L1 control (\% of circuit } \\
\text { filled) }\end{array}$ & $50 \%$ & $50 \%$ & $50 \%$ & $50 \%$ \\
\hline$\beta^{\mathrm{a}}$ & 0.73 & 0.608 & 0.613 & 0.618 \\
\hline Fuel fraction & 0.492 & 0.625 & 0.619 & 0.612 \\
\hline Heat pipe inside radius $(\mathrm{cm})$ & 0.744 & 0.422 & 0.422 & 0.422 \\
\hline Heat pipe capillary radius $(\mathrm{cm})$ & 0.05 & 0.05 & 0.05 & 0.05 \\
\hline Percent burnup $(20,000 \mathrm{hr})$ & 0.570 & 0.686 & 0.706 & 0.727 \\
\hline$\Delta \mathrm{k}\left(\mathrm{Li}^{6}, 0-100 \%\right)$ & $3.93 \%$ & $3.92 \%$ & $3.46 \%$ & $2.98 \%$ \\
\hline$\Delta \mathrm{k}(1 \mathrm{~cm} \mathrm{Mo})$ & $3.54 \%$ & $3.92 \%$ & $3.92 \%$ & $3.93 \%$ \\
\hline $\begin{array}{l}\text { Mean energy of neutrons } \\
\text { causing fission (reflected } \\
\text { core) (keV) }\end{array}$ & 374 & 397 & 401 & 404 \\
\hline
\end{tabular}

\footnotetext{
${ }^{a}$ Ratio of fuel inside diameter to width across flats of the hexagonal shaped fuel elements.
}

greatly facilitated in the double-ended design. The assembly sketches in Fig. 20 illustrate this point. By ending the heat pipes at the center of the core, it was possible to pretest the two heat pipe end assemblies before "beading" with fuel. The two core/boiler halves would be joined by a single girth weld of the core can. We have assumed that a reasonable heat pipe capillary radius is $0.05 \mathrm{~cm}$ and that the minimum heat pipe inside radius should be $\sim 0.4 \mathrm{~cm}$.

In the version-1 design now under consideration the reactor heat pipes extend from the active core to make twice the heat transfer area of the core available for boiling of the turbine working fluid (potassium). Data on boiling of potassium ${ }^{36}$ indicate that high-quality vapor is obtained with average heat flux rates of 25 to $50 \mathrm{~W} / \mathrm{cm}^{2}$. Thus, it appears that the heat flux will not be limited by the heat pipes, and that the pipes can deliver sufficient heat to boil the turbine working fluid.

Liquid potassium working fluid enters the projecting heat pipe region at each end of the core, and then vaporizes as it flows away from the core. The potassium vaporized on the outboard end of the core is brought back through a central return duct, 


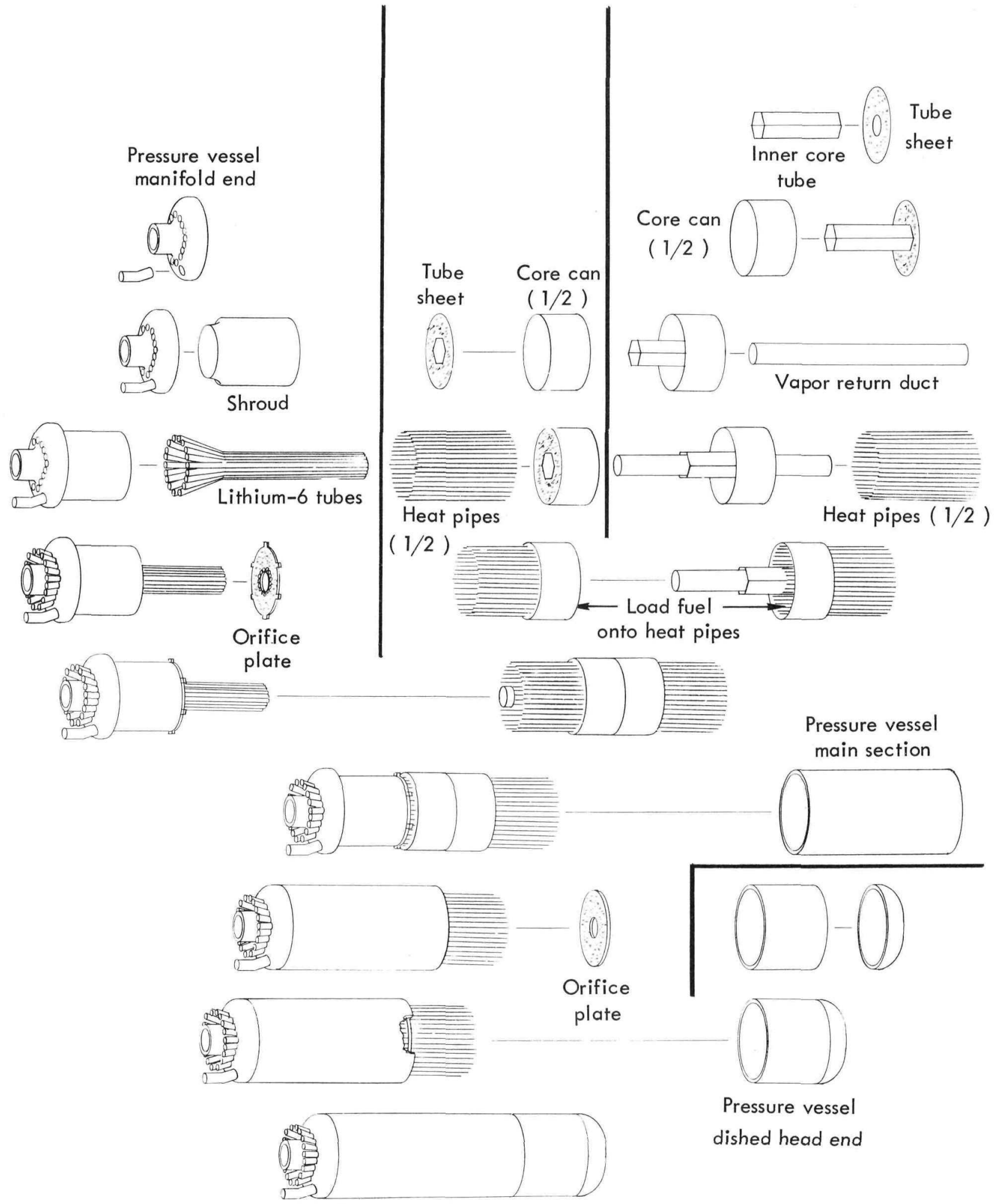

Final reactor assembly

Fig. 20. Sketch of a plausible assembly procedure for the SPR-4 integrated reactor and boiler. 
which as indicated previously, occupies $\sim 4 \%$ of the core frontal area. The pressure drop in this duct is $<0.2$ bar.

A generously sized shield for an unmanned payload is provided to cast a circular shadow of diameter about one-half the reactor-payload distance. This shield accounts for a major part of the system mass; very close attention must be given to the design of the shield when the actual application of the system is known.

For the given constraints, shield laminations of LiH and W are being optimized. The shield must have several penetrations. A minimum number and size might be as indicated below:

1. One potassium liquid return line, o. d. $=2.5 \mathrm{~cm}$

2. One potassium vapor feed line, o. d. $=7 \mathrm{~cm}$

3. Six $\mathrm{Li}^{6}$ control liquid lines, o. d. $=1 \mathrm{~cm}$
4. Two reflector control "pneumatic" lines, o. d. $=1 \mathrm{~cm}$

5. Twelve instrumentation leads.

The remainder of the SPR-4 system is located on the other side of the shield: the turboalternator, potassium pump, and radiators. An isometric sketch is shown in Fig. 21. A schematic diagram of the thermodynamic cycle is shown in Fig. 22. A separator may be required to obtain dry vapor. Preliminary calculations indicate system specific masses as estimated below:

\begin{tabular}{lc} 
Component & Specific mass \\
\cline { 2 - 2 } Shield & 6 \\
Reactor boiler & 2 \\
Radiator & 1.5 \\
Turboalternator & 1.5 \\
Miscellaneous & 0.5 \\
& 11.5
\end{tabular}

Heat pipe reactors coupled to a turboalternator cycle were first considered at

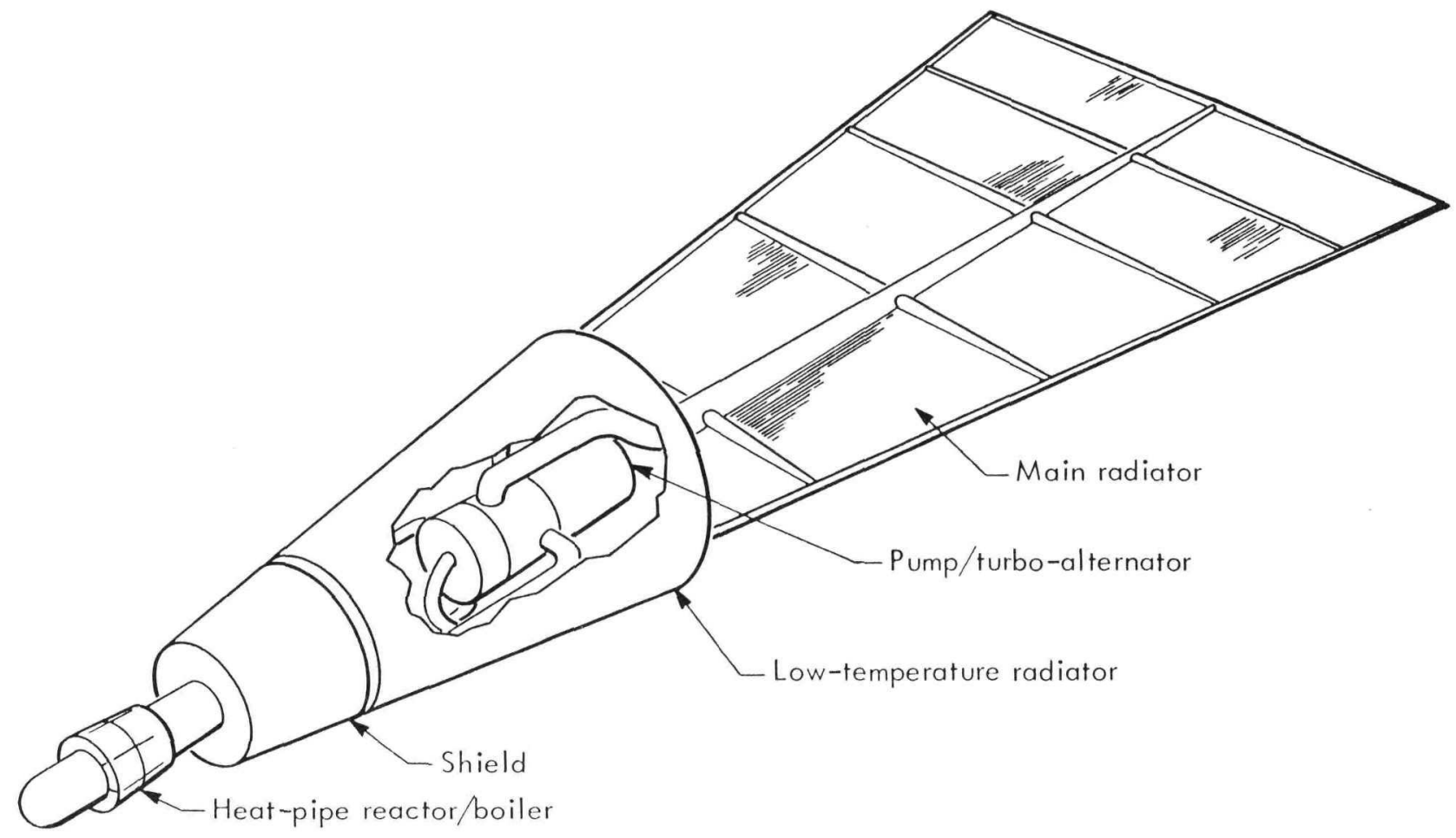

Fig. 21. The SPR-4 Rankine power system. 


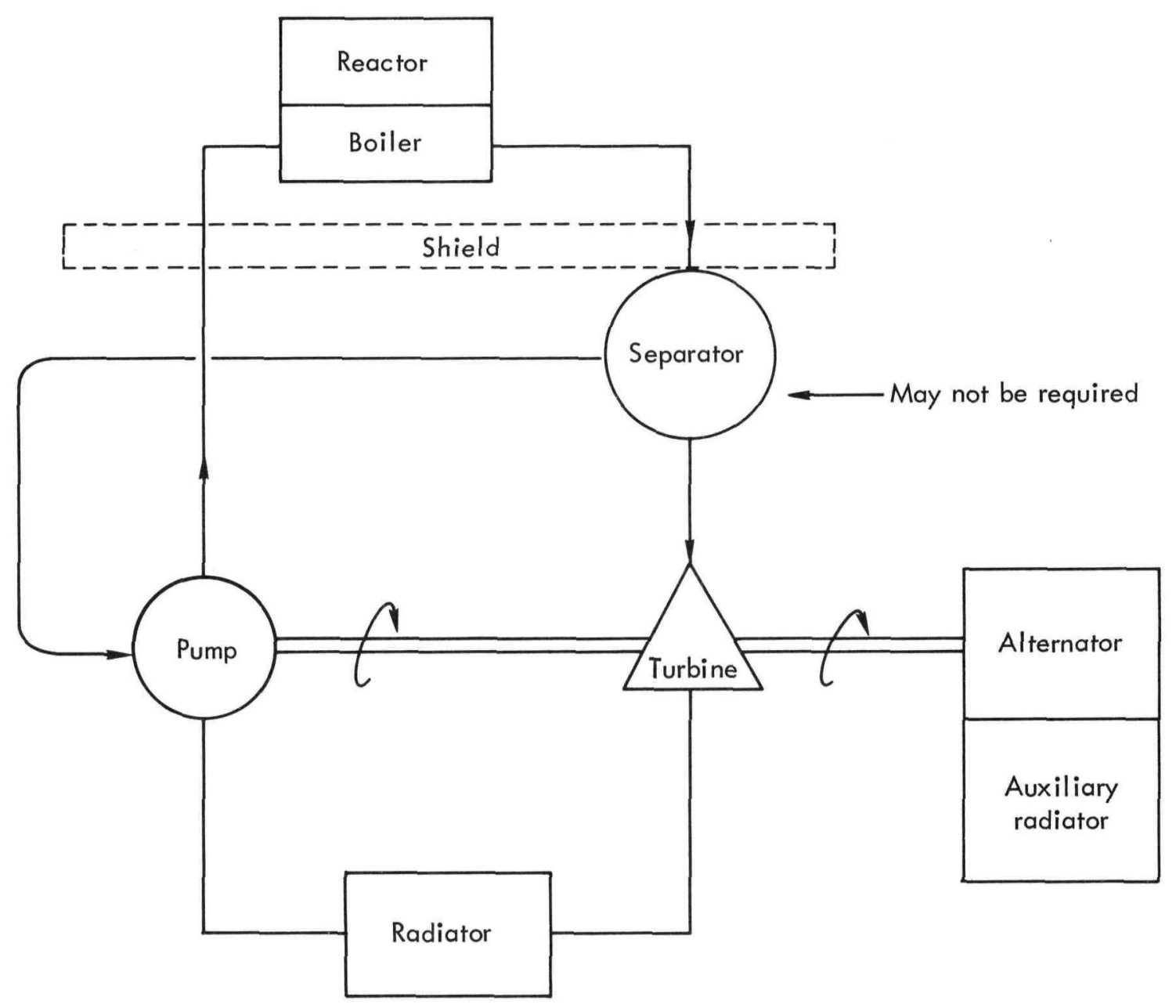

Fig. 22. Schematic diagram of the SPR-4 Rankine power system.

LRL some time ago. Sodium is chosen for the heat pipe working fluid at a nominal temperature of $1500^{\circ} \mathrm{K}$. Sodium results in a smaller core size than does lithium or potassium at that temperature, because of its heat transfer and vapor pressure characteristics. At a higher temperature lithium would be better than sodium, because of its lower vapor pressure. One disadvantage in using sodium in the heat pipe instead of potassium is the adverse pressure gradient it places on the heat pipe. The turbine working fluid must be at its saturation pressure (18 bars at $1470^{\circ} \mathrm{K}$ ) and the heat pipe working fluid at its saturation pressure (11 bars at $1500^{\circ} \mathrm{K}$ ). Furthermore, the bonding fluid in the core cannot be potassium, as unless its pressure were considerably in excess of 18 bars it would not always be liquid and a low tolerance to hot spots would result.

The isotope $\mathrm{K}^{41}$ activates

$$
\begin{aligned}
\mathrm{K}^{41}+\mathrm{n} \rightarrow \mathrm{K}^{42}+\gamma & \\
\stackrel{12.5 \mathrm{~h}}{\longrightarrow} & \mathrm{Ca}^{42}+\beta^{-} \\
& +\gamma 1.5,0.32 \mathrm{MeV} .
\end{aligned}
$$

Because of the proximity of the potassium 
to the reactor it will be necessary to remove the mass-41 isotope to reduce the dose rate at the payload. Natural potassium contains about $7 \% \mathrm{~K}^{41}$. Oak Ridge has studied the separation problem and concluded $^{37}$ that $\mathrm{K}^{39}$ (having 0.9993 isotopic purity) could be obtained by means of molecular distillation for $\sim \$ 200 / \mathrm{kg}$. The SPR-4 system requires less than $200 \mathrm{~kg}$ of potassium. (The Oak Ridge study was based on amortizing a $900-\mathrm{kg} /$ year plant over a 10-year period. The economics of producing a few 200-kg batches for the SPR-4 might be different.) The required purity of $\mathrm{K}^{39}$ is being examined.

Table XVII lists the fluids used in the SPR-4 system and the conditions at which they will operate.

Table XVII. Fluids used in the SPR -4 .

\begin{tabular}{ccc}
\hline Fluid & $\begin{array}{c}\text { Pressure } \\
\text { (bar) }\end{array}$ & $\begin{array}{c}\text { Temperature } \\
\left({ }^{\circ} \mathrm{K}\right)\end{array}$ \\
\hline $\begin{array}{l}\text { Sodium (heat pipe) } \\
\text { Sodium (bonding } \\
\text { medium) }\end{array}$ & 11 & 1500 \\
$\begin{array}{c}\text { Potassium } \\
\text { (turbine) }\end{array}$ & 18 & 1530 \\
\hline
\end{tabular}

The reactor-boiler pressure vessel is cooled by liquid potassium from the radiator at $1000^{\circ} \mathrm{K}$. The amount of power required to raise the incoming fluid temperature to saturation is $\sim 300 \mathrm{~kW}$. The amount of nuclear heat which must be removed from the pressure vessel by the coolant is less than $20 \%$ of this value, so that adequate cooling would be assured to remove this source of heat. Heat conducted from the core to the pressure vessel does represent a problem however, and means of insulating the core from the pressure vessel are being studied.

Heat pipes are made of $\mathrm{W}-25 \% \mathrm{Re}$ (at. \%), clad on the outside of their extended portions with tantalum to avoid possible dissimilar-metal corrosion effects in the potassium loop. The UN-fueled core is contained in a sealed can made from 0.15-cm W-25\%Re sheet. Since the can will be in contact with the turbine working fluid, its outer surface will be clad with tantalum (by chemical vapor deposition).

The assembly of the core and heat pipes was described above (Fig. 20). The core is positioned in the pressure vessel with a spline centering arrangement, and located axially with a very light pin at one end. There is only a slight net force acting on the core due to vapor flow in the central duct.

The outside radius of the pressure vessel for the double-ended heat pipe reactor with central liquid control is $\sim 18 \mathrm{~cm}$, considerably greater than that of the corresponding conventionally cooled reactor. The greater radius and additional length of the integrated reactor-boiler is of concern because of the large shield which is required. Whether or not the heat pipe reactor is justified will depend on results of a reliability analysis on the two systems.

Some power flattening can be achieved by using $100 \% \mathrm{U}^{235}$ in the outer regions of the reactor. The resulting radial power distribution is acceptably uniform (see Fig. 23). Additional flattening can be obtained by replacing some of the $\mathrm{U}^{235}$ near the periphery with $\mathrm{U}^{233}$. In the extreme, of course, the entire core could be made of $\mathrm{U}^{233}$; however, it appears that the $\mathrm{U}^{235}$ fueled reactor is as small as it can be and yet transport heat in the heat pipes properly, with the conservative assumptions utilized here on heat pipe performance; thus $\mathrm{U}^{233}$ would offer no advantage. 


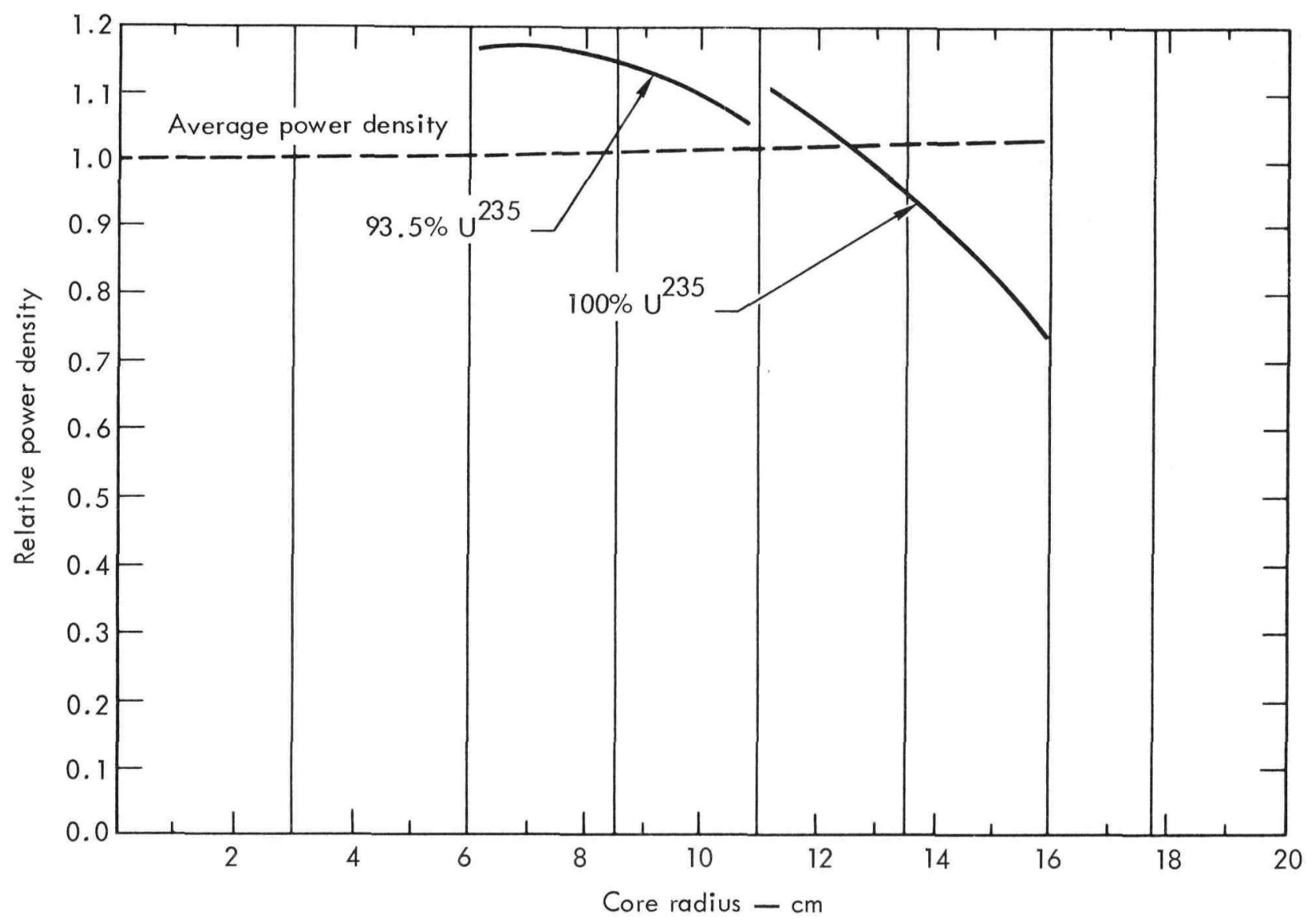

Fig. 23. SPR-4 radial power distribution employing two fuel enrichment regions.

Two means of controlling the reactor are available: One method is an axiallytranslating molybdenum reflector; the second is a compartmented central annulus containing $\mathrm{Li}^{6}$.

Of the materials we have considered for the side reflector, molybdenum appears to be the most desirable mechanically. A 2-cm Mo reflector has a neutronic worth of $\Delta \mathrm{k} \approx 0.09$, while $2 \mathrm{~cm}$ of $\mathrm{BeO}$ has a worth of $\Delta \mathrm{k} \approx 0.10$.

The control range for the $\mathrm{Li}^{6}$ circuits in the core is $\Delta \mathrm{k} \approx 0.035$ between empty circuits and full circuits. Means of emptying and filling these circuits are being studied.

A small amount of passive control,
$\Delta \mathrm{k}=0.0025 \mathrm{max}$, appears to be obtained from variable end reflection, the actual amount being dependent on the potassium density in the boiler. The amount of control which can actually be obtained is a subject for further study.

Several effects are considered to be key to the SPR -4 reactor design. These are:

1. Creep buckling effects on externally pressurized heat pipes.

2. Startup and shutdown of the reactor.

3. Control dynamics of the reactorpower system.

4. Long-time performance of the heat pipe.

5. Boiling stability of the working fluid. 
6. Importance of fuel thermal stress as a design criterion.

7. Fission gas bubbles in fuel bonding fluid.

8. Performance of the liquid-lithium control circuit.

9. Availability of suitable materials for structure and ducting.

Additional system studies are required to examine the trade-offs, both in system mass and reliability, between conventionally cooled and heat pipe cooled reactors to assure that the heat pipe cooled version of SPR-4 will indeed result in a better reference design. Also, a more precise system mass can be determined when an application is decided upon, allowing a detailed shield design. We are optimistic about successful resolution of the potential problems listed.

ANNULAR HEAT PIPE EXPERIMENT

The annular heat pipe experiment, as described in Quarterly UCRL-50004-67-3, was continued using sodium as the heat pipe working fluid, instead of potassium. A new electrical heater was installed in place of the original one (which failed during the potassium runs). The new heater is twice as long $(20 \mathrm{~cm})$. More thermocouples were also added to further define the temperature profile along the axis of the heat pipe.

In tests with sodium as the working fluid, the heat pipe performed as expected. Temperature control proved to be extremely accurate, with thermocouple readings within a few degrees of that predicted by the vapor pressure versus temperature curve for sodium (83.5 torr at $683^{\circ} \mathrm{C}$ ). The experimentally determined burnout point (power level at which the wick can no longer supply enough fluid to the evaporator) occurred at $6000 \mathrm{~W}$. The burnout point predicted from elementary theory was $5830 \mathrm{~W}$. 


\section{References}

1. W. R. Holman and F. J. Huegel, CVD Tungsten and Tungsten-Rhenium Alloys for Structural Application, Part I. Process Development, Lawrence Radiation Laboratory, Livermore, Rept. UCRL-70340 Preprint (1967).

2. L. I. Van Torne and G. Thomas, "Structure and Mechanical Properties of Ta-Mo Alloy Single Crystals," Acta Met. 14, 620-635 (1966).

3. M. A. DeCrescente, M. S. Freed, and S. D. Caplow, Pratt and Whitney Aircraft, Middletown, Conn., in a classified document (October, 1965).

4. W. M. Olson and R. N. R. Mulford, "The Decomposition Pressure and Melting Point of Uranium Mononitride," J. Phys. Chem. 67, 952-4 (1963).

5. S. Eros and J.R. Reitz, "Elastic Constants by the Ultrasonic Pulse Echo Method," J. Appl. Phys. 29, 683-686 (1958).

6. E. O. Speidel and D. L. Keller, Fabrication and Properties of Hot-Pressed Uranium Mononitride, Battelle Memorial Inst., Columbus, Ohio, Rept. BMI-1633 (1963).

7. K. M. Taylor and C. H. McMurtry, Synthesis and Fabrication of Refractory Uranium Compounds, Summary Report, May 1959 Through December 1960, Rept. ORO-400 (1961).

8. J. Bugl and D. Keller, "Uranium Mononitride-A New Reactor Fuel," Nucleonics 22, No. 9, 66 (1964).

9. J.F. Counsell, R. M. Dell and J.F. Martin, "Thermodynamic Properties of Uranium Compounds, Part 2," Trans. Faraday Soc. 62, 1736-1747 (1966).

10. C.P. Kempter and R. O. Elliott, "Thermal Expansion of $\langle\mathrm{UN}\rangle,\left\langle\mathrm{UO}_{2}\right\rangle$, $\left\langle\mathrm{UO}_{2} \cdot \mathrm{ThO}_{2}\right\rangle$, and $\left\langle\mathrm{ThO}_{2}\right\rangle$," J. Chem. Phys. 30, 1524-26 (1959).

11. L. S. Darken and R.W. Gurry, Physical Chemistry of Metals (McGraw-Hill Book Co., Inc., New York, 1953).

12. K. A. Gschneidner, Rare Earth Alloys (D. Van Nostrand Co., Inc., Princeton, N. J., 1961).

13. J. H. Hildebrand and R. L. Scott, The Solubility of Nonelectrolytes (Dover Publications, Inc., New York, 1950).

14. M. Hansen and K. Anderko, Constitution of Binary Alloys (McGraw-Hill Book Co., Inc., New York, 1958).

15. R. P. Elliott, Constitution of Binary Alloys, First Supplement (McGraw-Hill Book Co., Inc., New York, 1965).

16. F. A. Kanda, R. M. Stevens, and D. V. Keller, "The Barium-Sodium Equilibrium System," J. Phys. Chem. 69, 3867-3872 (1965).

17. R. Hultgren, R. L. Orr, P. D. Anderson, and K. K. Kelley, Selected Values of Thermodynamic Properties of Metals and Alloys (John Wiley \& Sons, Inc., New York, 1963).

18. J. Bohdansky and H. E. J. Schins, "Vapor Pressure of Different Metals in the Pressure Range of 50 to 400 Torr," J. Phys. Chem. 71, 215-217 (1967). 
19. P. Y. Achener and D. L. Fisher, The Specific Heat of Liquid Sodium and Lithium, Aerojet-General Corp., San Ramon, Calif., Rept. AGN-8191, vol 6 (1967).

20. T. B. Douglas, L. F. Epstein, J. L. Dever, and W. H. Howland, "Lithium: Heat Content from 0 to $900^{\circ}$, Triple Point and Heat of Fusion, and Thermodynamic Properties of the Solid and Liquid," J. Am. Chem. Soc. 77, 2144-2150 (1955).

21. W.D. Weatherford, Jr., J.C. Tyler, and P.M. Ku, Properties of Inorganic Energy-Conversion and Heat-Transfer Fluids for Space Applications, Wright Air Development Div., Wright-Patterson AFB, Ohio, Rept. WADD-TR-61-96 (1961).

22. T. W. Chapman, "The Heat Capacity of Liquid Metals," Mater. Sci. Eng. 1 , 65-69 (1966).

23. D. C. Ginnings, T. B. Douglas, and A. F. Ball, "Heat Capacity of Sodium Between $0^{\circ}$ and $900^{\circ} \mathrm{C}$, the Triple Point and Heat of Fusion," J. Res. Nat. Bur. Stds. $\underline{45}$, 23-33 (1950).

24. T. B. Douglas, A. F. Ball, D. C. Ginnings, and W. D. Davis, "Heat Capacity of Potassium and Three-Potassium-Sodium Alloys between $0^{\circ}$ and $800^{\circ}$, the Triple Point and Heat of Fusion of Potassium," J. Am. Chem. Soc. 74, 2472-2478 (1952).

25. J. P. Stone, C. T. Ewing, L. R. Spann, E. W. Steinkuller, D. D. Williams, and R. R. Miller, High-Temperature Properties of Sodium, Naval Research Lab., Washington, D. C., Rept. 6241 (1964), pp. 12-14.

26. C. T. Ewing, J. P. Stone, J. R. Spann, E. W. Steinkuller, D. D. Williams, and R. R. Miller, High-Temperature Properties of Potassium, Naval Research Lab., Washington, D. C., Rept. 6233 (1964), pp. 21-22.

27. E. I. Gol'tsova, "Densities of Liquid Lithium, Sodium, and Potassium," High Temp. 4 , 348-351 (1966). Translated from Russian.

28. Yu. S. Trelin, I. N. Vasil'ev, V. B. Proskurin, and T.A. Tsyganova, "Experimental Data on the Velocity of Sound in Alkali Metals at Temperatures up to $800^{\circ} \mathrm{C}, "$ High Temp. 4, 352-355 (1966). Translated from Russian.

29. E. A. Moelwyn-Hughes, Physical Chemistry (Pergamon Press, New York, 1961), 2nd ed., pp. 692-693.

30. K. A. Gschneidner, Jr., "Physical Properties and Interrelationships of Metallic Semimetallic Elements," in Solid State Physics, F. Seitz and D. Turnbull, Eds. (Academic Press, New York, 1964), vol 16.

31. C. Kittel, Introduction to Solid State Physics (John Wiley \& Sons, Inc., New York, 1956), pp. 135-251.

32. A. D. Pasternak, Isothermal Compressibility of the Liquid Alkali Metals, Lawrence Radiation Laboratory, Livermore, Rept. UCRL-70900 Preprint (1968).

33. J. G. Booth, R. I. Jaffee, and E.I. Salkovitz, "The Mechanisms of the RheniumAlloying Effect in Group VI-A Metals," in Plansee Seminar De Re Metallica, 5th, Reutte Tyrol, 1964 (Springer, New York, 1965).

34. A. Hansson, and G.E. Tardiff, "The Influence of Deformation Velocity on the Tensile Rupture Ductility of Strain-Aged Steel," Trans. Met. Soc. AIME 239, 596-597 (1967). 
35. J.H. Pitts and C. E. Walter, Eds., Conceptual Design of a 10-MW Nuclear Rankine System for Space Power, Lawrence Radiation Laboratory, Livermore, Rept. UCRL-50382 (1968).

36. J.R. Peterson, High Performance Once Through Boiling of Potassium in Single Tubes at Vapor Temperatures from $1500^{\circ} \mathrm{F}$ to $1750^{\circ} \mathrm{F}$, General Electric Co., Cincinnati, Ohio, Space Power and Propulsion Section, Topical Report (1966). See also Rept. NASA-CR-842 (1967).

37. R. M. McGill, R. W. Browell, J. W. Grisard, S. Blumkin, E. Von Halle, and D. B. Janney, The Separation of Potassium Isotopes by Molecular Distillation, Oak Ridge Gaseous Diffusion Plant, Tenn., Rept. K-1650 (1965). 


\section{Distribution}

\section{LRL Internal Distribution}

Michael M. May/D. Sewell

B. J. Weis

J. W. Hadley

R. E. Batzel

A. T. Biehl

E. Teller

J. S. Kane

W. B. Myers

B. Rubin

L. W. Roberts

R. A. Heckman

J. W. Kury

P. C. Stevenson

O. C. Kolar

J. O. Cowles

J. R. Long

H. F. Finn

W. C. Grayson, Jr.

H. L. Reynolds

J. P. Layton

G. Cummings

TID Berkeley

TID File

External Distribution

G. Newby

M. Klein

C. Johnson

U. S. Atomic Energy Commission

Space Nuclear Systems Division

Washington, D. C.

J. L. McDonnel

Defense Atomic Support Agency

Livermore, California

J. G. Whiteaker

Office of the Chief of Naval Operations

Washington, D. C.

W. O. Harms

Oak Ridge National Laboratory

Oak Ridge, Tennessee 
F. W. Hunton

San Francisco Operations Office

Berkeley, California

L. Humble

T. Moss

Lewis Research Center

Cleveland, Ohio

S. V. Manson

J. J. Lynch

National Aeronautics and Space Administration

Washington, D. C.

J. P. Davis

D. G. Elliott

Jet Propulsion Laboratory

Pasadena, California

L. Roberts

Ames Research Center

Moffett Field, Sunnyvale, California

R. J. Rosa

AVCO Everett Research Laboratory

Everett, Massachusetts

R. F. Cooper

Air Force Aero-Propulsion Laboratory

Wright-Patterson Air Force Base, Ohio

J. L. Kerrebrock

Massachusetts Institute of Technology

Cambridge, Massachusetts

LEGAL NOTICE

S. Siegel

L. Prem

North American Aviation, Inc.

Atomics International Division

Canoga Park, California

E. Pierson

University of Illinois

Chicago, Illinois

M. Petrick

Argonne National Laboratory

Argonne, Illinois Welther the United States nor the Commission, nor any person acting on behal of the Cominussion:

A. Makes any warranty or representation, expressed of implied, with respect to the accuracy. completeness. or usefulness of the information con tamed in this report of that the use of any information anparatus method or process disclosed in this report naay not infringe privately owned rights; or

B. Assumes any liabilities with respect to the use of of for damages resulting from the use of any information, apparatus, method or process dis closed in this report.

As used in the above "person acting on behalf of the Commission" includes any employee or contractor of the Commission, or employee of such contractor, to the exient that such employee or contractor of the Commission. of employee of such contractor prepares, disserrinates, or provides access to any information pursuant to his employment or contract with the Commission or his employment with such contractor

R. V. Mrozinski

National Aeronautics and Space Council

Washington, D. C.

TID-4500, UC-33, Propulsion Systems and Energy Conversion

Printed in USA. Available from the Clearinghouse for Federal

Scientific and Technical Information, National Bureau of Standards,

U. S. Department of Commerce, Springfield, Virginia 22151

Price: Printed Copy $\$ 3.00$; Microfiche $\$ 0.65$.

$\mathrm{CS} / \mathrm{lm}$ 